UNIVERSIDADE DE BRASÍLIA

PROGRAMA DE PÓS-GRADUAÇÃO EM CIÊNCIAS DA SAÚDE

ERICA CARINE CAMPOS CALDAS ROSA

COMPRIMENTO DOS TELÔMEROS DE LEUCÓCITOS DO SANGUE

PERIFÉRICO E ESTRESSE OXIDATIVO EM PORTADORES DE DIABETES

MELLITUS TIPO 2

BRASÍLIA, 2016 
UNIVERSIDADE DE BRASÍLIA

PROGRAMA DE PÓS-GRADUAÇÃO EM CIÊNCIAS DA SAÚDE

\author{
ERICA CARINE CAMPOS CALDAS ROSA
}

\title{
COMPRIMENTO DOS TELÔMEROS DE LEUCÓCITOS DO SANGUE PERIFÉRICO E ESTRESSE OXIDATIVO EM PORTADORES DE DIABETES MELLITUS TIPO 2
}

Tese apresentada ao Programa de PósGraduação em Ciências da Saúde, como requisito parcial para aquisição do grau de Doutor em Ciências da Saúde.

Orientadora: Profa. Angélica Amorim Amato Co-orientadora: Profa. Michella Soares Coêlho Araújo

BRASÍLIA 2016 


\section{RESUMO}

Introdução: Os telômeros constituem seqüências repetitivas de DNA que protegem as extremidades dos cromossomos lineares mantêm a estabilidade genômica. Com o envelhecimento, observa-se seu encurtamento progressivo. Fatores adicionais podem acelerar o encurtamento dos telômeros, sobretudo aqueles relacionados a estresse oxidativo (EO) e resposta inflamatória. É possível, assim, que o comprimento dos telômeros represente potencial indicador de dano oxidativo e inflamatório e de senescência celular. O diabetes mellitus tipo 2 (DM2) associa-se a EO e resposta inflamatória e é possível que associe-se também a encurtamento dos telômeros. Este estudo investigou o comprimento de telômeros e marcadores de EO em diabéticos tipo 2, em Brasília, DF. Métodos: Foram determinados, no soro de diabéticos tipo 2 e de sujeitos com tolerância normal à glicose (controles), a concentração de TBARS (substâncias reativas ao ácido tiobarbitúrico) e a capacidade antioxidante total (FRAP). O comprimento relativo dos telômeros foi determinado por PCR quantitativa em tempo real, utilizando como normalizador 0 gene de cópia única 36B4. Resultados: Foram incluídos 165 sujeitos com DM2, com mediana de idade de 49 anos, predomínio do sexo feminino (75,8\%), mediana do tempo de diagnóstico do DM2 de 2 anos, predominância de baixo nível de escolaridade e mediana do índice de massa corporal (IMC) de $30 \mathrm{~kg} / \mathrm{m}^{2}$. Para avaliação de marcadores de EO, os diabéticos foram comparados a um grupo de 130 controles com mediana de idade de 46 anos, predominância do sexo masculino, maior nível de escolaridade e IMC mediano de $27 \mathrm{~kg} / \mathrm{m}^{2}$. Os diabéticos tipo 2 apresentaram concentração sérica de TBARS significativamente maior que a dos controles e capacidade antioxidante total significativamente menor que a dos controles, independentemente do sexo ou IMC. Nos diabéticos tipo 2, a concentração sérica de TBARS foi correlacionada negativamente com a de colesterol LDL e a capacidade antioxidante total foi positivamente correlacionada como tempo de diagnóstico, hemoglobina glicada e concentração sérica de triglicerídeo. Para análise do comprimento relativo dos telômeros, os diabéticos foram comparados a 158 controles, com idade semelhante (mediana de 49 anos), predominância do sexo masculino, maior nível de escolaridade e mediana do IMC de 
$27 \mathrm{~kg} / \mathrm{m}^{2}$. O comprimento relativo dos telômeros foi superior no grupo de diabéticos tipo 2 em relação ao controle, porém a diferença não mais foi observada após exclusão dos valores discrepantes (outliers). Não foi observada associação entre o comprimento relativo dos telômeros e o sexo ou estado nutricional, nos dois grupos, nem com retinopatia, entre os diabéticos. Nos diabéticos tipo 2, foi observada correlação negativa do comprimento relativo dos telômeros com o tempo de diagnóstico do DM2, glicemia de jejum, hemoglobina glicada e capacidade antioxidante total, e positiva com a concentração sérica de TBARS. Nos controles, foi observada correlação negativa do comprimento relativo dos telômeros com a idade. Conclusão: Os resultados do presente estudo sugerem que o DM2 está associado a aumento de marcador sérico de peroxidação lipídica e redução da capacidade antioxidante total no soro, porém não a encurtamento dos telômeros. $O$ comprimento dos telômeros, no entanto, parece estar relacionado a indicadores metabólicos desfavoráveis no diabético tipo 2 , incluindo glicemia de jejum e hemoglobina glicada.

Palavras-chave: Comprimento de telômeros; diabetes mellitus tipo 2, estresse oxidativo. 


\section{ABSTRACT}

Introduction: Telomeres are repetitive sequences of DNA that protect the ends of linear chromosomes and maintain genomic stability. They gradually shorten with aging, but additional factors may accelerate telomere shortening, especially those related to oxidative stress (OS) and the inflammatory response. It is possible, therefore, that telomere length may represent a potential indicator of oxidative and inflammatory damage. Type 2 diabetes (T2D) is associated with OS and inflammatory response and can also lead to telomere shortening. This study investigated the telomere length and OS markers in type 2 diabetics, in Brasilia, DF. Methods: Serum concentration of TBARS (thiobarbituric acid reactive substances) and total antioxidant capacity (FRAP) were measured in patients with T2D and control subjects with normal glucose tolerance. Relative telomere length was determined by quantitative real-time PCR using as the normalizer the single copy gene 36B4. Results: 165 subjects with T2D were included, with a median age of 49 years, female predominance $(75.8 \%)$, median time of diagnosis of DM2 of 2 years, a high frequency of low educational attainment and median index body mass index (BMI) of $30 \mathrm{~kg} / \mathrm{m}^{2}$. Serum levels of OS markers in T2D patients were compared to those of 130 controls with a median age of 46 years, who were predominantly male, had a higher level of education and a median BMl of $27 \mathrm{~kg} / \mathrm{m}^{2}$. Serum levels of TBARS were significantly higher and total antioxidant capacity was significantly lower in T2D patients compared with controls, regardless of gender or BMI. In T2D patients, serum levels of TBARS were negatively correlated with serum LDL cholesterol levels; total antioxidant capacity was positively correlated to time since T2D diagnosis, glycated hemoglobin and serum triglyceride levels. Relative telomere length in T2D patients was compared to that of 158 age-matched controls (median age of 49 years), but who were predominantly male, had higher education level and a median BMl of $27 \mathrm{~kg} / \mathrm{m}^{2}$. Relative telomere length was higher in T2D patients compared with controls, but this difference was not observed after exclusion of outliers. No association was found between relative telomere length and gender or nutritional status defined by BMI, either in T2D patients or controls. In T2D patients, relative telomere length was no associated with the presence of retinopathy. In these 
patients, relative telomere length was negatively correlated with time since diagnosis of T2D, fasting blood glucose, glycated hemoglobin and total antioxidant capacity. On the other hand, it was positively correlated with serum levels of TBARS. Among controls, relative telomere length was negatively correlated with age. Conclusion: The results suggest that $\mathrm{T} 2 \mathrm{D}$ is associated with increased $\mathrm{OS}$ but not with telomere shortening. Reduced retive telomere length, however, seemed to be related to an unfavorable metabolic profile in T2D patients, including increased fasting blood glucose and glycated hemoglobin.

Key-words: telomere length; type 2 diabetes mellitus, oxidative stress. 


\section{ERICA CARINE CAMPOS CALDAS ROSA}

\section{"COMPRIMENTO DOS TELÔMEROS DE LEUCÓCITOS DO SANGUE PERIFÉRICO E ESTRESSE OXIDATIVO EM PORTADORES DE DIABETES MELLITUS TIPO 2"}

Tese de autoria de Erica Carine Campos Caldas Rosa, apresentada ao Programa de PósGraduação em Ciências da Saúde como requisito parcial para obtenção do grau de Doutor em Ciências da Saúde.

Aprovada em 19 de Outubro de 2016

BANCA EXAMINADORA

\begin{tabular}{c} 
Profa. Angélica Amorim Amato \\
Orientadora \\
Membro Presidente \\
Universidade de Brasília - FS-UnB \\
\hline $\begin{array}{c}\text { Profa. Juliana Forte Mazzeu de Araújo } \\
\text { Membro Interno (FM e FS/UnB) } \\
\text { Universidade de Brasília }\end{array}$ \\
\hline $\begin{array}{c}\text { Prof. Rinaldo W. Pereira } \\
\text { Membro Interno (FS/UnB) }\end{array}$ \\
Universidade de Brasília, Universidade Católica de Brasília \\
Profa. Rosângela Vieira de Andrade \\
Membro Externo \\
Universidade Católica de Brasília \\
\\
\hline Profa. Florência Barbé-Tuana \\
Membro Externo \\
Universidade Católica de Brasília \\
Membro Externo
\end{tabular}

Brasília, DF 


\section{DEDICATÓRIA}

\section{Ao meu Senhor e amado Jesus (Yeshua Hamashia)}

"Não tenho palavras para agradecer tua bondade Dia após dia me cercas com fidelidade nunca me deixes esquecer

Que tudo o que tenho

Tudo o que sou

O que vier a ser Vem de Ti Senhor" A honra, glória e louvor ao Deus Emanuel. Diante do Trono

Ao meu cônjuge amado David, apoiador, amigo e ajudador. Obrigada pelo amor, apoio e compreensão.

Ao meu filho Samuel Joshua. Sou grata por ter você como filho. A mamãe te ama muito

"Aos meus Pais Zelito e Conceição (in memoriam)". Sou grata pelo investimento em minha educação, pelo amor e por terem me ensinado a não desistir diante das dificuldades.

Sempre amarei vocês.

As minhas irmãs Cristina e Cristiane pelo apoio, irmãos e sobrinhos. Obrigada. 


\section{AGRADECIMENTOS}

À minha Orientadora Profa. Dra. Angelica Amato. Toda minha gratidão e admiração. Agradeço por estes quatro anos de convivência, pela excelente orientação e oportunidade. Sua competência, gentileza, calma, inteligência, dedicação e profissionalismo me inspiram. Obrigada pelos ensinamentos e incentivo. Foi um privilégio ter sido aceita para ser sua orientanda.

À minha Co-Orientadora Profa Dra. Michella Soares Coelho. Obrigada pelos conselhos, orientação, e apoio para a realização deste trabalho. Seu profissionalismo e dedicação são inspiradores.

À Profa. Dra Eliana fortes Gris. Agradeço pela orientação recebida no projeto de extensão, apoio e colaboração para a realização desta Tese.

\footnotetext{
Á Banca examinadora pela contribuição prestada durante a avaliação desta Tese.
}

Ao Prof Dr. Francisco Neves, Coordenador do Laboratório de Farmacologia Molecular pelo apoio para a realização deste trabalho.

Ao Prof Dr. Eduardo Antônio pelo apoio e ajuda durante a realização dos testes de capacidade antioxidante total. Agradeço pelos conselhos e orientação.

À Profa Dra Élida Geralda, minha gratidão. Agradeço por ter permitido usar as dependências dos laboratórios de Estresse Oxidativo e Radicais livres no Instituto de Biologia da UnB. Obrigada pela colaboração, apoio e gentileza.

À Dra Ana Beatriz, responsável pelo laboratório de Análises Clinicas do Hospital Universitário de Brasília. Obrigada por ter permitido a minha entrada no Laboratório e pela convivência maravilhosa com toda a equipe Técnica e toda ajuda durante e após as coletas.Agradeço em especial aos técnicos: Fábio, Jeovanes, Édson, e toda equipe. Sem a ajuda de vocês eu jamais teria conseguido concluir as coletas das amostras dos pacientes. 
Aos queridos amigos e parceiros de trabalho Renan Renato Cruz e Luis Fernando Amarante pela colaboração e ajuda.

À Dra. Miriam Daisy Calmon Scaggion, Diretora em exercício da Fundação Hemocentro de Brasília, e ao Dr. José Antônio de Faria Vilaça (diretor executivo em 2013-2014) pela oportunidade que foi concedida em poder realizar parte desta Tese com os doadores da Fundação.

À Dra Barbara Maciel S. Pimentel, Gerente dos Laboratórios, na área de Laboratórios de Triagem de Doadores de Sangue, Órgãos e Tecidos em exercício, e á Dra Delvânia Lima (Gerente dos laboratórios em 2013-2014) por todo apoio para a realização desta Tese. Toda minha gratidão.

Ao corpo técnico da Fundação Hemocentro de Brasília, em especial ao Renato e Ana Luísa. Obrigada pela ajuda para a realização e conclusão deste trabalho.

Aos amigos Dr. Renato Marano e Dra. Érica Garcia. Obrigada pela convivência e parceria. Foi um prazer trabalhar com vocês.

Ao Prof. Dr. Gustavo Barra e Profa. Dra. Monalisa pela oportunidade que me concederam de aprender com vocês.

Ao Prof. Dr. Thiago Rosa e ao Prof. Dr. Herbert Simões pela ajuda.

Aos Professores do Farmol. Obrigada pela ajuda e incentivo. Agradeço em especial à Profa. Dra. Djane Braz e Profa. Dra. Maria de Fátima Borin pelos conselhos e dicas.

Aos queridos Raphael Bonadio e Daniel Carneiro dos Laboratórios de Genética e Estresse oxidativo do IB. Obrigada pelo apoio e colaboração. 
À Profa. Dra. Silvienne Fabiana e à Profa. Dra. Aline Pic Taylor por permitirem a minha entrada no laboratório de Genética do IB.

Aos queridos Luciano, Rilva e Cristina Simeoni. Obrigada por serem tão especiais comigo. Pelo apoio, incentivo e ajuda.

Aos amigos e colegas do Farmol e da FCE. Obrigada pelos anos de convivência e colaboração. Agradeço em especial a: Yasmin, Laiza, Pedro, Simone, Lucas Ferni, Natália, Bel, Sidney, Kaian, Carol Lourenço, Wanessa, Janice, Cinthia, Natacha, Olivia, Bruna, Henrique, Nady, Daniela, Fernanda, Mariella e aos demais. Obrigada por tudo.

Meu agradecimento especial aos pacientes com DM2 e doadores da FHB. Obrigada pela colaboração para que esta Tese fosse realizada.

Á CAPES pela bolsa concedida e ao programa de Pós-Graduação em Ciências da Saúde da UnB. 
"Pois o Senhor é quem dá sabedoria de sua boca procedem o conhecimento e o discernimento"

Provérbios 2:5 


\section{LISTA DE QUADROS}

Quadro 1. Critérios para o diagnóstico de tolerância normal à glicose, pré-diabetes e DM2. .32

Quadro 2 Características de estudos que investigaram a associação entre o

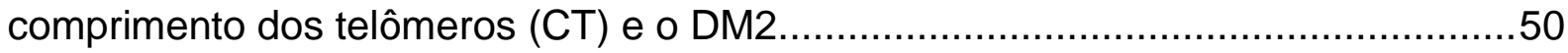

Quadro 3. Características dos métodos de determinação do comprimento dos

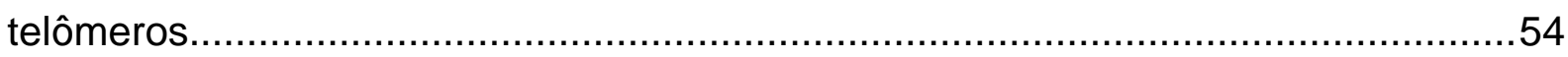

Quadro 4 Classificação do estado nutricional segundo o índice de massa corporal e risco de comorbidades. 64

Quadro 5 Métodos empregados para a determinação das variáveis bioquímicas analisadas e respectivas faixas de referência. .66

Quadro 6 Oligonucleotídeos iniciadores utilizados na reação de $\mathrm{PCRq}$, para determinação do comprimento relativo dos telômeros. 


\section{LISTA DE TABELAS}

Tabela 1. Características demográficas e socioeconômicas dos diabéticos tipo 2 (n $=165$ ). .73

Tabela 2. Tabagismo, etilismo e prática de atividade física entre os diabéticos tipo 2 $(\mathrm{n}=165)$ 74

Tabela 3. Variáveis relacionadas ao DM2 e comorbidades entre os diabéticos tipo 2 $(\mathrm{n}=165)$ .74

Tabela 4. Pressão arterial e estado nutricional dos diabéticos tipo $2(n=165)$. .75

Tabela 5. Resultados de variáveis bioquímicas dos diabéticos tipo 2 ( $n=165)$. .76

Tabela 6. Características demográficas e clínicas dos diabéticos tipo $2(n=165)$ e controles $(n=130)$ .77

Tabela 7 Eficiência de amplificação e coeficiente de regressão linear após elaboração das curvas-padrão. .85

Tabela 8. Características demográficas e clínicas dos diabéticos tipo $2(n=165)$ e controles $(n=158)$.

Tabela 9 Características demográficas, clínicas e bioquímicas de diabéticos tipo 2 com valores de $\mathrm{T} / \mathrm{S}$ relativo discrepantes (outliers) e não discrepantes. 


\section{LISTA DE FIGURAS}

Figura 1. Esquema simplificado da fisiopatologia do DM2. 29

Figura 2. Tecido adiposo, estresse oxidativo e fisiopatologia de doenças metabólicas.

Figura 3. Formação de Espécies Reativas de Oxigênio (EROS) e estresse oxidativo. O EO desempenha papel importante em processos fisiológicos e patológicos.. 35 Figura 4. Reação entre o ácido tiobarbitúrico (TBARS) e malondialdeído (MDA) e absorbância máxima de 532nm (nanômetros) .36

Figura 5. Estrutura proposta para o complexo telomérico humano.)...... 42

Figura 60 complexo Telomerase..

Figura 7. Replicação incompleta da fita 3', conhecida como "problema da replicação final", e atividade da telomerase. .46

Figura 8 O complexo Shelterin.

Figura 9 Concentração de TBARS nos diabéticos tipo 2 e controles com tolerância normal à glicose (teste de Mann-Whitney). 78

Figura 10 Representação gráfica da concentração de Trolox em função da absorbância da amostra e regressão linear para obtenção da equação da reta e determinação da capacidade antioxidante total nas amostras dos sujeitos do estudo.

Figura 11 Capacidade antioxidante total (A), analisada pelo ensaio FRAP, e relação FRAP/TBARS (B) nos diabéticos tipo 2 e controles com tolerância normal (teste de Mann-Whitney).

Figura 12 Concentração de TBARS no sexo feminino e masculino, nos diabéticos tipo 2 e controles com tolerância normal à glicose $\left({ }^{*} p<0,05\right.$, teste de Kruskal-Wallis seguido do pós-teste de Dunn). Cont: grupo controle; DM2: diabéticos tipo 2; F: sexo feminino; M:masculino.

Figura 13 Capacidade antioxidante total (FRAP) no sexo feminino e masculino, nos diabéticos tipo 2 e controles com tolerância normal à glicose. Cont: grupo controle; DM2: diabéticos tipo 2; F: sexo feminino; M: sexo masculino. .82

Figura 14 Concentração de TBARS, segundo o IMC, nos diabéticos tipo 2 e controles com tolerância normal à glicose $\left({ }^{*} p<0,05\right.$, teste de Kruskal-Wallis 
seguido do pós-teste de Dunn). Cont: grupo controle; DM2: diabéticos tipo 2; E: eutrófico; SP: sobrepeso; OB: obeso.

Figura 15 Concentração da capacidade antioxidante total, segundo o IMC, nos diabéticos tipo 2 e controles com tolerância normal à glicose $\left({ }^{*} p<0,05\right.$, teste de Kruskal-Wallis seguido do pós-teste de Dunn). Cont: grupo controle; DM2: diabéticos tipo 2; E:eutrófico.

Figura 16 Curvas de dissociação do produto de amplificação da reação conduzida para amplificação $(A)$ de sequência do gene de cópia única (36B4) e (B) da sequência telomérica.

Figura 17 Curvas padrão das reações de amplificação $(A)$ de sequência do gene de copia única (36B4) e (B) da sequência telomérica na amostra referência de DNA. Eficiência e coeficiente de correlação após análise e estabelecimento da curva padrão para cada sequência.

Figura 18 Comprimento relativo dos telômeros (T/S relativo) nos diabéticos tipo 2 e grupo controle, sem (A) e com (B) exclusão dos outliers. Teste de Mann-Whitney. .95 Figura 19 Comprimento relativo dos telômeros (T/S relativo), no sexo feminino e masculino, nos diabéticos tipo 2 e controles com tolerância normal à glicose. Cont: grupo controle; DM2: diabéticos tipo 2; F: sexo feminino; M: sexo masculino. .96 Figura 20 Comprimento relativo dos telômeros (T/S relativo), segundo o IMC, nos diabéticos tipo 2 e controles com tolerância normal à glicose. Cont: grupo controle; DM2: diabéticos tipo 2; E: eutrófico; SP: sobrepeso; OB: obesidade. .96 Figura 21 Comprimento relativo dos telômeros (T/S relativo), segundo a presença de retinopatia diabética. Teste de Mann-Whitney.

Figura 22 Correlação entre o comprimento relativo dos telômeros e o tempo de diagnóstico de DM2, nos diabéticos tipo $2\left(r^{2}\right.$ Spearman -0,25, $\left.p=0,0015\right)$. 98

Figura 23 Correlação entre o comprimento relativo dos telômeros e (A) a glicemia de jejum $\left(r^{2}\right.$ Spearman -0,26, $\left.p=0,0004\right)$ e $(B)$ a hemoglobina glicada $\left(r^{2}\right.$ Spearman $0,35, p<0,0001)$, nos diabéticos tipo 2 . .98

Figura 24 Correlação entre o comprimento relativo dos telômeros e (A) a concentração sérica de TBARS $\left(r^{2}\right.$ Spearman $\left.+0,19, p=0,02\right)$ e $(B)$ a capacidade antioxidante total no soro $\left(r^{2}\right.$ Spearman $\left.-0,28, p<0,0002\right)$, nos diabéticos tipo 2...99 Figura 25 Correlação entre o comprimento relativo dos telômeros e a idade nos diabéticos tipo $2\left(r^{2}\right.$ Spearman $\left.-0,05, p=0,53\right)$ e nos sujeitos do grupo controle $\left(r^{2}\right.$ Spearman $-0,51$ e $p<0,0001)$. 100 


\section{LISTA DE SIGLAS E ABREVIATURAS}

A - adenina

ADA - Associação Americana de Diabetes

AGNES - ácidos graxos não esterificados

C - citosina

CAT - catalase

CAOT - capacidade antioxidante total

CA - circunferência abdominal

$\mathrm{CN}$ - controle negativo

CNVs-Variação do número de cópias (copy number variation)

$\mathrm{CQ}$ - circunferência do quadril

CT - Comprimento dos telômeros

ct - cicle threshold

DM - Diabetes mellitus

DM2 - Diabetes mellitus tipo 2

DNAmt - DNA mitocondrial

DK1 - diskerina 1

DNA - ácido desoxirribonucleico

D-loop-parte da extremidade dos telômeros

dNTP - desoxirribonucleotídeos

DP - desvio padrão

EO - estresse oxidativo

eNOS - óxido nítrico sintetase endotelial

ERN - espécie reativa de nitrogênio

EROS - espécie reativa de oxigênio

Eq - equivalente

$\mathrm{FADH}_{2}$ - forma reduzida do dinucleotídeo de flavina-adenina

FEPECS - Fundação de Ensino e Pesquisa em Ciências da Saúde

FHB - Fundação Hemocentro de Brasília

FRAP - Ferric reducing ability of plasma

$\mathrm{G}$ - guanina 
GSH - glutationa antioxidante não enzimática

GPX - glutationa peroxidase

$\mathrm{H}_{2} \mathrm{O}_{2}$ - peróxido de hidrogênio

IDF - Federação Internacional de Diabetes

IBGE - Instituto Brasileiro de Geografia e Estatística

IMC - índice de massa corpórea

IL-1ß -interleucina 1 beta

$\mathrm{kb}$ - kilobase

LPO - lipoperoxidação

MDA - malondialdeído

$\mathrm{mL}-$ mililitro

$\mathrm{mM}$ - milimolar

mTert - gene da telomerase

$\mu \mathrm{L}-$ microlitro

$\mathrm{n}$ - número

NADPH oxidase - coenzima fosfato de dinucleotídeo de adenina e nicotinamida

ng - nanograma

$\mathrm{O}_{2}{ }^{-}-$ânion do radical superóxido

PAS - pressão arterial sistólica

PAD - pressão arterial diastólica

$\mathrm{PKC}$ - proteína quinase $\mathrm{C}$

POT1 - protection of telomeres

qPCR - PCR quantitativa em tempo real (quantitative real time PCR)

dPCR--PCR digital

$\mathrm{R}^{2}$ - coeficiente de correlação

RAP1 - repressor/activator protein 1

RNA - ácido ribonucleico

RNAm - RNA mensageiro

$R Q$ - quantificação relativa

rpm - rotação por minuto

SASP - fenótipo secretor associado à senescência

SOD - superóxido dismutase antioxidante mitocondrial

SBD - Sociedade Brasileira de Diabetes

$T$ - timina 
TBA - ácido tiobarbitúrico

TBARS - substâncias reativas ao ácido tiobarbitúrico

Telo - telômero

Telo F- oligonucleotídeo iniciador direto do gene da sequência telomérica

Telo $\mathrm{R}$ - oligonucleotídeo iniciador reverso do gene da sequencia telomérica

TG - triglicerídeos

TERC - componente de RNA não codificante

TERT - transcriptase reversa

Tm-temperatura de melting

TNF- $\alpha$ - fator de necrose tumoral alfa

TIN2 - -interacting nuclear protein 2

T-loop - extremidade dos telômeros

TPP1 - interacting protein 1

TRF1 - telomere repeat binding 1

TRF2 - telomere repeat binding 2

Trolox - análogo hidrossolúvel da vitamina $\mathrm{E}$

$\%$ PC - percentual do peso corporal

$\Delta \mathrm{Ct}$ - delta CT

$\Delta \Delta \mathrm{Ct}$ - delta delta CT

36B4-gene que codifica a fosfoproteína ribossomal(RPBL0)

36B4F - oligonucleotídeo iniciador direto do gene de cópia única $36 B 4$

36B4R - oligonucleotídeo iniciador reverso do gene de cópia única 36B4

$U$ - uracila

UCP - proteína de desacoplamento mitocondriais 


\section{SUMÁRIO}

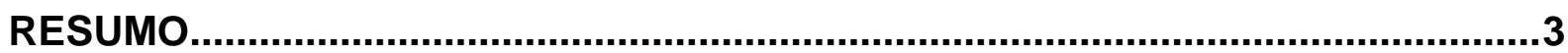

ABSTRACT

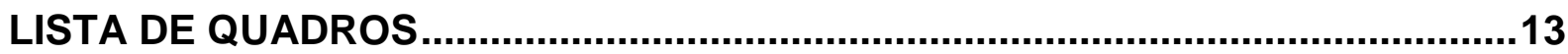

LISTA DE TABELAS

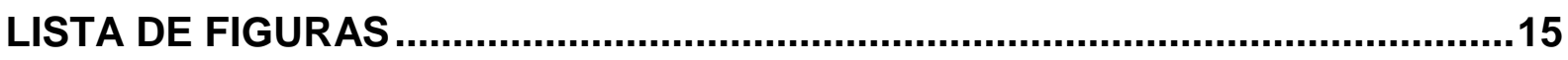

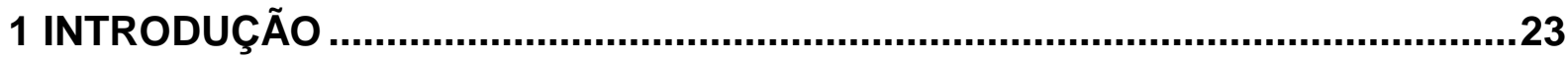

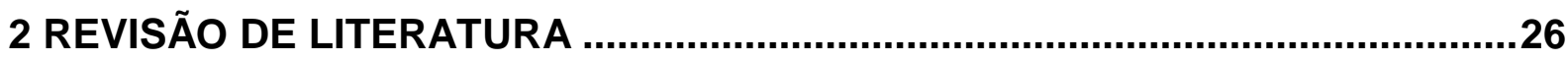

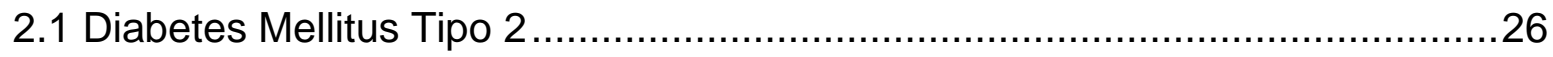

2.1.1 Aspectos epidemiológicos do diabetes mellitus .......................................27

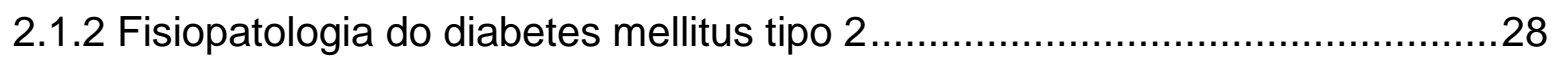

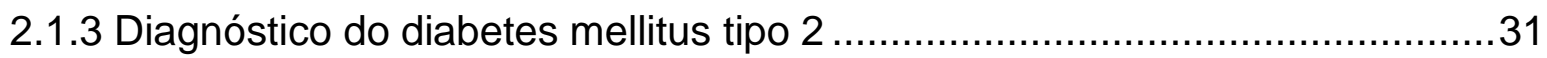

2.1.4 Estresse oxidativo e lipoperoxidação no diabetes mellitus tipo 2 ...................32

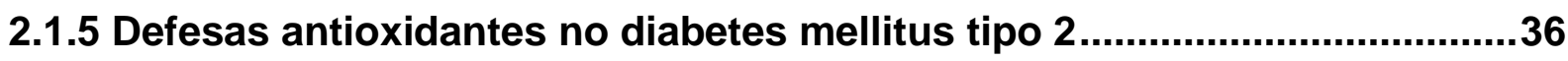

2.2 TELÔMEROS E TELOMERASE ...............................................................

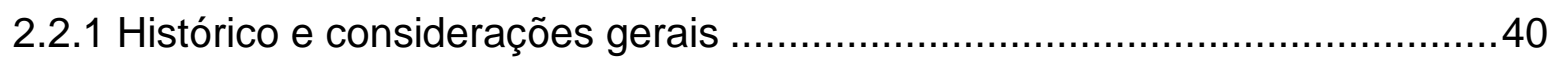

2.2.2 Estrutura dos telômeros e atividade da telomerase ..................................41

2.2.3 Comprimento dos telômeros e diabetes mellitus tipo 2 …............................48

2.2.4.1 Análise do fragmento de restrição terminal por Southern blot ...................55

2.4.4.2 Reação em cadeia da polimerase quantitativa em tempo real (PCRq) ......55

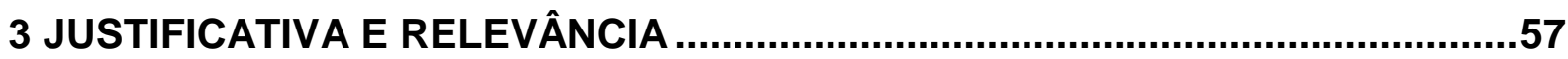

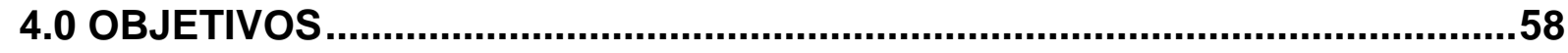

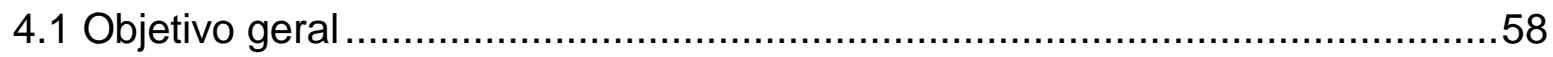

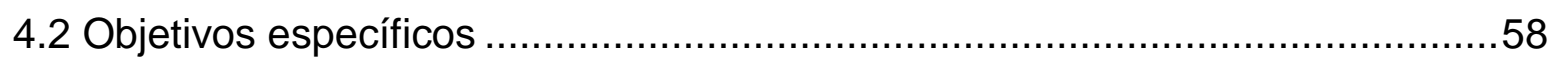

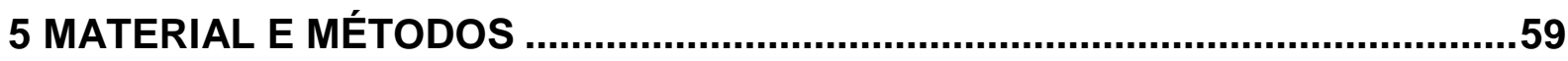

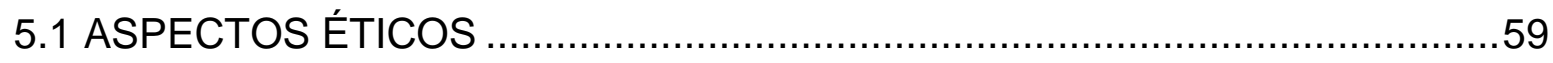




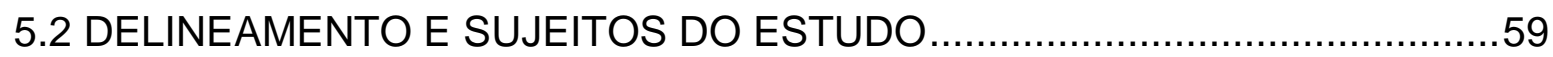

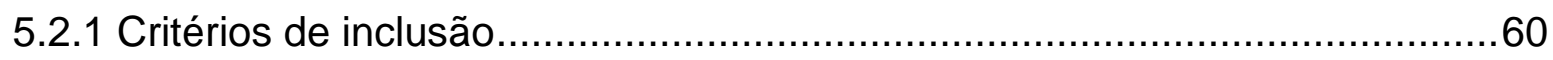

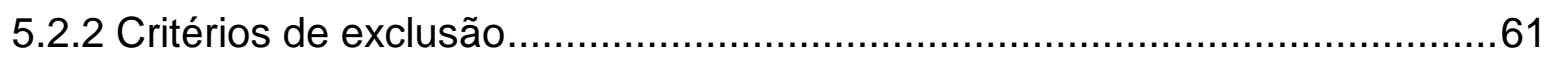

5.2.3 Cálculo amostral após os critérios de exclusão ..........................................61

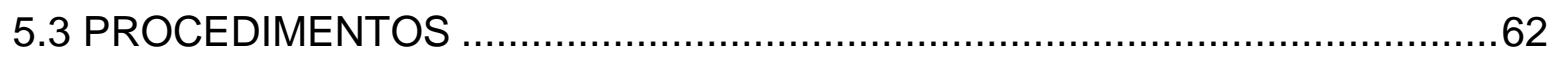

5.3.1 Coleta de amostra de sangue venoso periférico ........................................62

5.3.2 Obtenção de informações relativas às variáveis do estudo ..........................62

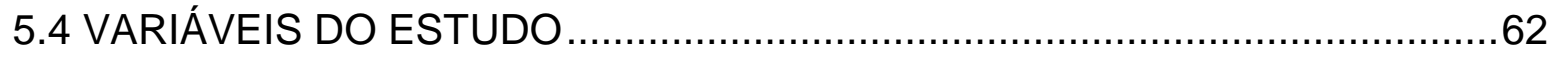

5.4.1 Variáveis demográficas, clínicas e antropométricas ..................................62

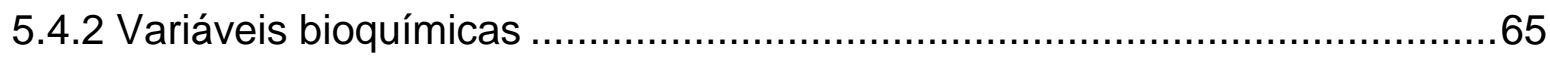

5.6 AVALIAÇÃO DA CAPACIDADE ANTIOXIDANTE TOTAL DO PLASMA.........67

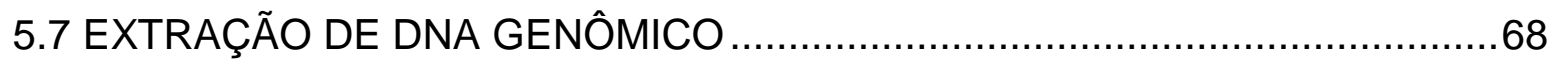

5.8 DETERMINAÇÃO DO COMPRIMENTO RELATIVO DOS TELÔMEROS .......69

5.8.1 Análise da curva de eficiência de amplificação dos iniciadores ....................71

5.8.2 Análise e determinação do comprimento relativo dos telômeros ...................71

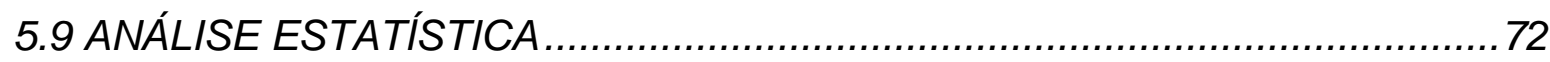

6.0 RESULTADOS

6.1 CARACTERIZAÇÃO DEMOGRÁFICA, CLÍNICA E BIOQUÍMICA DOS

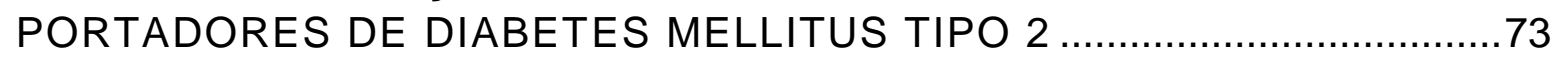

6.2 PEROXIDAÇÃO LIPÍDICA E CAPACIDADE ANTIOXIDANTE TOTAL ............76

6.3 COMPRIMENTO RELATIVO DOS TELÔMEROS DE LEUCÓCITOS DO

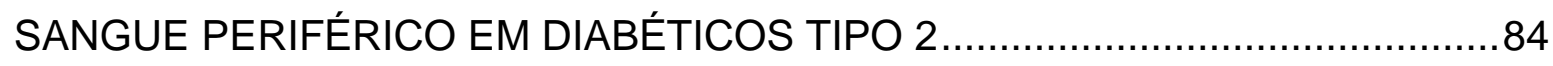

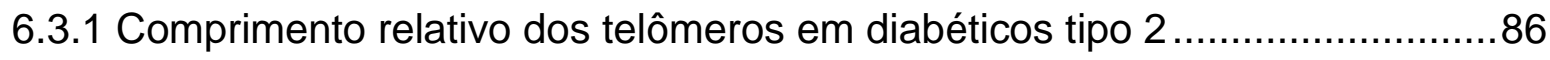

6.3.2 Comparação de características demográficas, clínicas e bioquímicas dos diabéticos tipo $2 \mathrm{com}$ valores de T/S relativo considerados discrepantes e não discrepantes

6.3.3 Comprimento relativo dos telômeros em diabéticos tipo 2 e variáveis clínicas e bioquímicas

6.3.3 Comprimento relativo dos telômeros em indivíduos com tolerância normal à glicose e variáveis clínicas ...............................................................................99

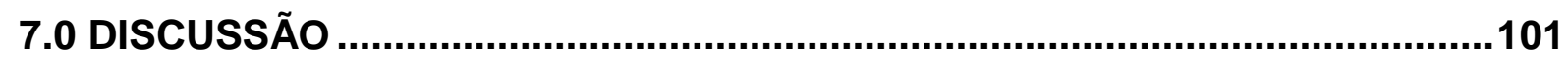

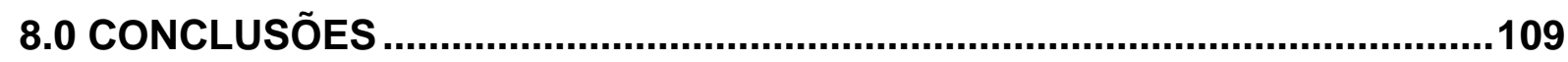




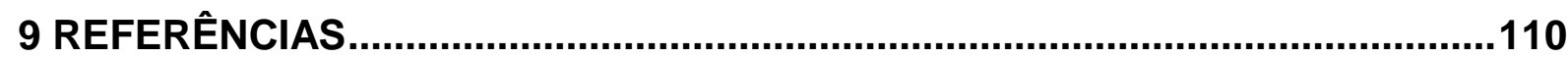

ANEXO 


\section{INTRODUÇÃO}

O diabetes mellitus tipo 2 (DM2) é distúrbio metabólico prevalente e constitui importante problema de saúde pública no mundo. É esperada que esta doença crônica, em 2020, seja a maior causa morte e, de acordo com a Federação internacional de Diabetes, a projeção do número de pessoas diagnosticadas com diabetes aumentará de 415 milhões em 2015 para 642 milhões em 2040 (1-5) e segundo a Federal Internacional de Diabetes. Sua etiologia não é completamente definida, porém parece envolver interações variadas que abrangem componentes genéticos, comportamentais e socioeconômicos $(6,7)$ que, por sua vez, resultam em combinação de resistência periférica à ação da insulina e disfunção secretória das células beta pancreática. Caracteriza-se por hiperglicemia crônica e alterações no metabolismo de carboidratos, lipídios e proteínas (8-11).

O DM2 pode ser considerado modelo de aceleração do envelhecimento biológico (de acordo com a teoria do envelhecimento), devido ao aumento da exposição ao estresse oxidativo e inflamação crônica, com manifestações vasculares prematuras do envelhecimento, como a doença isquêmica do coração (12-15).

Os telômeros constituem seqüências repetitivas de ácido desoxirribonucleico (DNA) encontradas nas extremidades de cromossomos lineares e que se complexam a proteínas, cuja função é proporcionar estabilidade genômica (16). Em vertebrados, os telômeros são constituídos pela seqüência TTAGGG; o número de repetições desta seqüência, que determina o comprimento dos telômeros, é variável de indivíduo para indivíduo $(9,17,18)$. Vários fatores são associados a redução do comprimento dos telômeros, entre eles o envelhecimento, o estresse oxidativo e a resposta inflamatória, de forma que o comprimento dos telômeros é considerado potencial marcador destes processos (19-21). Além disso, o comprimento dos telômeros, em alguns estudos, é associado à ocorrência de algumas doenças cuja fisiopatologia envolve estresse oxidativo e resposta inflamatória, como é o caso do DM2 (12, 19, 21-27).

Os leucócitos do sangue periférico constituem o tipo celular mais comumente utilizado para investigar o comprimento dos telômeros em associação com diferentes desfechos metabólicos, devido ao fácil acesso a este tipo celular $(28,29)$. Em estudo 
envolvendo adultos jovens, foi observada correlação positiva entre o encurtamento dos telômeros de leucócitos do sangue periférico e a presença de resistência à insulina, um processo associado a estresse oxidativo e resposta inflamatória de baixo grau (30).

As espécies reativas de oxigênio (ERO) estão envolvidas na indução e progressão da senescência celular. Vários estudos indicam que as ERO podem acelerar o encurtamento dos telômeros (31) e podem danificar o DNA diretamente e, assim, induzir uma resposta a danos no DNA (DDR, DNA damage response) e senescência $(32,33)$. Há vários outros estudos que descrevem a associação entre dano oxidativo, encurtamento dos telômeros e envelhecimento (27, 34-36).

Em concordância com a associação entre estresse oxidativo e o DM2, vários estudos descrevem a associação entre o encurtamento dos telômeros de leucócitos do sangue periférico e a presença de DM2. Entre esses estudos, destacam-se um envolvendo a população do sul asiático avaliada no Estudo em Diabetes Asiático do Reino Unido (UK Asian Diabetes Study) (37), da Índia (38), do México (39) e Itália (40), além de dois estudos envolvendo a população Chinesa $(41,42)$ e um estudo envolvendo índios americanos (43). A associação também foi observada em uma metanálise de 9 estudos, com um total de 5759 casos e 6518 controles (44).

Foi observada, ainda, associação entre o comprimento dos telômeros e o prognóstico em pacientes com DM2. Em estudo recente envolvendo 568 pacientes com DM2, foi observado que o tempo de duração da doença e o comprimento dos telômeros de leucócitos do sangue periférico correlacionou-se com o risco de mortalidade (45).Em outros estudos, no entanto, a associação entre comprimento dos telômeros e presença de DM2 não foi observada. Entre eles, destacam-se o estudo tipo caso-controle aninhado realizado a partir de dados do estudo multiétnico observacional de Coorte Iniciativa em Saúde da Mulher (Women's Health Initiative Observational Study Cohort, WHI-OS), conduzido nos Estados Unidos da América (46), e o estudo envolvendo a população finlandesa analisada no Estudo de Prevenção em Diabetes (Diabetes Prevention Study) (47).

A associação entre encurtamento de telômeros e presença de DM2, observada em muitos estudos, não tem ainda os possíveis mecanismos envolvidos definidos. Não está claro se há associação causal entre comprimento dos telômeros e DM2, nem a 
eventual direcionalidade da associação. É possível, como mencionado anteriormente, que o estresse oxidativo e resposta inflamatória de baixo grau, observados no DM2, expliquem, pelo menos em parte, essa associação (30, 48-52).

Estudo recente relacionou o comprimento dos telômeros a alterações metabólicas observadas no DM2. Esta investigação verificou, em culturas primárias de fibroblastos humanos, o efeito do tratamento com alta concentração de glicose e com a citocina pró-inflamatória IL1ß, isolados ou em combinação, e observou que apenas o grupo de células tratado com IL1ß apresentou encurtamento acelerado dos telômeros, mesmo após ajuste para o número de divisões celulares (53).

Cabe destacar, ainda, que embora a associação entre DM2 e comprimento de telômeros seja observada utilizando-se leucócitos do sangue periférico, é possível que seja reflexo do encurtamento dos telômeros nas células beta pancreáticas, processo potencialmente relacionado à maior taxa de apoptose destas e, assim, maior risco de DM2 e suas complicações (54). A diversidade de resultados dos estudos encontrados na literatura pode, ainda, refletir que a dinâmica dos telômeros seja influenciada pela variabilidade genética/grupo populacional $(43,55)$.

Considerando-se que a associação entre o comprimento dos telômeros e a ocorrência de DM2 não foi estudada na população brasileira e que a associação entre estas variáveis possa variar conforme a grupo populacional, a proposta desse estudo foi de investigar a associação entre o comprimento dos telômeros e a presença de DM2. 


\section{REVISÃO DE LITERATURA}

\subsection{Diabetes Mellitus Tipo 2}

O DM2 constitui grupo de doenças metabólicas que apresenta, como característica comum, hiperglicemia crônica resultante de defeitos da secreção e ação da insulina (56-59). A hiperglicemia crônica, por sua vez, é associada ao desenvolvimento de danos em longo prazo, que incluem disfunção e insuficiência de diferentes órgãos, em especial rins, nervos, retina e coração. Sua etiologia é multifatorial e sua prevalência, morbidade e mortalidade vêm aumentando rapidamente em todo o mundo $(5,60,61)$.

O DM2 tem como principais componentes fisiopatológicos a resistência à ação da insulina e deficiência secretória relativa das células beta $(62,63)$. Entre os fatores de risco para a sua ocorrência, destacam-se o excesso de peso (sobrepeso ou obesidade), história familiar de DM2 e/ou de diabetes gestacional, bem como hipertensão arterial e dislipidemia (64-66).

A obesidade, especificamente, não apenas constitui fator de risco significativo para o desenvolvimento do DM2, como também resulta em impacto negativo sobre a progressão do diabetes, sendo observado aumento da morbidade e mortalidade entre pacientes obesos com $\operatorname{DM} 2(9,67,68)$. A obesidade freqüentemente se apresenta no contexto da síndrome metabólica (SMet). Esta é caracterizada por associação de alterações metabólicas interconectadas, que aumentam 0 risco de doenças cardiovasculares. As características clínicas e bioquímicas da SMet, além da obesidade e do DM2, incluem a dislipidemia aterogênica [triglicerídeos (TGL) aumentados, diminuição da lipoproteína de alta densidade (HDL-c) e aumento da quantidade de partículas pequenas e densas lipoproteína de baixa densidade (LDL-c), mais aterogênicas], hipertensão arterial sistêmica, elevação de marcadores pró-inflamatórios e pró-trombóticos, bem como aumento de anti-fibrinolíticos(69). A SMet também está associada a variedade de outras condições, como a doença hepática gordurosa não alcoólica, síndrome de apneia obstrutiva do sono, síndrome dos ovários policísticos, cálculos biliares de colesterol e periodontite $(67,70-72)$. 


\subsubsection{Aspectos epidemiológicos do diabetes mellitus}

A incidência do DM2 está aumentando, nas últimas décadas, em proporções epidêmicas, sobretudo na faixa etária entre 30 e 69 anos $(73,74)$, e em paralelo à epidemia da obesidade, constituindo um dos maiores problemas de saúde pública mundial $(75,76)$. A doença está associada a elevada morbidade e mortalidade, comprometimento da qualidade de vida e aumento dos custos relacionados à saúde.

Em 2010, os custos relacionados ao tratamento do DM2 e de suas complicações totalizaram 376 bilhões de dólares, ou $12 \%$ das despesas de saúde global o que representa gasto anual de 1330 dólares por pessoa $(77,78)$.A prevalência do DM2 aumentou muito em todos os países, inclusive os de baixa e média renda, nas últimas décadas. Os dados mais recentes da Federação Internacional de Diabetes (IDF) indicam que o DM2 afetou 415 milhões de pessoas em todo o mundo em 2015, número que deverá crescer para 462 milhões até 2040(3,79).

A prevalência global estimada em 2013 foi de 8,3\% entre as pessoas com idades entre 20 e 79 anos, com os países mais populosos do mundo, a Índia e a China, atingindo taxas de prevalência entre 9 e 10\%, correspondentes a 65 e 100 milhões em números absolutos, respectivamente. Particularmente, elevadas taxas de prevalência são encontradas no México $(12,6 \%)$ e Egito $(16,8 \%)$, superando as taxas da maioria dos países de alta renda, incluindo os EUA $(9,2 \%)$ e Alemanha $(8,2 \%)(5,79-81)$.

Dados mais recentes apontam que a prevalência global entre os sexos masculino e feminino em 2015 é mais frequente em mulheres (199,5 milhões) do que homens (215,2 milhões) (5).O aumento da prevalência de diabetes em países de média e baixa renda parece estar relacionado à rápida urbanização, à transição da nutrição e a estilos de vida cada vez mais sedentários (75). A forma mais comum de diabetes, o DM2, afeta cerca de $90 \%$ das pessoas com diabetes, enquanto os $10 \%$ restantes são representados principalmente pelo DM1 e diabetes gestacional $(75,79,82)$.

No Brasil, o DM2 foi responsável por 5,3\% dos óbitos ocorridos em 2011, com taxa de mortalidade de 33,7 óbitos a cada 100 mil habitantes, apesar da redução de $1,7 \%$ ao ano verificado no período entre 2000 e 2011. A mortalidade por complicações 
agudas da doença, quase sempre preveníveis pelo pronto atendimento, foi de 2,45 óbitos por 100 mil habitantes em 2010, sendo de 0,29 por 100 mil habitantes entre os menores de 40 anos de idade (83).

Estima-se que o número de adultos com intolerância à glicose, ou pré-diabetes, vai aumentar de 344 milhões em 2010 para 472 milhões em 2030 (73, 75). O aumento da prevalência da doença, por sua vez, ameaça reverter os ganhos econômicos dos países em desenvolvimento, que apresentam, em geral, infraestrutura limitada para tratamento da doença (84).

\subsubsection{Fisiopatologia do diabetes mellitus tipo 2}

A hiperglicemia que caracteriza o DM2, como comentado anteriormente, é resultado, sobretudo, da combinação de resistência à insulina e de secreção inadequada de insulina pela célula beta- pancreática (Figura 1). A contribuição relativa de cada um desses fatores é variável entre diferentes pacientes (85) e ambos são influenciados por interações entre fatores genéticos e ambientais $(6,86,87)$. Sua conseqüência, a hiperglicemia crônica, apresenta importante papel na gênese das complicações crônicas da doença $(57,65,88)$. 


\section{DISFUNÇÃO SECRETÓRIA DA CÉLULA BETA PANCREÁTICA}

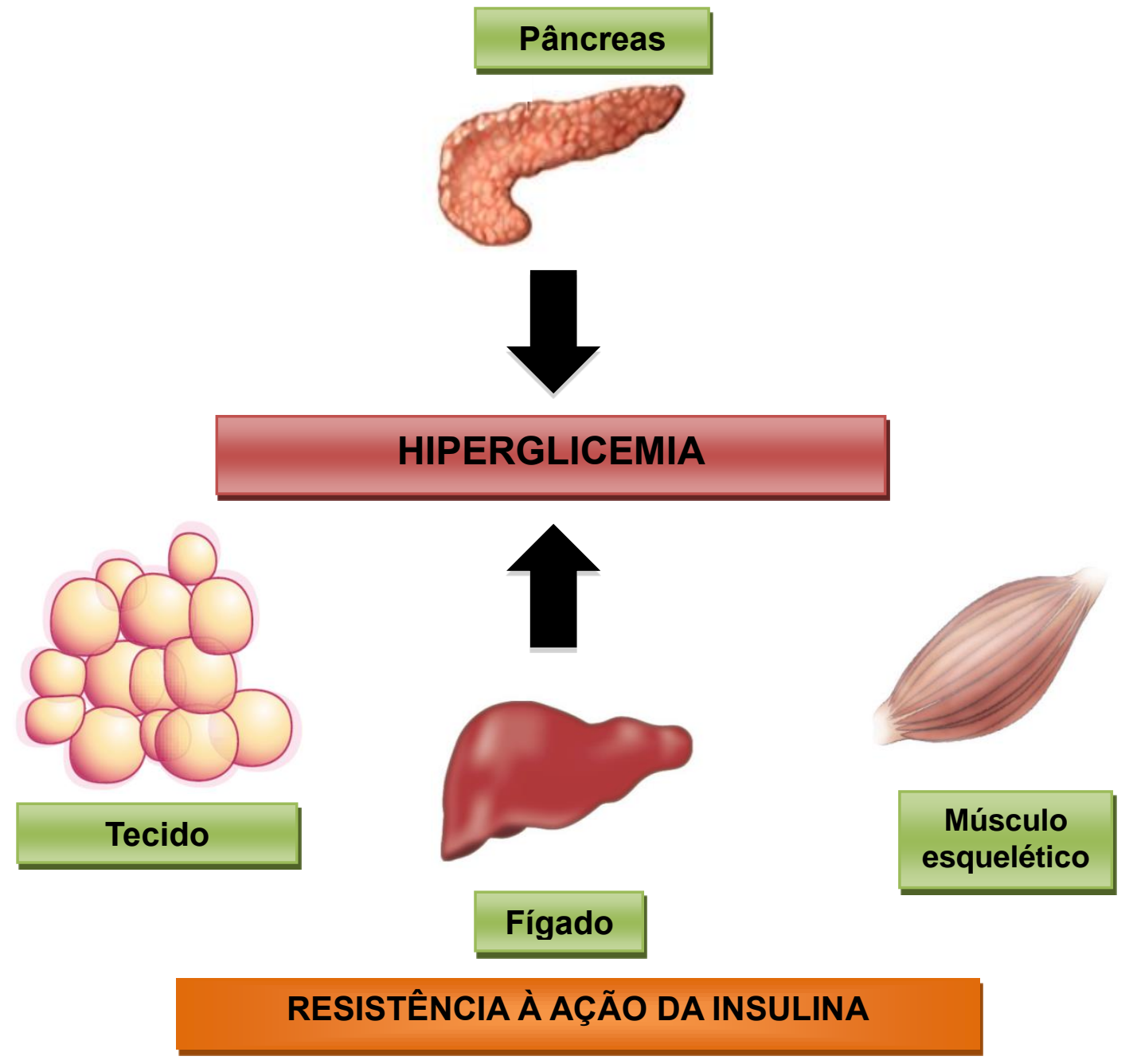

Figura 1. Esquema simplificado da fisiopatologia do DM2. A resistência à ação da insulina, em particular no fígado, tecido adiposo e músculo esquelético, em conjunto com disfunção secretória da célula beta pancreática, determinam a hiperglicemia crônica, característica do DM2. A contribuição de cada componente fisiopatológico, resistência à insulina e disfunção da célula beta, são variáveis nos diferentes portadores de DM2. 
Os mecanismos patogênicos em DM2 não envolvem apenas insulina, mas também o glucagon, um hormônio produzido pelas células alfa das ilhotas e principal hormônio contrarregulador da glicose. Fisiologicamente, a insulina inibe a secreção do glucagon; em situações como o jejum, a redução da concentração circulante de glicose, em presença de menores concentrações circulantes de insulina, estimula a secreção do glucagon que, por sua vez, estimula uma série de processos que apresentam como efeito final comum o aumento da concentração circulante de glicose (65).

No DM2, com o declínio progressivo da função secretória das células beta pancreáticas, ocorre diminuição da secreção de insulina e supressão insuficiente de secreção de glucagon $(57,73)$. Em conjunto com a resistência à insulina, o aumento da secreção de glucagon se traduz em redução das respostas metabólicas à insulina (65, 89)

Em populações de alto risco para desenvolvimento de DM2, em especial de obesos, a resistência à insulina está bem estabelecida muito antes do desenvolvimento de hiperglicemia, particularmente em indivíduos com acúmulo de gordura abdominal ou ectópica $(65,77)$. Neste contexto, a resistência à insulina é compensada por aumento da secreção de insulina pelas células beta. Quando se soma a disfunção secretória da célula beta, no entanto, a resistência insulínica não é mais compensada e observa-se o desenvolvimento de glicemia de jejum alterada e/ou intolerância oral à glicose, estados conhecidos como pré-diabetes ou disglicemia, e caracterizados por concentrações circulantes de glicose superiores às normais porém não suficientes para o diagnóstico de diabetes. Quando a disfunção secretória da célula beta se torna mais grave, a hiperglicemia atinge valores compatíveis com o diagnóstico do diabetes $(65,90)$.

A hiperglicemia crônica resulta em dano tecidual por cinco mecanismos principais: (i) aumento do fluxo de glicose e outros açúcares através da via do poliol, (ii) aumento da formação de produtos finais de glicação avançada, (iii) aumento da expressão dos receptores de produtos finais de glicação avançada, (iv) ativação da proteína quinase $C(P K C)$ e $(v)$ aumento da atividade da via da hexosamina. Todos estes eventos resultam em aumento da produção mitocondrial de $\operatorname{ERO}(91,92)$ no endotélio da micro e macrocirculação, e constituem eventos essenciais ao desenvolvimento das complicações vasculares (57) (14). 
As complicações diabéticas microvasculares, específicas da doença, são determinadas por hiperglicemia crônica. Há também a contribuição de fatores genéticos e outros fatores de risco para desenvolvimento de aterosclerose, como hipertensão arterial e dislipidemia (61, 93-95).

\subsubsection{Diagnóstico do diabetes mellitus tipo 2}

A hiperglicemia que caracteriza o DM2 é muitas vezes assintomática ou acompanhada de sintomas inespecíficos, como tonturas, turvação visual e cãibras, de forma que quando não rastreada de rotina a doença pode ser diagnosticada tardiamente. A Associação Americana de Diabetes (American Diabetes Association, ADA) recomenda que a doença seja rastreada a partir dos 45 anos, em indivíduos assintomáticos, ou mais precocemente, na presença de fatores de risco, incluindo sedentarismo, sobrepeso/obesidade, história familiar de DM, história pessoal de doença cardiovascular, mulheres com antecedente de macrossomia fetal, hipertensão arterial, síndrome dos ovários policísticos, HDL baixo ou hipertrigliceridemia $(96,97)$.

O rastreamento, assim como o diagnóstico, deve ser realizado pela investigação de hiperglicemia, avaliada pela glicemia de jejum, glicemia aleatória (independentemente do último horário da última refeição), glicemia pós-sobrecarga oral de glicose ou hemoglobina glicada (98).

No Quadro 1, são apresentados os valores de glicemia considerados normais, indicativos de pré-diabetes ou de DM para cada um desses testes. Segundo a Sociedade Brasileira de Diabetes, a glicemia de jejum e a hemoglobina glicada constituem a maneira mais usual de avaliação para diagnóstico do DM2. A hemoglobina glicada constitui o produto da reação não enzimática entre a glicose e um grupo aminoterminal de resíduo de valina na cadeia beta da hemoglobina. O percentual de hemoglobina glicada depende da concentração plasmática média de glicose e constitui indicador da concentração média de glicose nos 3 meses anteriores, período que representa o tempo médio de vida de uma hemácia. Quanto maior a concentração plasmática de glicose, maior será a porcentagem de hemoglobina glicada (1, 57, 99, 100). 
Em 1997 e 2003, o Comitê de Especialistas em Diagnóstico e Classificação do diabetes mellitus reconheceu um grupo intermediário de indivíduos cujas concentrações circulantes de glicose não satisfazem aos critérios para o diagnóstico do DM, mas são mais elevados que os normais $(57,96,101-103)$. Estes indivíduos, indicados como prédiabéticos, podem ser separados em duas diferentes condições: glicemia de jejum alterada (GJA) e intolerância oral à glicose (IOG), dependendo do tipo de teste utilizado para o diagnóstico (65)

Quadro 1. Critérios para o diagnóstico de tolerância normal à glicose, pré-diabetes e DM2.

\begin{tabular}{|c|c|c|c|}
\hline Categoria diagnóstica & $\begin{array}{l}\text { Glicemia de } \\
\text { jejum } \\
(\mathrm{mg} / \mathrm{dL})^{1}\end{array}$ & $\begin{array}{c}\text { Glicemia pós- } \\
\text { sobrecarga oral de } \\
\text { glicose }(\mathrm{mg} / \mathrm{dL})^{2}\end{array}$ & $\begin{array}{c}\text { Hemoglobina } \\
\text { glicada (\%) }\end{array}$ \\
\hline Tolerância normal à glicose & $<99$ & $<140$ & $<5,7$ \\
\hline Pré-diabetes & $100-125$ & $140-199$ & 5,7 a 6,4 \\
\hline Diabetes $^{3,4}$ & $\geq 126$ & $\geq 200$ & $\geq 6,5$ \\
\hline \multicolumn{4}{|c|}{ Fonte: Associação Americana de Diabetes e Sociedade Brasileira de Diabetes. } \\
\hline \multicolumn{4}{|c|}{$\begin{array}{l}\text { 'Glicemia de jejum: glicemia após jejum de } 8 \mathrm{~h} ; 2 \text { avaliada pela administração de } 75 \mathrm{~g} \text { de glicose anidra, por via oral, } \\
\text { e avaliação da glicemia após duas horas; } 30 \text { diagnóstico do diabetes pode ser realizado também pela determinação } \\
\text { da glicemia aleatória; para valores superiores a } 200 \mathrm{mg} / \mathrm{dL} \text {, em presença de sintomas de diabetes, o diagnóstico } \\
\text { é confirmado; } 4 \text { Para confirmação diagnóstica do DM, a presença de qualquer um dos } 3 \text { testes positivos (glicemia de } \\
\text { jejum, glicemia pós-sobrecarga ou hemoglobina glicada) deve ser confirmada pela repetição do teste realizado } \\
\text { ou realização de segundo teste diferente. }\end{array}$} \\
\hline
\end{tabular}

\subsubsection{Estresse oxidativo e lipoperoxidação no diabetes mellitus tipo 2}

O estresse oxidativo (EO) pode ser definido como desequilíbrio entre compostos oxidantes e antioxidantes, em favor da geração excessiva de radicais livres ou em detrimento da velocidade de remoção destes, e que potencialmente determina dano oxidativo em células e tecidos(104).

O crescimento excessivo do tecido adiposo pode ocasionar aumento da produção de ácidos graxos não esterificados (AGNE), o que dá início à disfunção mitocondrial, que se configura pela redução de ATP (adenosina-trifosfato), acúmulo de sódio e cálcio intracelulares, com aumento da produção de ERO. Estes, por sua vez, 
constituem importante componente fisiopatológico da resistência à ação da insulina, alterações da homeostase da glicose e doença cardiovascular $(68,92,95)$.

No contexto da obesidade abdominal e SMet, o tecido adiposo constitui tecido chave de início da resposta inflamatória e EO que determinam a resistência à ação da insulina. O tecido adiposo é considerado hoje não um simples órgão para armazenamento energético, mas um tecido dinâmico, que participa ativamente da comunicação intertecidual responsável pela regulação do metabolismo energético (105108) (Figura 2).

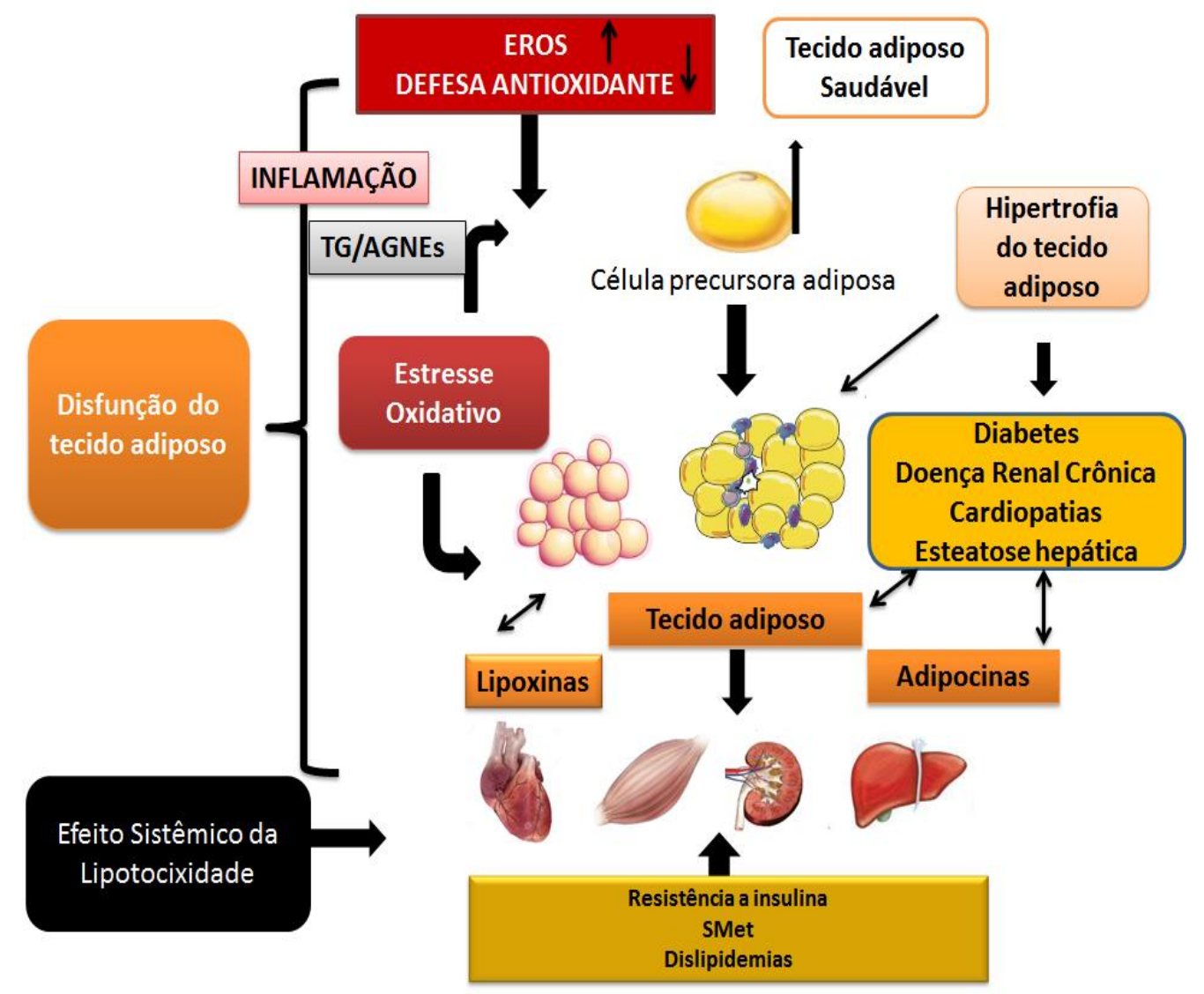

Figura 2. Tecido adiposo, estresse oxidativo e fisiopatologia de doenças metabólicas. A disfunção do tecido adiposo ocasiona processo inflamatório e lipotoxicidade, cujas manifestações são a esteatose hepática e deposição muscular de lipídeos e dislipidemias, que podem ser fator de risco para DM, doença renal crônica e cardiopatias. Adaptado de Murdolo e Colaboradores(2013) (68).

Alterações da homeostase energética são associadas ao envelhecimento por meio da teoria do envelhecimento relacionada aos radicais livres, que postula que o 
aumento da produção de ERO resulta em dano celular $(68,109)$. As ERO, assim como espécies reativas de nitrogênio (ERN), em condições normais, são importantes reguladores de processos fisiológicos. No entanto, o excesso de produção destes compostos leva ao aumento da atividade de algumas vias intracelulares que estão relacionadas ao aparecimento de várias doenças (110). O EO é implicado como potencial mecanismo na patogênese de complicações diabéticas micro e macrovasculares, tanto por aumento e produção de radicais livres $(111,112)$, como por diminuição da defesa antioxidante $(113,114)$.

Acredita-se que um dos importantes desencadeadores do EO no DM seja a hiperglicemia $(66,115,116)$. No entanto, alguns autores não indicam ligação direta entre hiperglicemia e o EO (117).

Os mecanismos que determinam aumento do EO no DM2 incluem fatores relacionados diretamente à hiperglicemia, como aumento não enzimático da glicosilação de biomoléculas $(118,119)$ e auto-oxidação da glicose, além da resposta inflamatória $(51,120,121)$, resistência à insulina e dislipidemia. Cada um destes contribui para a superprodução de superóxido mitocondrial em células chave das complicações da doença, como as células endoteliais (26). O principal determinante de mortalidade entre portadores de DM2 são as doenças cardiovasculares, associadas à aterosclerose acelerada (122). A fisiopatologia da aterosclerose no contexto do DM2 é complexa, envolvendo a hiperglicemia crônica e a dislipidemia característica de estados de resistência à insulina $(92,123-127)$.

O aumento do EO é evidente pouco tempo após a instalação das alterações metabólicas relacionadas ao DM2 e antes que as complicações vasculares tornem-se manifestas (128-130), em concordância com seu papel causal no desenvolvimento destas complicações. Além disso, os efeitos do EO em indivíduos com DM2 são agravados pela inativação de duas enzimas envolvidas em proteção vascular, a sintetase de óxido nítrico endotelial e sintetase de prostaciclina (26).

As alterações glicêmicas e a resistência à insulina estão associadas à liberação de citocinas pró-inflamatórias, como interleucina 1 beta (IL-1ß) e fator de necrose tumoral alfa (TNF- $\alpha)(131,132)$. 
O estado pró-inflamatório resultante também pode levar à maior formação de ERO e, assim, contribuir para o EO (132-135). A lipoperoxidação (LPO) é conseqüência da ação de ERO sobre lipídeos. Os ácidos graxos interagem com as ERO que, por sua vez, alteram a estrutura dos lipídeos da membrana celular e isto desencadeia uma seqüência de eventos que resulta em lesão celular $(136,137)$ (Figura 3).

Além do dano aos lipídeos celulares, os ER danificam outras biomoléculas, incluindo ácidos nucleicos e proteínas $(138,139)$. O radical hidroxila é reage com todos os componentes da molécula de DNA: bases nitrogenadas e também a desoxirribose. Uma das conseqüências da reação com o DNA é a formação de 8-OH-G(8hidroxiguanidina) que, por sua vez, modifica permanentemente o material genético (14, 140).

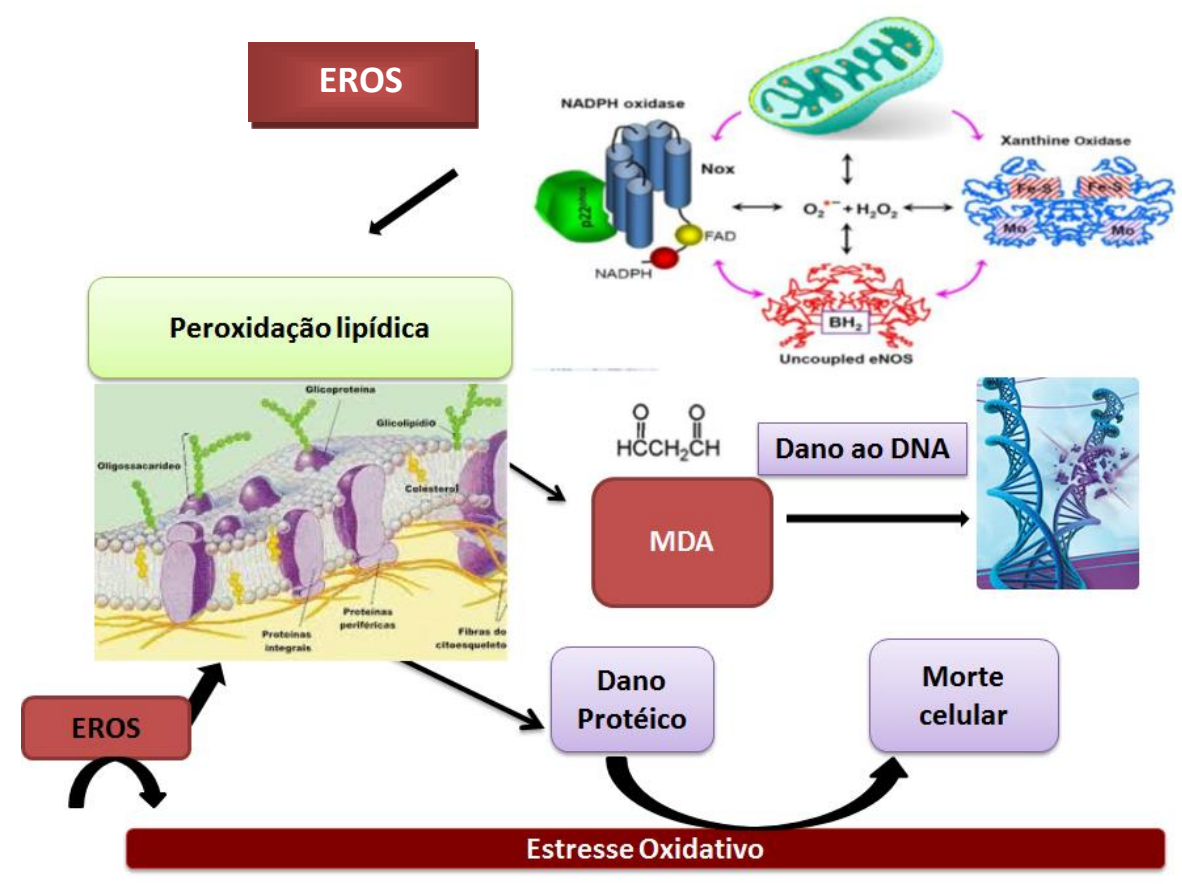

Figura 3. Formação de Espécies Reativas de Oxigênio (EROS) e estresse oxidativo. O EO desempenha papel importante em processos fisiológicos e patológicos. A produção de ERO a partir de qualquer fonte pode conduzir à ativação das oxidases de NADPH, e a conversão da xantina desidrogenase em xantina oxidase, pode estimular a produção de espécimes reativas de oxigênio na mitocôndria ou resultar no desacoplamento da óxido-nítrico sintetase endotelial (eNOS). Adaptado de Dikalov e colaboradores (2011) (141). 
Todas estas alterações celulares relacionadas ao EO resultam, em conjunto, em comprometimento da integridade celular (132, 142-144). Diante destes aspectos, o EO e a peroxidação lipídica a ele associada, vêm sendo considerados mecanismo importante na fisiopatologia de doenças associadas à resposta inflamatória e senescência celular, como o DM2 e suas complicações micro e macrovasculares (145150).

Marcadores de LPO podem ser utilizados para monitorar o estado de estresse oxidativo. Entre eles, destaca-se a determinação de substâncias reativas ao ácido tiobarbitúrico (TBARs) (151) que quantifica hidroperóxidos de lipídeos e aldeídos, como o malondialdeído (MDA) (152), em amostra de soro através do método colorimétrico (153). Uma molécula de MDA reage com duas moléculas do ácido 2-tiobarbitúrico, via condensação tipo Knoevenagel, para gerar cromóforos com absorbância máxima em 532 nm (Figura 4). Em consistência com a utilidade destes marcadores, há diversos estudos que sugerem a associação entre o DM2 e a elevação da concentração de marcadores de EO circulantes (101, 154-156).

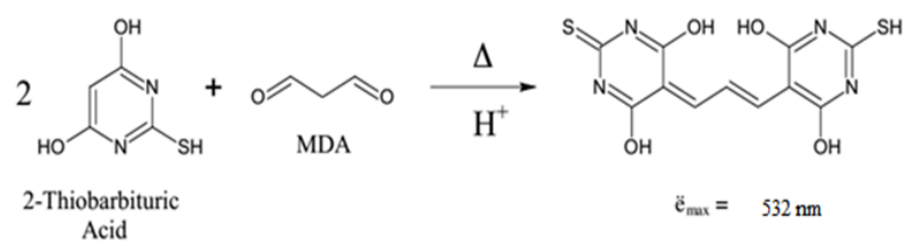

Figura 4. Reação entre o ácido tiobarbitúrico (TBARS) e malondialdeído (MDA) e absorbância máxima de 532nm (nanômetros) Benzie e Colaboradores (1996)(157).

\subsubsection{Defesas antioxidantes no diabetes mellitus tipo 2}

O DM2 é caracterizado por vários distúrbios metabólicos que comprometem o equilíbrio entre as ERO e defesas antioxidantes celulares (12). O EO, como descrito anteriormente, decorre de desequilíbrio entre a geração de compostos oxidantes e a atuação dos sistemas de defesa antioxidante (121). No DM2, além do aumento da 
produção de $\mathrm{ERO}$, é observada também redução da capacidade antioxidante(158, 159).

A exposição a radicais livres a partir de variedade de fontes levou os organismos desenvolverem uma série de mecanismos de defesa antioxidante (160). Os antioxidantes são agentes químicos ou biológicos capazes de neutralizar a ação potencialmente prejudicial dos radicais livres (114). Durante o processo evolutivo, em resposta à criação de radicais livres, mecanismos de defesa antioxidantes protetores foram criados. Em um corpo saudável, há um equilíbrio entre processos oxidativos e sua capacidade antioxidante; mas quando o equilíbrio é perturbado, "moléculas biologicamente hiperativas de oxigênio" gerado, podem atuar como agentes de sinalização através de vários caminhos chamados de "sinalização-redox"(121).

Assim é possível que a redução dos sistemas de defesa antioxidante estejam envolvidos no desenvolvimento de doenças neurodegenerativas, DM2, cardiopatias, entre outras $(138,139,161,162)$.Os antioxidantes atuam por diferentes mecanismos, denominados mecanismos preventivos, físicos ou enzimáticos. Entre os sistemas de defesa enzimáticos estão as enzimas superóxido dismutase (SOD), glutationa peroxidase (GPx) e a catalase (CAT). Os antioxidantes não enzimáticos são representados pelo ácido ascórbico (vitamina $\mathrm{C}$ ), tocoferol (vitamina E), glutationa (GSH), carotenoides, flavonoides, licopeno, beta-caroteno, vitamina A, retinol, coenzima Q10, entre outros $(139,163)$.

O plasma e soro humanos representam excelente fonte de marcadores in vivo de estresse oxidativo, uma vez que nele são transportados e redistribuídos antioxidantes e endobióticos modificados por ação de $\operatorname{ERO}$ e $\operatorname{ERN}(138,164,165)$. Há muitos compostos presentes no plasma que protegem células e biomoléculas do EO. A ação combinada de todas as moléculas com atividade antioxidante no plasma representa a capacidade antioxidante do plasma $(166,167)$.

De acordo com a Sociedade Brasileira de Diabetes(59) um marcador de estresse oxidativo ideal deve ser capaz de fornecer indicação precoce da doença e/ou de sua progressão. Suas características devem ser: 
i. Um produto estável, não suscetível à indução por artefatos, oxidação ou perda durante o processamento, a análise e o armazenamento; acessível por meio do tecido-alvo ou de um material biológico derivado deste tecido;

ii. Detectado em concentrações suficientes; específico da ERO a ser avaliada e não sofrer interferência de fatores que possam alterar os resultados.

iii. Reprodutível; de fácil detecção em estudos populacionais; e apresentar pouca variabilidade intraindividual.

Sabe-se que há evidência clínica e experimental do aumento do estresse oxidativo em ambos os tipos de diabetes, inclusive em suas fases precoces; há, no entanto, controvérsias sobre qual marcador de estresse oxidativo seria mais confiável e aplicável na prática clínica $(168,169)$.

Um dos marcadores que podem ser utilizados para avaliação da peroxidação lipídica são os isoprostanos que constituem uma série de compostos semelhantes às prostaglandinas formados in vivo por um mecanismo não enzimático envolvendo peroxidação do ácido araquidônico por ERO, independente da ciclo-oxigenase(170172).

Em concordância com o papel do EO na fisiopatologia do DM2, alguns estudos sugerem que marcadores de defesa antioxidantes estão presentes em baixa concentração no plasma e soro de pacientes com a doença, quando comparados a controles com tolerância normal à glicose (173-175). O aumento de marcadores de EO e a diminuição da capacidade antioxidante estão correlacionados também com as complicações crônicas do DM2 (176), incluindo retinopatia, nefropatia, neuropatia e cardiopatia(177).

Diversas abordagens metodológicas foram desenvolvidas para avaliar as defesas antioxidantes. A capacidade antioxidante total (CAOT) foi primeiramente utilizada para caracterizar a capacidade do plasma em diminuir a oxidação, induzida quimicamente, de substrato facilmente detectável (178). O termo "CAOT" foi introduzido como denominação genérica (179) e, atualmente, inclui ensaios diferentes $(180,181)$ 
utilizados para avaliar as defesas antioxidantes em fluidos corporais, alimentos, bebidas e outros sistemas biológicos ou químicos.

A avaliação da CAOT é baseada na mistura de um substrato oxidável e um agente oxidante para obtenção de oxidação máxima do substrato a ausência ou presença da amostra em que se pretende avaliar a capacidade antioxidante. A extensão da oxidação do substrato define a proteção conferida por defesas antioxidantes na amostra. A maioria destes ensaios apresenta bom desempenho e execução simples daí sua realização frequente (182).

Uma molécula de antioxidante pode ser identificada pela sua estrutura química. Este tipo de molécula participa de reações de eliminação de radicais livres e / ou a quelação de metais redox-ativos. Um ensaio baseado neste princípio é o de capacidade de absorção de radicais oxigenados (ORAC), em que a amostra a ser testada é "desafiada" com o radical peroxila; este ensaio avalia apenas substâncias capazes de interceptar estes radicais.

A medida plasmática direta de ERO é difícil, devido à alta reatividade dessas moléculas. Alguns estudos têm focado a medida da capacidade total antioxidante do plasma (total antioxidant buffering capacity of plasma), que reflete a resposta do sistema antioxidante à presença de ERO (176).

Outro ensaio para medida de defesas antioxidantes, especificamente no plasma, é o poder antioxidante de redução do ferro (ferric reducing ability of plasma), considerado medida direta do "poder antioxidante total". Neste ensaio, realizado em pH baixo, os antioxidantes presentes no plasma reduzem $\mathrm{Fe}^{+3}$ a $\mathrm{Fe}^{+2}$, o qual é quelado pela 2,4,6-Tri(2-piridil)-s-triazina (TPTZ) para formar o complexo $\mathrm{Fe}^{+2}$-TPTZ, de coloração azul intensa, cuja formação pode ser detectada em espectrofotômetro a 593 nm $(157,183)$. 


\subsection{TELÔMEROS E TELOMERASE}

\subsubsection{Histórico e considerações gerais}

Os telômeros constituem repetições da seqüência TTAGGG, com comprimento total variável, implicadas na manutenção da integridade dos cromossomos eucarióticos lineares e, assim, da estabilidade cromossômica $(44,184)$.

As extremidades cromossômicas foram descritas por Muller e Bárbara McClintock em 1938, em seus estudos com Drosophila (mosca da fruta). Este pesquisador inicialmente observou que as extremidades de cromossomos lineares apresentavam propriedades únicas, e as denominou de telômeros (do grego telos, "fim" e mero, "parte"), com base em sua posição cromossômica. Em experimentos de indução de quebras cromossômicas por raios $\mathrm{X}$, Muller observou que as extremidades cromossômicas apresentavam resistência significativa aos efeitos dos raios $\mathrm{X}$, e postulou que estas regiões apresentariam um gene "terminal", com função de proteger o cromossomo e garantir sua estabilidade (185).

Subseqüentemente, observou-se, em estudos com o protozoário Tetrahymena e com leveduras, que as extremidades dos cromossomos eram protegidas por seqüência repetidas de hexanucleotídeos (5'-CCCCAA-3' em uma fita e 5'-TTGGGG-3' na outra, na Tetrahymena), e que não eram codantes, ou seja, não representavam genes como Muller havia postulado (186-189). Mais recentemente, foi mostrado que as extremidades dos cromossomos eucarióticos apresentam a mesma estrutura geral (seqüência repetitivas ricas em guanina e timina), o que indica sua conservação ao longo da evolução e reforça, assim, sua importância $(190,191)$.

Quando esta estrutura é ausente, a fusão de extremidades cromossômicas pode ocorrer, com subsequente morte celular. Na década de 1970, James D. Watson descreveu o que ele chamou de "problemas de replicação final". Durante a replicação do DNA, a DNA polimerase não replica totalmente a extremidade 5' terminal do cromossomo, deixando uma pequena região do telômero não copiada. Ele postulou que seria necessário mecanismo compensatório para preencher esta lacuna terminal do cromossomo $(192,193)$. Em meados dos anos 1980, no trabalho seminal de Blackburn 
e Greider, foi descrita a existência de atividade enzimática em extratos de células embrionárias capazes de acrescentar seqüência repetidas de hexanucleotídeos às extremidades dos cromossomos naturais, o que levou, mais tarde, à identificação da enzima telomerase $(189,194)$.

A integridade dos telômeros é condição essencial à manutenção da capacidade de divisão celular. Acreditava-se, inicialmente, que células normais mantidas em cultura apresentavam capacidade indefinida de se dividir. Entretanto, 0 processo de senescência celular ficou bem estabelecido. Existem dois tipos de senescência celular: (i) a replicativa proposta por Hayflick e (ii) a senescência prematura(195-197).

Leonard Hayflick's observou que fibroblastos humanos normais mantidos em cultura apresentavam sobrevida limitada, diferentemente de células tumorais (198), e denominou esta capacidade finita das células normais de "limite de Hayflick", conhecido também como senescência replicativa. Subseqüentemente, inúmeros experimentos foram conduzidos para compreender os mecanismos responsáveis pelo "limite de Hayflick" e foi observado que um de seus principais determinantes é o comprimento dos telômeros $(197,199)$. A cada divisão celular, o comprimento do DNA telomérico tende a diminuir e, depois que atinge limite crítico, a sobrevida da linhagem celular é limitada por mecanismos como apoptose e degeneração, caracterizando a senescência celular (200-202).

De acordo com as teorias estocásticas do envelhecimento, os danos que se acumulam com o tempo nos componentes celulares são responsáveis pelo envelhecimento celular que pode dar início à senescência prematura, e esta pode ser acionada por fatores distintos tais como: estresse oxidativo e à presença de agentes que atuem ao nível subcitotóxico, infecções virais, ativação de oncogenes, processos inflamatórios crônicos ("fenótipo secretor associado à senescência" -SASP)e danos ao DNA(195, 196, 203-206)

\subsubsection{Estrutura dos telômeros e atividade da telomerase}

Os telômeros dos humanos consistem de repetições da seqüência TTAGGG seguidas, na extremidade 3', de seqüência rica em guanina em cadeia simples (194), 
conforme esquematizado na Figura 5. Nesta extremidade, o DNA dobra-se sobre si mesmo para formar uma alça, denominada alça $T$ (T-loop) (18). As seqüência teloméricas se ligam a complexos proteicos, com funções variadas, entre elas a de promover a formação da alça $\mathrm{T}$, regular o comprimento do telômeros e proteger as extremidades dos cromossomos lineares (18, 190, 191, 207)(Figura 5).

A atividade de telomerase, observada inicialmente no protozoário Tetrahymena thermophila por Blackbun e Greider em 1985 (208), foi identificada em células humanas em 1989, por Morin. A pequena quantidade de telomerase em células humanas dificultava os avanços das pesquisas, até que em 1994 foi desenvolvido um ensaio baseado em PCR, denominado protocolo de amplificação de repetições teloméricas (TRAP, telomeric repeat amplification protocol), por Shay, Wright e colaboradores, que aprimorou a capacidade de detecção da atividade da enzima em células humanas. A partir daí, uma série de investigações foi realizada e permitiu melhor caracterização da telomerase. A importância dos achados destas investigações foi destacada em 2009, quando 3 pesquisadores envolvidos nestas investigações, Elizabeth Blackburn, Jack Szostak e Carol Greider, foram laureados com o Prêmio Nobel da Medicina $(209,210)$

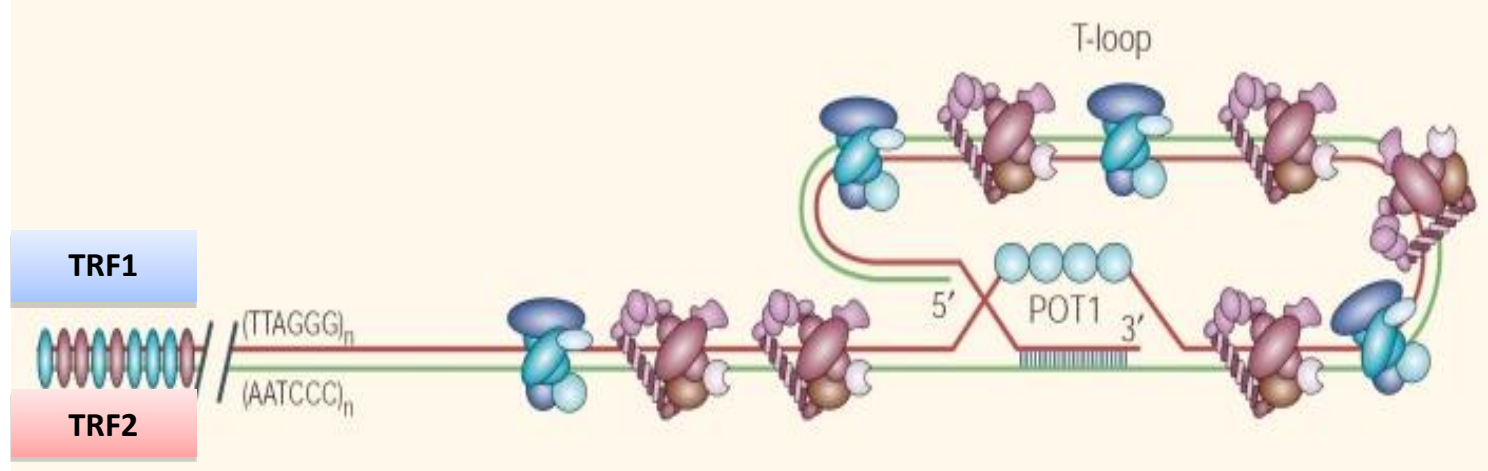

Figura 5. Estrutura proposta para o complexo telomérico humano. Os telômeros são constituídos de repetições da seqüência TTAGGG (e de sua seqüência complementar, na estrutura da dupla hélice de DNA), e na fita com extremidade 3' livre há protrusão das repetições TTAGGG de fita simples seguida de seqüência, também fita simples, rica em guanina. Esta região forma uma alça (alça-T, T-loop) e o segmento de fita simples na extremidade invade a dupla hélice, desloca uma porção da fita contendo as repetições TTAGGG (que se liga à proteína POT1) e pareia-se com a fita complementar. As outras proteínas representadas esquematicamente (TRF, TTAGGG repeat-binding factors, 1 e 2) associam-se às repetições TTAGGG na fita dupla. Fonte: de Lange, 2004 (191). 
A telomerase é um complexo ribonucleoproteico único composto pela subunidade catalítica denominada transcriptase reversa da telomerase (hTERT, human telomerase reverse transcriptase), um componente de RNA da telomerase (TR ou TERC, telomerase RNA) e pela disquerina (DKC1). O componente de RNA atua como molde para a extensão dos telômeros, na medida em que é constituído por repetições da seqüência complementar à dos telômeros (5'-CCCTGG-3') $(211,212)$ (Figura 6). A função da telomerase é altamente regulada em células normais, por mecanismos complexos, que incluem o controle transcricional e pós-transcricional da subunidade catalítica hTERT $(194,213)$.A maturação do complexo da telomerase, formado pelas subunidades TERT e TR, ocorre através de diversas associações de proteínas no corpo Cajal $(212,214,215)$.

Embora TERT e TR sejam suficientes para gerar a atividade da enzima in vitro, a telomerase depende de outras proteínas para a sua montagem e regulação $(212,216)$. Uma das proteínas do complexo da telomerase em mamíferos, melhor caracterizada é a proteína disquerina. A disquerina (DK1) forma um complexo central com três proteínas menores, NHP2, NOP10 e GAR1 (217), que se liga a um motivo H/ACA de RNA estrutural dentro da TERC (bem como pequenas moléculas de RNA nucleolar) e é essencial para a estabilidade e função telomerase in vivo $(218,219)$ (Figura 06). 


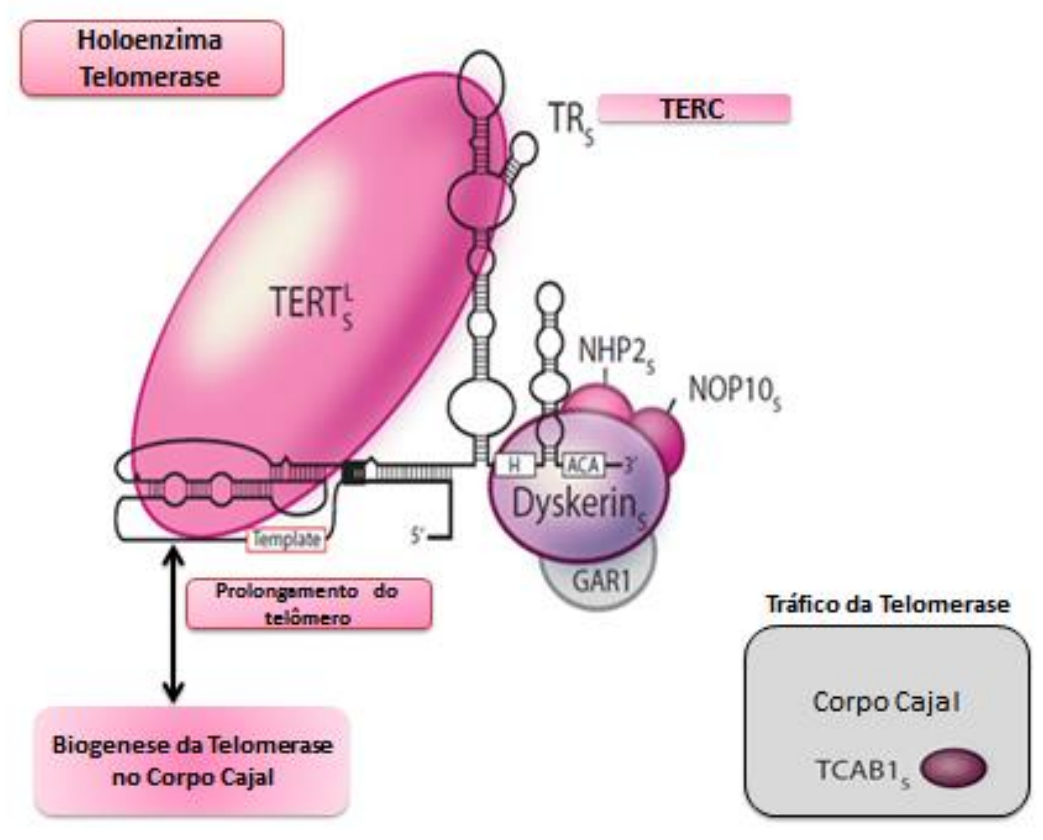

Figura 6 o complexo Telomerase. O complexo de enzima telomerase é composto pela TERT (transcriptase reversa) e TERC(TR ou RNA telomerase)que contém um motivo 3'H/ACA que se liga à proteína disquerina, a qual faz parte de um complexo de disquerina, maior, que também consiste em NHP2, NOP10 e GAR1. A proteína do corpo Cajal (TCAB1) se liga em um motivo de localizado no corpo Cajal em TERC cuja função é na biogênese da telomerase. Adaptado de Stanleye colaboradores (2015) (220).

Durante a duplicação do DNA de cromossomos lineares, ocorre replicação incompleta fita 3', conhecida como "problema da replicação final". A DNA polimerase requer pequenas seqüência de RNA, conhecidas como iniciadores ou primers, para iniciar a replicação, conduzida do sentido 5' para o 3'. Considerando-se que as duas fitas que compõem o DNA molde são antiparalelas, a replicação ocorre em dois sentidos. A fita molde com sentido 3' para 5' é replicada de forma contínua (uma vez que a fita "filha", antiparalela à fita molde, será sintetizada do sentido 5' para o 3', pela DNA polimerase) e a fita molde com sentido 5' para 3' é replicada de forma descontínua ou fragmentada, uma vez que a fita "filha" será sintetizada em fragmentos, do sentido 5' para o 3', à medida que o DNA é desnaturado. Estes fragmentos são conhecidos como fragmentos de Okazaki, e cada um deles, apresentam seu próprio iniciador ou primer. A fita assim sintetizada, conhecida como fita tardia apresenta diversos iniciadores, que 
são subsequentemente degradados e reconstituídos com desoxirribonucleotídeos complementares à fita molde, pela maquinaria de reparo do $\operatorname{DNA}(215,221)$.

Na extremidade 3' da fita molde, replicada de forma descontínua, não é possível o reparo da lacuna resultante da remoção do último iniciador de RNA, de forma que a molécula recém-sintetizada de DNA apresenta uma de suas fitas mais curta e, com sucessivas divisões celulares, há tendência de encurtamento progressivo dos telômeros (222). Sem um mecanismo especial para auxiliar a replicação das extremidades, os cromossomos lineares seriam um pouco mais curtos a cada geração celular, até que se tornariam tão curtos que haveria instabilidade cromossômica e morte da linhagem celular. Postula-se que este processo possa atuar como mecanismo de contagem molecular, marcando o número de divisões celulares e funcionando como relógio mitótico e indicador de senescência celular (223).

A enzima telomerase, no entanto, resolve este problema "do final da replicação" por meio da adição de seqüência teloméricas às extremidades dos cromossomos (210). A enzima é uma DNA polimerase especializada que sintetiza novas seqüência dos telômeros no final dos cromossomos $(189,224)$. A telomerase tem dois componentes conservados que desempenham a função de adição das sequencias teloméricas: a proteína do núcleo da telomerase, TERT, que contém o domínio da transcriptase reversa da telomerase, e um componente de RNA essencial, TR (também conhecido como TERC), que se complexa com TERT e fornece o modelo para a síntese da seqüência telomérica $(208,225)$, conforme esquematizado na Figura 7. 


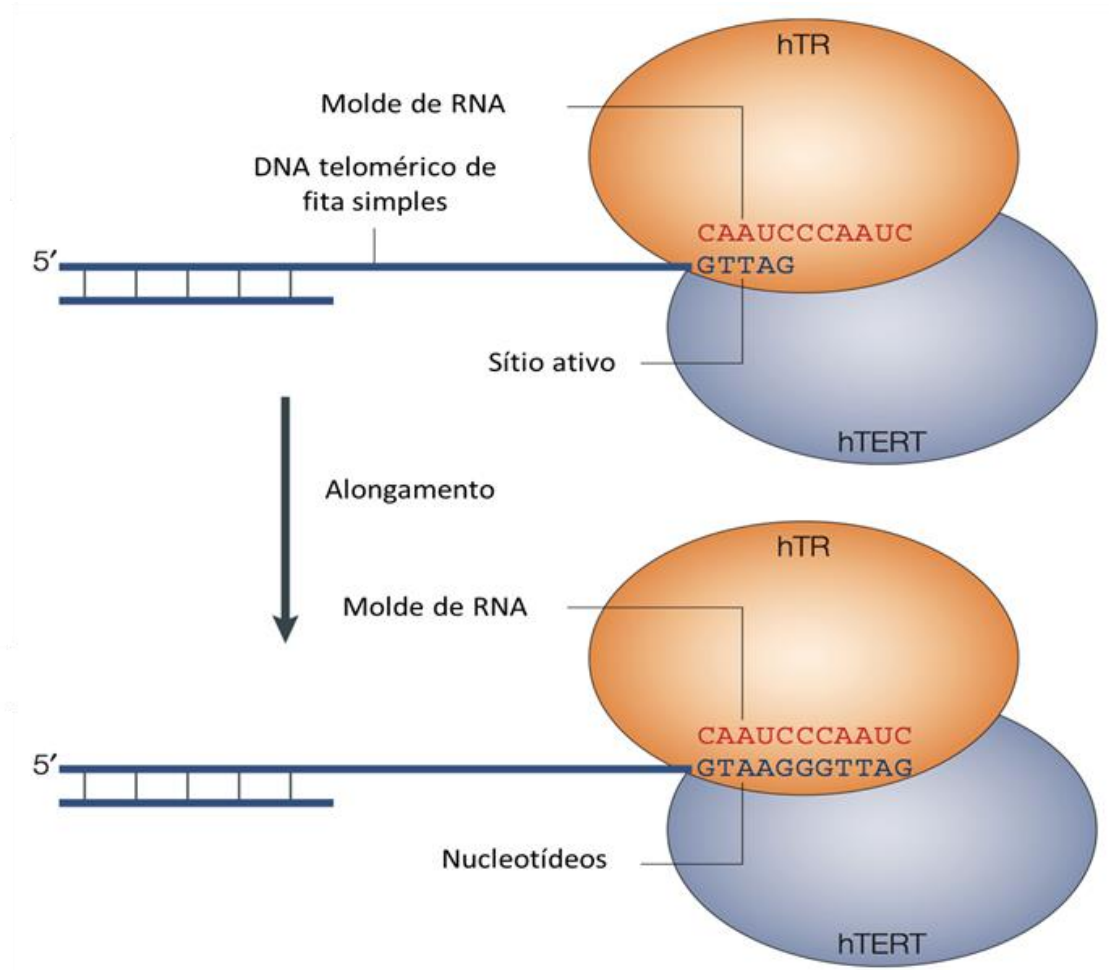

Figura 7. Replicação incompleta da fita 3', conhecida como "problema da replicação final", e atividade da telomerase. . Imagem superior: os nucleotídeos na extremidade 3' do iniciador de DNA no telômero são hibridizados com o molde de RNA no domínio de RNA do complexo da telomerase. Imagem inferior: o hiato formado ao final do molde é então preenchido pela adição de nucleotídeos complementares, no sítio catalítico do complexo da telomerase (hTERT), de modo que a extremidade telomérica é alongada de modo complementar ao molde de RNA. Adaptado de (Neidle and Parkinson 2002 (226).

O recrutamento da telomerase para os telômeros e sua atividade enzimática é modulado por ampla rede de complexos proteicos. O principal deles é conhecido como o telossomo ou Shelterin e, em humanos, é formado por seis proteínas: TRF1 e 2 (fator de ligação à repetição telomérica, telomeric repeat-binding factor 1 e 2), RAP1 (proteína ativadora de repressor, repressor activator protein 1), POT1 (proteção dos telômeros, protection of telomeres 1), TPP1 (telomeric protein 1) e TIN2 (proteína de interação com TRF1, TRF1 interacting protein) $(18,227)$, conforme esquematizado na Figura 8.

Estas estruturas estão localizadas na extremidade dos cromossomos e as protegem formando a alça-T (T-loop) $(220,228)$. 


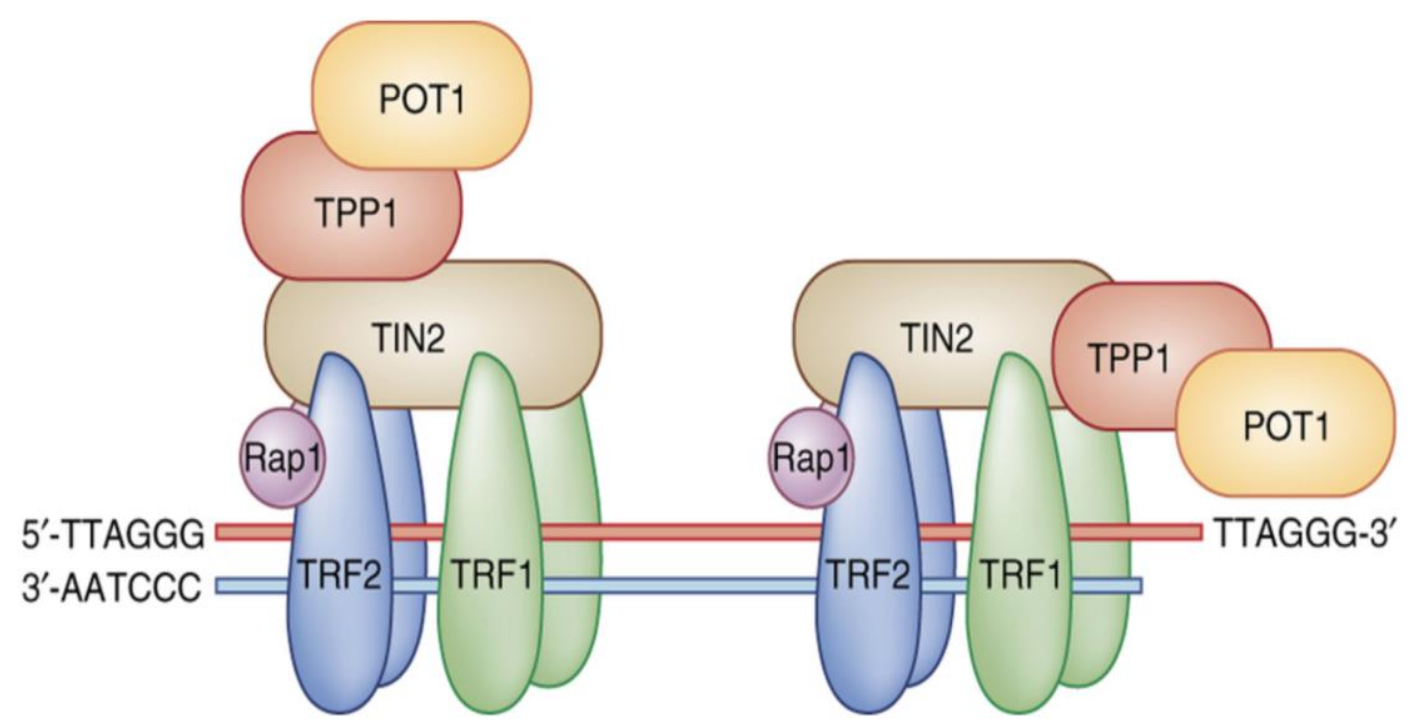

Figura 80 complexo Shelterin. Apresenta 6 subunidades e associa-se com a seqüência telomérica. $\mathrm{O}$ complexo shelterin é formado por TRF1, TRF2 (fator de ligação à repetição telomérica, telomeric repeat-binding factor 1 e 2), POT1((proteção dos telômeros 1), TIN2(proteína de interação com TRF1, TRF1), RAP1(proteína ativadora de repressor) e TPP1(proteína telomérica 1). As proteínas TRF1 e 2 estabelecem a especificidade do complexo pela seqüência telomérica em Razão de sua capacidade de reconhecer a seqüência TTAGG. A proteína POT1 liga-se ao segmento de fita simples TTAGGG. Adaptado de Sarek e colaboradores (2015) (229).

As proteínas TRF1 e 2 ligam-se às unidades teloméricas de fita dupla formando homodímeros. ATRF1 tem ação direta na homeostase do comprimento do telômero e regula a progressão do ciclo celular e a TRF2 contribui na formação da alça T (T-loop ) e na regulação do comprimento telomérico, inibindo a recombinação não homóloga de cromossomos (194).A RAP1, altamente conservada e com três domínios (RCT, BRCT e Myb), associa-se ao telômero por interação com a TRF2 . A POT1 e a TPP1 interagem e ligam-se à parte telomérica de fita dupla e a POT1 protege a extremidade 3' do telômero da ação da telomerase e também de danos ao DNA e a TTP1 interage diretamente coma telomerase para o recrutamento do telômero (194). A TIN2, por sua vez, é um componente central do telossomo que se liga à TRF1 e TFR2. As seis proteínas descritas parecem funcionar como plataforma que recruta proteínas de diversas vias para a manutenção e proteção dos telômeros (194, 230, 231) (Figura 8).

A atividade da telomerase em mamíferos humanos é regulada diferencialmente de acordo com o tipo celular. A desregulação da atividade da telomerase é observada em mais de $90 \%$ dos cânceres humanos e em doenças degenerativas, enquanto 
expressão haplo-insuficiente de componentes da telomerase está associada a várias síndromes de envelhecimento precoce de etiologia genética $(232,233)$. Alterações do DNA observadas com sucessivos ciclos celulares são observadas com 0 envelhecimento e parecem estar relacionadas ao aparecimento de doenças relacionadas ao processo envelhecimento; para estas doenças, contribuem, também, a resposta inflamatória e alterações do equilíbrio redox (234-236).

\subsubsection{Comprimento dos telômeros e diabetes mellitus tipo 2}

Nos últimos anos, alterações da biologia dos telômeros vêm sendo associadas a doenças crônicas como o DM2 (237). A associação entre o comprimento dos telômeros e o DM2 foi inicialmente descrita por Adaikalakoteswar e cols. em 2005, na população indiana asiática (149).

Estudos subseqüentes foram conduzidos em diferentes grupos populacionais, incluindo europeus, asiáticos, africanos, americanos e mexicanos (40, 42, 43, 148, 238240). Os resultados foram variáveis, conforme apresentado no Quadro 2. Alguns estudos mostram que pacientes com DM2 apresentam menor comprimento dos telômeros (24, 30, 40, 44, 45, 148, 237, 240-248), enquanto em outras investigações não é observada esta associação $(43,249)$.

$\mathrm{Na}$ maioria destes estudos, o comprimento dos telômeros é determinado em leucócitos do sangue periférico em diferentes grupos populacionais. É possível que este tipo celular reflita a dinâmica dos telômeros de outros tipos celulares (250) e possa desta forma, representar indicador global de senescência celular (251), incluindo das células beta-pancreáticas $(251,252)$, que apresentam papel chave na fisiopatologia do DM2. A senescência das células beta poderia associar-se à sua disfunção secretória e explicar a associação entre o comprimento dos telômeros e a ocorrência da doença.

Alguns estudos que descrevem associação entre o comprimento dos telômeros e - DM2 indicam também que o encurtamento dos telômeros é correlacionado positivamente com a duração do diabetes. Este achado pode sugerir que o tempo de exposição à hiperglicemia, inflamação ou EO, característicos da doença, desempenhe papel potencial no encurtamento dos telômeros $(44,148,228,253-256)$. 
Em concordância com esta possibilidade, O EO e a resposta inflamatórios crônicos característicos de doenças crônico-degenerativas, são considerados a base do envelhecimento celular e, neste processo, contribuem para o encurtamento dos telômeros $(12,243,254,257-259)$. 
Quadro 2 Características de estudos que investigaram a associação entre o comprimento dos telômeros (CT) e o DM2.

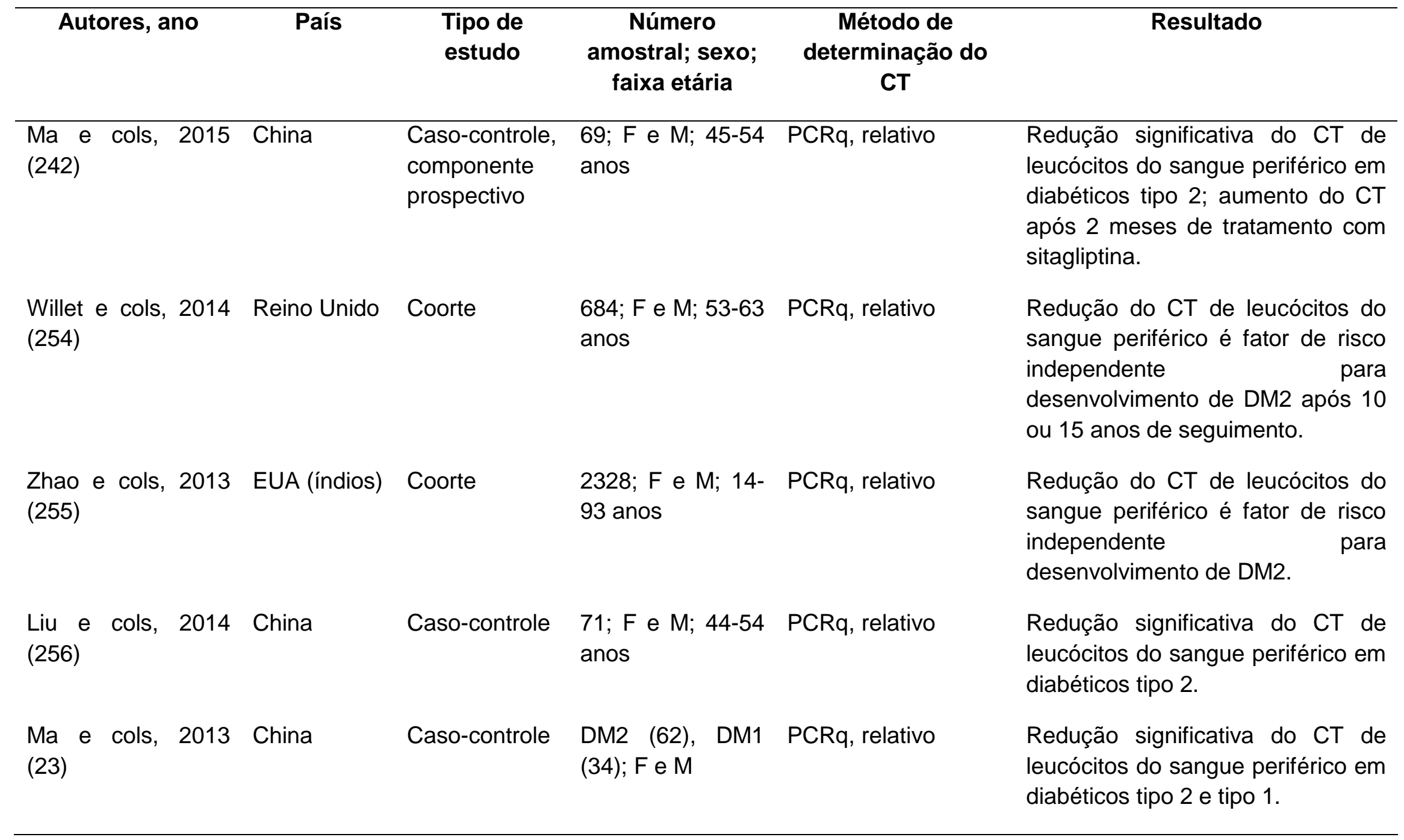


Continuação Quadro 2. Características de estudos que investigaram a associação entre o comprimento dos telômeros (CT) e o DM2.

\begin{tabular}{|c|c|c|c|c|c|c|}
\hline Autores, ano & País & $\begin{array}{ll}\text { Tipo de } \\
\text { estudo }\end{array}$ & $\begin{array}{l}\text { Número } \\
\text { amostral; sexo; } \\
\text { faixa etária }\end{array}$ & $\begin{array}{l}\text { Método } \\
\text { determinação } \\
\text { CT }\end{array}$ & $\begin{array}{l}\text { de } \\
\text { do }\end{array}$ & Resultado \\
\hline $\begin{array}{l}\text { Hovatta e cols, } \\
2012(238)\end{array}$ & Finlândia & Coorte & $\begin{array}{l}\text { 522; F e M; 40-64 } \\
\text { anos }\end{array}$ & PCRq, relativo & & $\begin{array}{l}\text { Não foi encontrada associação } \\
\text { entre o CT de leucócitos do } \\
\text { sangue periférico e o risco de } \\
\text { progressão de IOG para DM2 após } \\
4,5 \text { anos de seguimento. }\end{array}$ \\
\hline
\end{tabular}


Continuação Quadro 2. Características de estudos que investigaram a associação entre o comprimento dos telômeros (CT) e o DM2.

\begin{tabular}{|c|c|c|c|c|c|}
\hline Autores, ano & País & $\begin{array}{ll}\text { Tipo } & \text { de } \\
\text { estudo } & \end{array}$ & $\begin{array}{l}\text { Número } \\
\text { amostral; sexo; } \\
\text { faixa etária }\end{array}$ & $\begin{array}{ll}\text { Método } & \text { de } \\
\text { determinação } & \text { do } \\
\text { CT } & \end{array}$ & Resultado \\
\hline $\begin{array}{l}\text { Xiao e cols, } 2011 \\
(259)\end{array}$ & China & Caso-controle & $\begin{array}{l}1797 ; \mathrm{F} \text { e } \mathrm{M} ; 56- \\
73 \text { anos }\end{array}$ & PCRq, relativo & $\begin{array}{l}\text { Redução significativa do CT de } \\
\text { leucócitos do sangue periférico } \\
\text { em diabéticos tipo } 2 \text {. }\end{array}$ \\
\hline $\begin{array}{l}\text { Salpea e cols,2010 } \\
(261)\end{array}$ & Inglaterra & Caso-controle & $\begin{array}{l}569 \text { caucasianos, } \\
103 \text { sul-africanos, } \\
70 \quad \text { afro- } \\
\text { caribenhos; F e } \\
\text { M; 24-92 anos }\end{array}$ & PCRq, relativo & $\begin{array}{l}\text { Redução significativa do CT de } \\
\text { leucócitos do sangue periférico } \\
\text { em diabéticos tipo } 2 \text {. }\end{array}$ \\
\hline
\end{tabular}




\subsubsection{Métodos de determinação do comprimento dos telômeros}

Os métodos para determinação do comprimento dos telômeros são variados e entre os principais destacam-se:

(i) Análise de fragmentos de restrição terminal (TRF, telomere restriction fragment);

(ii) Análise única do comprimento do telômero (STELA-single telomere length analysis);

(iii) Hibridização fluorescente in situ (FISH) e suas variantes, tais como o método baseado em microscopia digital (Q-FISH, quantitative fluorescent in situ hybridization) ou em citometria de fluxo (Flow-FISH), o método de alta capacidade (high-throughput, HT-Q-FISH), mapeamento telomérico (telomapping); (

(iv) Ensaio dot-blot,

(v) Análise de hibridização de proteção (HPA, hybridization protection assay) e quantificação da saliência 3'OH de fita simples;

(vi) (v) método de PCR quantitativa em tempo real.

O Quadro 3 apresenta algumas características de alguns destes metodos. A seguir, serão descritas a análise de fragmentos de restrição terminal-TRF (considerada padrão-ouro) e a análise por PCR quantitativa em tempo real, empregada no estudo. 
Quadro 3. Características dos métodos de determinação do comprimento dos telômeros.

\begin{tabular}{|c|c|c|c|c|}
\hline & Método & Resolução & $\begin{array}{l}\text { Número de células } \\
\text { requerido }\end{array}$ & Capacidade \\
\hline \multirow{2}{*}{$\begin{array}{l}\text { Medida de } \\
\text { telômeros por } \\
\text { amostra }\end{array}$} & TRF & $1 \mathrm{~kb}$ & $1 \times 10^{6}$ células & Baixa \\
\hline & qPCR & ND & 20 ng de DNA & Alta \\
\hline $\begin{array}{l}\text { Medida de } \\
\text { telômeros por } \\
\text { células }\end{array}$ & Flow-FISH & $0,3 \mathrm{~kb}$ & $0,5 \times 10^{6}$ células & Alta \\
\hline Telômeros & Q-FISH & $0,3 \mathrm{~kb}$ & 15-20 metáfases & Baixa \\
\hline \multirow{4}{*}{ Pontos teloméricos } & $\begin{array}{c}\text { Intérfase Q- } \\
\text { FISH }\end{array}$ & $0,3 \mathrm{~kb}$ & 30 intérfases & Baixa \\
\hline & HT Q-FISH & $0,3 \mathrm{~kb}$ & $\begin{array}{c}0,01 \times 10^{6} \text { células } \\
\text { aderentes } \\
0,07 \times 10^{6} \text { células } \\
\text { linfoides }\end{array}$ & Alta \\
\hline & $\begin{array}{c}\text { Telomappin } \\
\mathrm{g}\end{array}$ & $0,3 \mathrm{~kb}$ & $\begin{array}{c}\text { Secção histológica } \\
\text { fixada }\end{array}$ & Baixa \\
\hline & STELA & $0,1 \mathrm{~kb}$ & $0,1 \times 10^{6}$ células & Baixa \\
\hline
\end{tabular}




\subsubsection{Análise do fragmento de restrição terminal por Southern blot}

O método considerado padrão-ouro para determinação do comprimento dos telômeros é a análise dos fragmentos de restrição terminal por meio de Southern blot. Esta técnica permite detectar fragmentos específicos de DNA em amostras de composição complexa, como é o caso das que contêm DNA genômico. Este método foi descrito por Edwin Southern em 1975(261) e fornece estimativa do número médio de repetições teloméricas por amostra, pois os TRF incluem não apenas repetições teloméricas, mas também quantidades variáveis de sequências subteloméricas. Apesar de suas limitações, o uso da análise TRF foi fundamental para desvendar as associações entre o comprimento dos telômeros e o envelhecimento e doenças humanas, e ainda permanece como um dos métodos mais utilizados para análise comprimento dos telômeros (260).

Na década de 1990, o desenvolvimento de métodos de medida do comprimento dos telômeros baseados em hibridização in situ por fluorescência (FISH) e suas variantes resolveu o problema de precisão e representou um grande avanço para a quantificação do comprimento dos telômeros $(262,263)$.

\subsubsection{Reação em cadeia da polimerase quantitativa em tempo real (PCRq)}

A PCRq para determinação do comprimento dos telômeros foi desenvolvida por Cawthon (2002) constitui método amplamente utilizado para determinação do comprimento dos telômeros de leucócitos $(48,264)$. Por este método, é determinado o comprimento relativo dos telômeros com base na razão entre telômero / gene de cópia única.

O procedimento foi modificado por O'Callaghan e cols (2011), que adaptaram o ensaio de medida do comprimento dos telômeros por PCRq comparando a amplificação da amostra teste com a de oligonucleotídeos sintéticos correspondendo à sequência telomérica, para se obter o comprimento médio absoluto dos telômeros estimado em kb por escala genoma diploide. Este método foi denominado "PCRq absoluta" $(265,266)$. 
Para a medida do comprimento do telômero, um gene de cópia única é utilizado como controle para a amplificação de cada amostra e para determinar o número de cópias do genoma por amostra. A escolha do gene de cópia única é fundamental para a confiabilidade dos resultados, uma vez que qualquer alteração do número de cópias pode influenciar consideravelmente a medida do comprimento médio dos telômeros (266).

Assim como o ensaio de TRF, técnicas baseadas em PCRq requerem DNA de alta qualidade. No entanto, ao contrário do TRF, os métodos baseados em PCRq requerem pequenas quantidades de DNA (nanogramas) da amostra a ser avaliada. Técnicas baseadas em PCRq tornaram-se método frequentemente utilizado para a estimativa do comprimento de telômeros devido ao relativo baixo custo, receptividade para os ensaios de alto rendimento e a facilidade de acesso dos investigadores ao equipamento necessário utilizado no ensaio $(263,266)$.

Essa técnica possui também a vantagem de ser bem adequada para grandes estudos epidemiológicos, embora os resultados sejam limitados para comparações devido a diferenças na qualidade de DNA com base no método utilizado para a extração de DNA genômico, assim como diferenças nos métodos de fixação da amostra, no caso de amostras de tecido embebidas e fixadas em parafina $(267,268)$ e por apresentar níveis relativamente elevados de variação entre as estimativas replicadas(269). 


\section{JUSTIFICATIVA E RELEVÂNCIA}

O encurtamento do comprimento dos telômeros pode resultar em fusões terminais gerando instabilidade cromossômica, que por sua vez podem estar relacionadas a numerosos tipos de câncer (pulmão, cólon, mama, próstata, leucemia), risco cardíaco e diabetes mellitus (244, 270-274). O estudo do tamanho dos telômeros tem sido utilizado como uma das ferramentas para estudo de doenças relacionadas com a idade, na medida em que é considerado biomarcador biológico de envelhecimento, com potencial de predizer a morbidade e mortalidade.

Os leucócitos são a células mais estudas para verificar o comprimento dos telômeros devido ao seu fácil acesso. Nos seres humanos, as evidências mais fortes da associação entre o comprimento de telômeros de leucócitos e a mortalidade vêm sendo alvo de estudos(28, 29)..Além disso, uma investigação recente em adultos jovens, demonstrou que a taxa de desgaste dos telômeros do indivíduo é altamente variável e fortemente correlacionada com a resistência à insulina, um fenômeno que provavelmente relaciona-se com o estresse oxidativo e condições inflamatórias (19, 270, 272).

Pesquisas sobre a associação entre comprimento do telomero e DM2 tem sido realizadas e estas indicam que telômeros mais curtos podem levar a fenótipos em vários tipos de células, incluindo as células beta que levam a apoptose consequente e acelera o aparecimento de diabetes $(272,275,276) . O$ tamanho mais curto de telômeros pode ser atribuído no momento do nascimento, em indivíduos com predisposição para a diabetes ou a aceleração da perda de telômeros durante a divisão celular pode estar diretamente corelacionado ao aumento de estresse oxidativo em condições prédiabéticas (48, 49).

Portanto, devido à importância do tema, é possível que os dados assim gerados neste estudo, contribuam para ampliar os conhecimentos a respeito dos mecanismos envolvidos no comprimento dos telômeros e a diabetes mellintus tipo 2 neste grupo populacional. 


\subsection{OBJETIVOS}

\subsection{Objetivo geral}

Comparar o comprimento relativo dos telômeros de leucóticos do sangue periférico de diabéticos tipo 2 e controles com tolerância normal à glicose.

\subsection{Objetivos específicos}

- Descrever características demográficas, socioeconômicas, clínicas, antropométricas e bioquímicas de diabéticos tipo 2 acompanhados no Hospital Universitário de Brasília.

- Comparar a concentração sérica de TBARS e a capacidade antioxidante total no soro de diabéticos tipo 2 e controles com tolerância normal à glicose.

- Correlacionar a concentração sérica de TBARS e a capacidade antioxidante total no soro com variáveis clínicas e bioquímicas de diabéticos tipo 2 e com variáveis clínicas de controles com tolerância normal à glicose.

- Comparar o comprimento relativo de telômeros de leucócitos do sangue periférico de diabéticos tipo 2 e controles com tolerância normal à glicose.

- Correlacionar o comprimento relativo de telômeros de leucócitos do sangue periférico de diabéticos tipo 2 com variáveis clínicas e bioquímicas.

- Correlacionar o comprimento relativo de telômeros de leucócitos do sangue periférico de controles com tolerância normal à glicose com variáveis clínicas. 


\section{MATERIAL E MÉTODOS}

\subsection{ASPECTOS ÉTICOS}

Este estudo seguiu todas as normas estabelecidas pela Resolução 466/2012 do Conselho Nacional de Saúde, que trata da pesquisa em seres humanos. O projeto foi aprovado pelos Comitês de Ética em Pesquisa da Faculdade de Ciências da Saúde da Universidade de Brasília (em 02/08/2013, CAAE 23433013.4.0000.5553) e da Secretaria de Estado de Saúde do Distrito Federal - Fundação de Ensino e Pesquisa em Ciências da Saúde CEP/FEPECS (em 26/11/2013, CAAE 23433013.4.0000.5553), conforme apresentado nos Anexos I e II.

\subsection{DELINEAMENTO E SUJEITOS DO ESTUDO}

Trata-se de estudo observacional, com componentes descritivo e analítico, em que foram selecionados 165 portadores de DM2, com idades entre 43 e 55 anos, de ambos os sexos, acompanhados no Hospital Universitário de Brasília (HUB), que constituíram o "grupo caso". O grupo controle, composto por sujeitos com tolerância normal à glicose e da mesma faixa etária dos casos, foi recrutado do quadro de doadores de sangue da Fundação Hemocentro de Brasília da Secretaria de Estado de Saúde do Distrito Federal (FHB/SES-DF). Foram constituídos dois grupos controles, um para a avaliação de cada desfecho do estudo:

(i) Grupo controle composto por 130 indivíduos, que foi comparado ao grupo de diabéticos tipo 2 com relação a marcadores de EO.

(ii) Grupo controle composto por 158 indivíduos, que foi comparado ao grupo de diabéticos tipo 2 com relação ao comprimento relativo dos telômeros.

O rastreamento de doadores na FHB/SES-DF é baseado nas Resoluções da Agência Nacional de Vigilância Sanitária que dispõem sobre as Boas Práticas no Ciclo do Sangue (RDC N 34, de 11 de junho de 2014 e RDC no 57, de 16 de dezembro de 
2010) (277, 278), que determinam o Regulamento Sanitário para Serviços que desenvolvem atividades relacionadas ao ciclo produtivo do sangue humano e componente e procedimentos transfusionais. Os doadores da FHB/SES-DF (http://www.fhb.df.gov.br/) passam por seis etapas para a doação (Anexo III), que incluem (i) identificação (características demográficas e tipo de doação, se comunitária ou de reposição), (ii) pré-triagem (obtenção de dados clínicos, antropométricos e rastreamento de anemia), (iii) lanche, (iv) triagem clínica (questionário a respeito de doenças prévias, comportamento sexual, alimentação e uso de medicamentos, Anexo IV), (v) coleta e (vi) lanche.

Para avaliação dos marcadores de EO, foram selecionados 130 controles. Para avaliação do comprimento dos telômeros, foram selecionados 165 controles, pareados com os casos de acordo com a idade.

\subsubsection{Critérios de inclusão}

Para o "grupo caso", os critérios de inclusão foram:

- Ser portador de DM2.

- Apresentar idade entre 43 e 55 anos.

- Concordância em participar do estudo e assinatura do Termo de Consentimento Livre e Esclarecido (Anexo V).

Para o "grupo controle", os critérios de inclusão foram:

- Apresentar tolerância à glicose normal.

- Apresentar idade entre 43 e 55 anos.

- Concordância em participar do estudo e assinatura do Termo de Consentimento Livre e Esclarecido (Anexo VI).

No HUB adotam-se, para o diagnóstico do DM, os critérios propostos pela Associação Americana de Diabetes, que incluem (81):

- Glicemia de jejum $\geq 126$ mg/dL; 
- Glicemia aleatória $\geq 200 \mathrm{mg} / \mathrm{dL}$, na presença de sintomas de hiperglicemia (poliúria, polidipsia, perda de peso);

- Glicemia 2 horas pós-sobrecarga oral de $75 \mathrm{~g}$ de glicose anidra $\geq 200 \mathrm{mg} / \mathrm{dL}$;

- Hemoglobina glicada $(\mathrm{HbA} 1 \mathrm{c})>6,5 \%$.

Neste grupo, ainda que não se tenha tido acesso aos valores de glicemia ou HbA1c do período do diagnóstico, a presença do DM2 foi corroborada pela informação, fornecida pelo sujeito e revisada no prontuário médico e do uso de medicamentos antihiperglicemiantes.

No grupo controle, a tolerância normal à glicose foi definida pela presença de $\mathrm{HbA1c}$ normal $(<6,5 \%)$, cuja dosagem é realizada por cromatografia líquida de alta resolução, e pela ausência de uso de medicamentos anti-hiperglicemiantes. A dosagem da HbA1c, assim como as informações sobre medicamentos em uso, fazem parte da avaliação rotineira destes indivíduos (Anexo VII).

\subsubsection{Critérios de exclusão}

Para ambos os grupos, caso e controle, foram excluídos portadores de neoplasias malignas, infecção pelo vírus da imunodeficiência humana e de infecções de outra natureza que estivessem ativas (tuberculose, micoses profundas).

\subsubsection{Cálculo amostral após os critérios de exclusão}

De acordo com cálculo amostral previamente realizado, cada grupo deveria conter um mínimo de 165 participantes para um nível de significância de 80\%, considerando as probabilidades de erros alfa e beta (279), totalizando 330 participantes para o alcance satisfatório dos objetivos deste estudo. $O$ tamanho do efeito foi de 0.3 (efeito médio). Após os critérios de exclusão o t critico foi de 2,82. Para o cálculo foi utilizado o software $G^{*}$ Power $3.0 .10 \AA(280,281)$. 


\subsection{PROCEDIMENTOS}

\subsubsection{Coleta de amostra de sangue venoso periférico}

Todos os sujeitos do grupo caso foram submetidos à coleta de $8 \mathrm{~mL}$ de sangue venoso periférico realizada pelos técnicos do Laboratório de Análises Clínicas do HUB, na ocasião da coleta de sangue para a realização dos exames solicitados pelo médico assistente. Quatro $\mathrm{mL}$ foram armazenados em tubo contendo EDTA e $4 \mathrm{~mL}$, em tubo sem anticoagulante e com gel para separação do soro.

Amostras de $2 \mathrm{~mL}$ de sangue venoso de cada sujeito do grupo controle foram disponibilizadas pela FHB/SES-DF, em tubo contendo EDTA e $2 \mathrm{~mL}$, em tubo sem coagulante com gel contendo o soro.

\subsubsection{Obtenção de informações relativas às variáveis do estudo}

Os portadores de DM2 (grupo caso) que concordaram em participar do estudo responderam a uma entrevista estruturada, que abordou dados de identificação, demográficos, socioeconômicos, antropométricos e clínica. Alguns dados clínicos relativos a resultados de exames laboratoriais realizados no Laboratório de Análises Clínicas do HUB foram obtidos por consulta ao prontuário médico (Anexo VII).

As informações relativas ao grupo controle foram obtidas a partir do banco de dados da FHB/SES-DF, para obtenção de dados demográficos, clínicos e antropométricos (Anexo VII).

\subsection{VARIÁVEIS DO ESTUDO}

\subsubsection{Variáveis demográficas, clínicas e antropométricas}

Foram obtidas informações acerca das seguintes variáveis: 
(i) Idade (calculada a partir da data de nascimento, verificada em documento de identidade com foto e no prontuário médico);

(ii) Sexo;

(iii) Peso (verificado uma única vez em balança digital com capacidade de $150 \mathrm{~kg}$ e intervalos de $100 \mathrm{~g}$ );

(iv) Altura (verificada uma única vez em estadiômetro com precisão de $1 \mathrm{~mm}$, mantendo o sujeito em posição ereta, com braços estendidos ao longo do corpo e olhar fixo em um ponto do horizonte);

(v) Índice de massa corporal (calculado pela divisão do peso em $\mathrm{kg}$ pela altura em metros ao quadrado e utilizado para classificação do estado nutricional de acordo com as informações descritas no Quadro 4);

(vi) Circunferência da cintura (verificada durante a expiração, com o indivíduo em posição ereta, abdome relaxado e desnudo, com braços estendidos ao longo do corpo e pés juntos. Foi utilizada fita métrica inelástica, posicionada na metade da altura entre o último arco costal e a parte superior da crista ilíaca ântero-superior);

(vii) Circunferência do quadril (verificada com o indivíduo em posição ereta, por meio do posicionamento da fita métrica inelástica em um plano horizontal na área de maior proeminência da região glútea, sem enrugar a pele e tampouco comprimir os tecidos subcutâneos);

(viii) Pressão arterial sistólica e diastólica (aferida por métodos padrão e registrada em $\mathrm{mmHg}$ conferida no prontuário; foi considerado hipertenso o sujeito com pressão arterial sistólica igual ou superior a $130 \mathrm{mmHg}$ e/ou pressão arterial diastólica igual ou superior a $85 \mathrm{mmHg}$, ou em uso de medicação anti-hipertensiva). 
(iv) Comorbidades (dislipidemia, hipertensão arterial, distúrbios tireoidianos, complicações crônicas do DM - neuropatia, nefropatia e retinopatia - verificados no prontuário e exames do paciente);

(x) Uso de medicamentos (informações coletadas durante a entrevista com o paciente e confirmadas por revisão do prontuário médico);

(xi) Escolaridade;

(xii) Renda mensal estimada;

(xiii) Prática de atividade física;

(xix) Consumo de álcool e

(x) Hábito de fumar.

Quadro 4 Classificação do estado nutricional segundo o índice de massa corporal e risco de comorbidades.

\begin{tabular}{lcc}
\hline \multicolumn{1}{c}{ Classificação } & IMC $\mathbf{( k g / \mathbf { m } ^ { 2 } )}$ & Risco de comorbidades \\
\hline Eutrofia & $18,5-24,9$ & Médio \\
Sobrepeso (pré-obesidade) & $25-29,9$ & Aumentado- \\
Obesidade grau I & $30-34,9$ & Moderado \\
Obesidade grau II & $35-39,9$ & Grave \\
Obesidade grau III & $\geq 40$ & Muito Grave \\
\hline
\end{tabular}

IMC: índice de massa corporal.

Fonte: Organização Mundial da Saúde, 2008 (282). 
Quanto à prática de atividade física, os sujeitos com DM2 foram classificados, de acordo com Haskell (2007) (283) o tipo de atividade, em cinco categorias:

(1) Muito ativo (atividade vigorosa $\geq 5$ dias por semana e $\geq 30$ minutos por sessão e/ou atividade vigorosa $\geq 3$ dias por semana e $\geq 20$ minutos por sessão + atividade moderada e/ou caminhada $\geq 5$ dias por semana e $\geq 30$ minutos por sessão).

(2) Ativo (atividade vigorosa $\geq 3$ dias por semana e $\geq 20$ minutos por sessão e/ou atividade moderada ou caminhada $\geq 5$ dias por semana e $\geq 30$ minutos por sessão e/ou qualquer atividade somada - caminhada, moderada, vigorosa - $\geq 5$ dias por semana $e \geq$ 150 minutos por semana).

(3) Irregularmente ativo (atividade física em nível insuficiente para ser classificado como ativo, considerado irregularmente ativo $\mathrm{A}$ quando atinge pelo menos um dos critérios de recomendação quanto à freqüência ou duração da atividade - 5 dias por semana ou duração de 150 minutos por semana, ou considerado irregularmente ativo $B$ quando não atinge critérios de recomendação quanto à frequência e duração).

(4) Sedentário: aquele que não realiza nenhuma atividade física por pelo menos 10 minutos contínuos durante a semana.

\subsubsection{Variáveis bioquímicas}

No grupo de casos (portadores de DM2), dados relativos às seguintes variáveis bioquímicas foram coletados a partir do banco de dados do Laboratório de Análises Clínicas do HUB ou do registro no prontuário médico: glicemia em jejum, hemoglobina glicada, colesterol total e frações (LDL, HDL e VLDL), triglicerídeos, ureia, creatinina, aspartato aminotransferase (AST ou TGO), aspartato alaninotransferase (ALT ou TGP), gamaglutamiltransferase (GT), depuração endógena de creatinina, microalbuminúria ou proteinúria e PCR ultrassensível. Foram coletados resultados de avaliações realizadas até três meses antes do momento da coleta da amostra de sangue para o presente estudo. Estes exames são realizados rotineiramente como parte do acompanhamento 
de portadores de DM2, após 12 horas de jejum, necessária à avaliação dos resultados da concentração sérica de triglicerídeos. O Quadro 5 apresenta os métodos utilizados para determinação de cada uma das variáveis bioquímicas mencionadas, assim como a respectiva faixa valor de referência.

Quadro 5 Métodos empregados para a determinação das variáveis bioquímicas analisadas e respectivas faixas de referência.

\begin{tabular}{lcc}
\hline \multicolumn{1}{c}{ Variável } & Método & Faixa de referência \\
\hline Glicemia de jejum $(\mathrm{mg} / \mathrm{dL})$ & Hexoquinase & $70-99$ \\
Hemoglobina glicada (\%) & HPLC & $<6,5 \%$ \\
Colesterol total $(\mathrm{mg} / \mathrm{dL})$ & Esterase-oxidase & $<200$ \\
Colesterol-LDL $(\mathrm{mg} / \mathrm{dL})$ & Fórmula de Friedwald & $<130$ \\
& & (meta no DM: $<100)$ \\
Colesterol-VLDL $(\mathrm{mg} / \mathrm{dL})$ & Fórmula de Friedwald & $<30$ \\
Colesterol-HDL $(\mathrm{mg} / \mathrm{dL})$ & Homogêneo direto & $>60$ \\
Triglicerí́deo $(\mathrm{mg} / \mathrm{dL})$ & Oxidase-peroxidase & $<150$ \\
AST $(\mathrm{U} / \mathrm{L})$ & IFCC - com piridoxal fosfato & $<60$ \\
ALT $(\mathrm{U} / \mathrm{L})$ & IFCC - com piridoxal fosfato & $<52$ \\
GGT $(\mathrm{U} / \mathrm{L})$ & Szasz modificado & 9 a 54 \\
Ureia $(\mathrm{mg} / \mathrm{dL})$ & UV cinético automatizado & 17 a 43 \\
Creatinina $(\mathrm{mg} / \mathrm{dL})$ & Reação de Jaffé & 0,3 a 1,3 \\
PCR ultrassensível $(\mathrm{mg} / \mathrm{dL})$ & BN2 & $0,3 \mathrm{a} 3,0$ \\
\hline
\end{tabular}

Fonte: Laboratório de Análises Clínicas do HUB.

\subsection{AVALIAÇÃO DA PEROXIDAÇÃO LIPÍDICA}

A análise da formação de substâncias reativas ao ácido tiobarbitúrico (thiobartituric acid reactive substances, TBARS) é o principal método para quantificar os produtos finais da peroxidação lipídica, que corresponde à oxidação do radical livre de ácidos graxos poliinsaturados nos sistemas biológicos. Este método é utilizado para avaliar quantitativamente $O$ estresse oxidativo de tecidos e células (284). O malondialdeído (MDA) é o produto final da peroxidação lipídica e reage com o ácido tiobarbitúrico (thiobarbituric acid, TBA) para formar o aduto MDA-TBA na proporção de 1:2 com o TBA, sendo os resultados expressos em termos de TBARS.

A concentração de MDA, como marcador de peroxidação lipídica, foi avaliada pelo ensaio de TBA, segundo protocolo previamente descrito (151), e quantificada pelo método colorimétrico descrito por Ohkawa (153).Para avaliar a concentração de MDA/TBARS, foi coletado $1 \mathrm{~mL}$ de soro dos sujeitos do grupo caso e do grupo controle. 
Em microtubo de $2 \mathrm{~mL}$ imerso em gelo, foram adicionados $80 \mu \mathrm{L}$ do soro diluído em 320 $\mu \mathrm{L}$ de água ultra pura MiliQ (diluição 1:5). Em seguida, foi acrescentado $1 \mathrm{~mL}$ de ácido tricloroacético (TCA) 17,5\%, pH 2,0, para separação dos ácidos graxos de cadeia longa, e, depois, foi acrescentado $1 \mathrm{~mL}$ TBA a 0,6\%, $\mathrm{pH} 2,0$. Após esse processo, as amostras foram homogeneizadas e mantidas a $95^{\circ} \mathrm{C}$ (em banho-maria) por 20 minutos.

Essa reação foi interrompida com o resfriamento dos microtubos em gelo. Em seguida, $1 \mathrm{~mL}$ de ácido tricloroacético a $70 \%, \mathrm{pH} 2,0$, foi adicionado aos microtubos e os mesmos incubados por $20 \mathrm{~min}$. Depois desse período, os microtubos contendo as amostras foram centrifugados por 15 minutos a $3000 \mathrm{rpm}$, a $20^{\circ} \mathrm{C}$, e $280 \mu \mathrm{L}$ do sobrenadante de cada amostra foi colocado em um poço de microplaca de 96 poços. A densidade óptica do sobrenadante obtido foi lida em espectrofotômetro SpectraMax 5.4 a $534 \mathrm{~nm}$. no Laboratório de Estresse Oxidativo e Radicais Livres do Instituto de Biologia da Universidade de Brasília.

A concentração dos produtos da peroxidação lipídica foi calculada utilizando-se coeficiente de extinção molar equivalente para malondialdeído (MDA-equivalente) de $1,56 \times 10^{5} \mathrm{M}^{-1} \mathrm{~cm}^{-1}$ (utilizado para o complexo malondialdeído e ácido tiobarbitúrico). $\mathrm{O}$ conteúdo de MDA no soro foi expresso em $\mathrm{nmol} / \mathrm{mL}$.

\subsection{AVALIAÇÃO DA CAPACIDADE ANTIOXIDANTE TOTAL DO PLASMA}

A capacidade antioxidante do soro foi determinada pelo potencial antioxidante redutor férrico (ferric reducing antioxidant potential, FRAP), que representa medida direta de "poder antioxidante total". Neste ensaio, realizado em $\mathrm{pH}$ baixo, os antioxidantes presentes no plasma ou soro reduzem $\mathrm{Fe}^{+3}$ a $\mathrm{Fe}^{+2}$, o qual é quelado pela 2,4,6-tripiridil-s-triazina (TPTZ) para formar o complexo $\mathrm{Fe}^{+2}$-TPTZ, de coloração azul intensa por ação de compostos antioxidantes no plasma sanguíneo, entre eles ácido úrico e vitaminas $\mathrm{C}$ e E. A formação do complexo $\mathrm{Fe}^{+2}-\mathrm{TPTZ}$ pode ser monitorada a 593 $\mathrm{nm}$ (157).

Para o ensaio, foram preparadas as seguintes soluções:

i. Tampão acetato de sódio a 0,3 M, pH 3,6.

ii. Solução de ácido clorídrico $(\mathrm{HCl})$ a $40 \mathrm{mM}$. 
iii. TPTZ a $10 \mathrm{mM}$.

iv. Cloreto férrico $\left(\mathrm{FeCl}_{3} 6 . \mathrm{H}_{2} \mathrm{O}\right)$ a $20 \mathrm{mM}$.

v. Padrão de ácido ascórbico a $250 \mu \mathrm{M}$.

vi. Solução de trabalho, que consiste na mistura de 10 volumes de tampão de acetato de sódio, 1 volume de TPTZ e 1 volume de cloreto férrico, preparada, obrigatoriamente, no momento do ensaio.

Para elaboração de curva padrão, foi utilizada solução de trolox $(50,100,200$, 500800 e $1000 \mu \mathrm{M}$.

Para o ensaio, foram pipetados, em placa de 96 poços, $300 \mu \mathrm{L}$ de solução de trabalho. Dois poços da placa funcionaram como branco. Aos outros poços, foram adicionados, em duplicata, $10 \mu \mathrm{L}$ cada uma das concentrações do padrão (Trolox) e 10 $\mu \mathrm{L}$ das amostras de soro dos sujeitos do estudo. Foi realizada leitura no espectrofotômetro a $593 \mathrm{~nm}$ (tempo zero), a placa foi incubada no espectrofotômetro a $37^{\circ} \mathrm{C}$ por 4 minutos e, em seguida, efetuada nova leitura no espectrofotômetro, a 593 nm (tempo 4 minutos). A densidade óptica foi lida em espectrofotômetro SpectraMax 5.4 a 593 ๆm. no Laboratório de Estresse Oxidativo e Radicais Livres do Instituto de Biologia da Universidade de Brasília.

Para o cálculo da capacidade antioxidante total, subtraiu-se, do valor da absorbância no tempo 0 , o valor da absorbância no tempo 4. Com os resultados dos padrões (Trolox), foi elaborado gráfico com as concentrações de Trolox no eixo $\mathrm{x}$ e as respectivas médias das duplicatas das absorbâncias (T0-T4) no eixo y para que a equação da reta fosse calculada. A partir da equação da reta da curva padrão, foram calculados os valores de FRAP da amostra expressos em nM por equivalente de Trolox.

De posse destes dados e dos resultados do ensaio de peroxidação lipídica, foi determinada a razão FRAP/TBARS.

\subsection{EXTRAÇÃO DE DNA GENÔMICO}

Para extração do DNA genômico de leucócitos do sangue venoso periférico, foram utilizados $200 \mu \mathrm{L}$ das amostras de sangue venoso dos sujeitos. A extração foi 
realizada com o kit comercial PureLink® Genomic DNA Mini (Life Technologies ${ }^{\circledR}$ ), conforme instruções do fabricante.

As amostras obtidas foram avaliadas no espectrofotômetro de microvolume Nanodrop 200 (Thermo Scientific) para determinação da concentração de DNA (ng/ $\mu \mathrm{L}$ ) e do grau de pureza da amostra, fornecido pela razão entre as absorbâncias nos comprimentos de onda de 260 e $280 \mathrm{~nm}$ (260/280). Foram consideradas satisfatórias amostras com razão 260/280 entre 1.7 e 2.0 (266).

\subsection{DETERMINAÇÃO DO COMPRIMENTO RELATIVO DOS TELÔMEROS}

A análise do comprimento relativo dos telômeros foi realizada pelo método de PCR quantitativa em tempo real, proposto por Cawthon em 2002 (264). O princípio deste método é a determinação, para cada amostra experimental, do fator segundo o qual a razão entre o número de cópias da sequência telomérica e o número de cópias de gene de cópia única, em determinada amostra, difere de amostra referência de DNA.

A quantidade de repetições teloméricas em cada amostra experimental é mensurada como nível de diluição de amostra referência de DNA (selecionada arbitrariamente) que tornaria as amostras, experimental e referência, equivalentes em termos de números de ciclos de PCR (cicle thershold) necessários para obtenção de determinada quantidade de produtos de amplificação da sequência telomêrica na fase exponencial da amplificação.

O mesmo é realizado para o gene de cópia única. Com isso, a razão entre esses fatores de diluição, ou $T / S$ relativa ( $T$, sequência telomérica; $S$, gene de cópia única) representa a relação entre o número de cópias da sequência telomérica e do gene de cópia única na amostra experimental e na amostra referência.

Os iniciadores (primers) utilizados para amplificação das sequências telomérica e do gene de cópia única (266) estão descritos no Quadro 6. O iniciador que amplifica a sequência telomérica pode se anelar a qualquer segmento complementar no DNA telomérico, de forma que são observados produtos de amplificação de tamanho variado. O gene de cópia única, autossômico, utilizado como normalizador foi o 36B4 
também conhecido como RPLP0 (https://www.ncbi.nlm.nih.gov/gene/6175) que codifica a fosfoproteína ácida ribossomal.

Quadro 6 Oligonucleotídeos iniciadores utilizados na reação de PCRq, para determinação do comprimento relativo dos telômeros.

\begin{tabular}{clc}
\hline & \multicolumn{1}{c}{ Sequência (5'-3') } & $\begin{array}{c}\text { Tamanho do } \\
\text { amplicon }\end{array}$ \\
\hline $\begin{array}{c}\text { Telo direto ou } \\
\text { forward }\end{array}$ & CGGTTTGTTTGGGTTTGGGTTTGGGTTTGGGTTTGGG & $>76 \mathrm{pb}$ \\
$\begin{array}{c}\text { Telo reverso } \\
\text { ou reverse }\end{array}$ & GGCTTGCCTTACCCTTACCCTTACCCTTACCCTTACC & \\
$\begin{array}{c}\text { 36B4 direto } \\
\text { ou forward }\end{array}$ & CAGCAAGTGGGAAGGTGTAATCC & $75 \mathrm{pb}$ \\
$\begin{array}{c}\text { 36B4 reverso } \\
\text { ou reverse }\end{array}$ & CCCATTCTATCATCAACGGGTACAA & \\
\hline
\end{tabular}

Fonte: O'Callaghan (2011) (266). Telo: sequência do oligonucleotideo iniciador do telômero.

Para as reações de PCRq, foram utilizados $20 \mathrm{ng}$ (4 $\mu \mathrm{L}$ de solução de DNA a 5 $\mathrm{ng} / \mu \mathrm{L}$ ), $100 \mathrm{nM}(1 \mu \mathrm{L})$ de cada iniciador (direto e reverso), $10 \mu \mathrm{L}$ de SYBR Green (Rox qPCR Master Mix Thermo Scientific) e $4 \mu \mathrm{L}$ de H2O Milli-Q, em volume final de $20 \mu \mathrm{L}$. A composição das reações de PCR (reagentes), com exceção dos iniciadores, foi a mesma para a amplificação da sequência telomérica e do gene de cópia única. As reações foram conduzidas em placas de 96 poços (Thermo Scientific).

Para cada amostra, foram conduzidas reações em duplicata, em placas separadas, uma para amplificação da sequência telomérica e outra, da sequência do gene de cópia única. Em cada placa, foi realizada reação de amplificação de controle negativo (água) e amplificação de amostra referência, em triplicata, a partir da diluição seriada 1:2, para determinação da eficiência da reação de amplificação com cada um dos pares de iniciadores (sequência telomérica e sequência do gene de cópia única).

Esta curva de eficiência foi constituída de 6 pontos; a maior quantidade de DNA da amostra referência foi de $40 \mathrm{ng}$ e a menor, de 1,25 ng (diluição seriada 1:2 a partir de $40 \mathrm{ng}$ ). A pipetagem foi realizada de forma automatizada, com a utilização do equipamento EpMotion ${ }^{\circledR} 5070$ (Eppendorf). O limiar (thershold) considerado para as 
análises de amplificação da sequência telomérica foi de 0,16 , e para o gene de cópia única, de 0,25.

As reações de amplificação foram conduzidas no equipamento StepOnePlus ${ }^{\mathrm{TM}}$ Real-Time PCR Systems-Life Technologies, de acordo como seguinte programa: desnaturação a 95ำ por 10 minutos; 40 ciclos de 15 segundos desnaturação a 95ํㅡ, 1 minuto a $60^{\circ} \mathrm{C}$; curva de dissociação ou melting.

\subsubsection{Análise da curva de eficiência de amplificação dos iniciadores}

Como descrito anteriormente, para a determinação da eficiência de amplificação dos iniciadores (sequência telomérica e 36B4) foi realizada amplificação de amostra referência, diluída de forma seriada 1:2, a partir de $40 \mathrm{ng}$ até 1,25 ng (6 pontos). A eficiência da amplificação foi determinada pela equação $E=\left(10^{-1 / \text { slope }}-1\right) \times 100$, em que E representa a eficiência e slope representa o valor da inclinação da reta obtida pela representação gráfica do Ct de cada quantidade da amostra referência (eixo y) e da quantidade da amostra referência (eixo x)(285). Os resultados das amostras (casos e controles) foram analisados quando a eficiência da amplificação foi calculada entre 85 a $110 \%$.

5.8.2 Análise e determinação do comprimento relativo dos telômeros

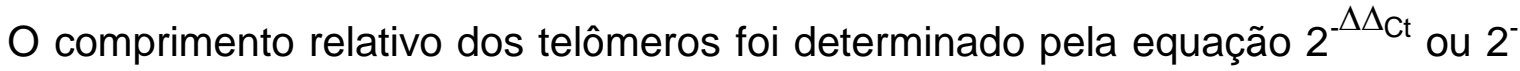

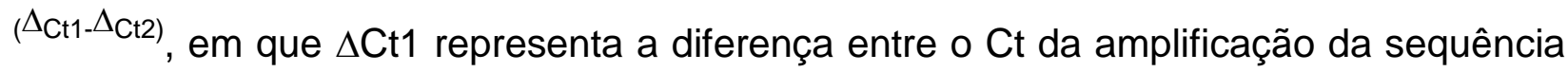
telomérica menos o Ct da amplificação da sequência do gene de cópia única, na amostra experimental, e $\Delta$ Ct2 representa esta diferença, na amostra referência. $O$ coeficiente de variação do T/S relativo, calculado pela divisão do desvio padrão pela média do $\mathrm{T} / \mathrm{S}$ relativo da amostra referência. 


\subsection{ANÁLISE ESTATÍSTICA}

Os dados relativos às variáveis categóricas foram apresentados como frequência absoluta e relativa (\%). Os dados relativos às variáveis contínuas foram avaliados quanto à normalidade pelo teste de Shapiro-Wilk e representados pela mediana e intervalo interquartil e, graficamente, pelo método de Tukey.

A comparação entre os dois grupos (controle e diabéticos) foi realizada pelo teste de Mann-Whitney. Para comparações múltiplas, foi realizado o teste de Kruskal-Wallis seguido pelo pós-teste de Dunn. Para avaliar a correlação entre marcadores de estresse oxidativo e comprimento de telômeros e outras variáveis, foi realizado o teste de correlação não paramétrico de Spearman. Todos os procedimentos estatísticos foram realizados utilizando-se dos softwares Statistical Package for the Social Sciences 22.0 para Windows ${ }^{\circledR}$ (SPSS 22.0) (286) e GraphPad Prism versão 5.0 (287). O nível de significância foi fixado em $5 \%(p<0,05)$. 


\subsection{RESULTADOS}

\subsection{CARACTERIZAÇÃO DEMOGRÁFICA, CLÍNICA E BIOQUÍMICA DOS PORTADORES DE DIABETES MELLITUS TIPO 2}

Entre janeiro de 2014 e janeiro de 2016, foram incluídos 165 portadores de DM2, entre os pacientes acompanhados no Hospital Universitário de Brasília.

A maioria dos pacientes foi do sexo feminino e a mediana de idade, de 49 anos. A maioria apresentava ensino fundamental incompleto ou completo e renda mensal superior a 1 porém inferior a 3 salários mínimos, conforme apresentado na Tabela 1.

Tabela 1. Características demográficas e socioeconômicas dos diabéticos tipo 2 ( $\mathrm{n}$ $=165$ ).

\begin{tabular}{|c|c|c|c|}
\hline Variável & $\mathbf{N}$ & $\%$ & Mediana (IQ) \\
\hline Sexo (feminino/masculino) & $125 / 40$ & $75,8 / 24,2$ & \\
\hline Idade (anos) & & & $49(43-53)$ \\
\hline \multicolumn{4}{|l|}{ Escolaridade } \\
\hline Fundamental incompleto & 66 & 40,0 & \\
\hline Fundamental completo & 42 & 25,4 & \\
\hline Médio incompleto & 11 & 6,7 & \\
\hline Médio completo & 36 & 21,8 & \\
\hline Superior incompleto & 1 & 0,6 & \\
\hline Superior completo & 9 & 5,5 & \\
\hline \multicolumn{4}{|c|}{ Renda mensal (salários-mínimos ª) } \\
\hline 1 a 2,9 & 113 & 68,5 & \\
\hline 3 a 4,9 & 47 & 28,5 & \\
\hline 5 a 6,9 & 2 & 1,2 & \\
\hline 7 ou mais & 3 & 1,8 & \\
\hline
\end{tabular}

Mediana-IQ: intervalo interquartil; N: frequência absoluta.

a $\mathrm{O}$ valor do salário mínimo foi considerado de $\mathrm{R} \$ 722,00$ (atualizado em 01.05.2015)

Com relação aos hábitos de vida, a maioria dos pacientes não apresentava história pregressa ou atual de tabagismo e era sedentária (Tabela 2). 
Tabela 2. Tabagismo, etilismo e prática de atividade física entre os diabéticos tipo 2 (n $=165$ ).

\begin{tabular}{lcc}
\hline \multicolumn{1}{c}{ Variável } & $\mathrm{N}$ & $\%$ \\
\hline Tabagismo & 111 & 67,3 \\
Nunca & 8 & 4,8 \\
Anterior & 46 & 27,9 \\
Atual & 130 & 78,8 \\
Etilismo & 12 & 7,3 \\
$\quad$ Nunca & 23 & 13,9 \\
Anterior & 68 & 41,2 \\
Atual & & \\
Prática de atividade física & 38 & 23,0 \\
Nível de atividade física & 30 & 18,2 \\
Ativo & 97 & 58,8 \\
$\quad$ Irregularmente ativo & & \\
Sedentário &
\end{tabular}

N: frequência absoluta.

A mediana do tempo de diagnóstico do DM2 foi de 2 anos e a minoria dos pacientes apresentava alterações do fundo de olho sugestivas de retinopatia diabética. A maioria dos pacientes fazia uso de metformina para o tratamento do diabetes e apresentava, como comorbidade, hipertensão arterial sistêmica. A dislipidemia foi observada em menos da metade dos pacientes e apenas 8,38\% foram diganósticados com depressão (Tabela 3).

Tabela 3. Variáveis relacionadas ao DM2 e comorbidades entre os diabéticos tipo 2 $(n=165)$.

\begin{tabular}{lccc}
\hline \multicolumn{1}{c}{ Variável } & N & $\%$ & Mediana (IQ) \\
\hline Tempo de diagnóstico (anos) & & & $2(1-5)$ \\
Alteração de fundoscopia & 23 & 13,9 & \\
Tratamento do DM2 & 156 & 94,5 & \\
$\quad$ Metformina & 16 & 9,7 & \\
$\quad$ Sulfonilureia & 30 & 18,2 & \\
$\quad$ Insulina & 12 & 7,18 & \\
$\quad$ Fluoxetina & & & \\
Comorbidades & 58 & 35,1 & \\
$\quad$ Dislipidemia & 89 & 53,9 & \\
$\quad$ Hipertensão arterial sistêmica & 13 & 7,9 \\
$\quad$ Hipotireoidismo & 15 & 8,38 & \\
$\quad$ Depressão &
\end{tabular}

Mediana-IQ: intervalo interquartil; N: frequência absoluta.

A mediana da pressão arterial, sistólica e diastólica, foi normal e a do IMC, compatível com obesidade grau I. A maioria dos pacientes apresentava sobrepeso e 
obesidade grau I. Entre as mulheres e homens, a mediana da CA foi elevada, de 102 $\mathrm{cm}$ e $106 \mathrm{~cm}$, respectivamente (Tabela 4).

Tabela 4. Pressão arterial e estado nutricional dos diabéticos tipo $2(n=165)$.

\begin{tabular}{lccc}
\hline & $N$ & $\%$ & Mediana (IQ) \\
\hline PAS (mmHg) & & & $80(80-140)$ \\
PAD (mmHg) & & & $30,0(26,2-35,2)$ \\
IMC (kg/m $\left.{ }^{2}\right)$ & & 1,2 & \\
Estado nutricional & 2 & 18,8 & \\
$\quad$ Baixo peso & 31 & 29,7 & \\
$\quad$ Eutrófico & 49 & 24,2 & \\
$\quad$ Sobrepeso & 40 & 17,6 & $102,0(95,0-117,0)$ \\
Obesidade grau I & 29 & 8,5 & $106,0(95,3-119,5)$ \\
$\quad$ Obesidade grau II & 14 & & \\
$\quad$ Obesidade grau III & & & \\
Circunferência abdominal (cm) & & \\
$\quad$ Sexo feminino & &
\end{tabular}

Quanto às variáveis bioquímicas, foi observado que a mediana da glicemia de jejum e pós-prandial encontrava-se discretamente acima das metas de controle glicêmico $(<100 \mathrm{mg} / \mathrm{dL}$ para a glicemia de jejum e $<140 \mathrm{mg} / \mathrm{dL}$ para glicemia pósprandial) e a da $\mathrm{HbA1c}$, na meta. A mediana do colesterol LDL foi superior à meta de controle $(<100 \mathrm{mg} / \mathrm{dL}$ ), assim como a do triglicerídeo (meta $<150 / \mathrm{dL}$ ). A mediana do colesterol HDL foi baixa e a da PCR ultra-sensível, elevada (>0,3 $\mathrm{mg} / \mathrm{dL})$. A mediana dos indicadores de função renal (ureia e creatinina), assim como das enzimas hepáticas, foi normal (Tabela 5). 
Tabela 5. Resultados de variáveis bioquímicas dos diabéticos tipo 2 ( $n=165)$.

\begin{tabular}{lcc}
\hline \multicolumn{1}{c}{ Variável } & Número amostral & Mediana $(\mathbf{I Q})$ \\
\hline Glicemia de jejum $(\mathrm{mg} / \mathrm{dL})$ & 165 & $113(102-140)$ \\
Glicemia pós-prandial $(\mathrm{mg} / \mathrm{dL})$ & 54 & $144(121,3-190,5)$ \\
Hemoglobina glicada $(\%)$ & 165 & $6,4(5,9-7,3)$ \\
Colesterol total (mg/dL) & 161 & $193(159,5-216)$ \\
Colesterol LDL (mg/dL) & 152 & $110(92-138,8)$ \\
Colesterol HDL (mg/dL) & 161 & $41(34-48,5)$ \\
Triglicerídeo $(\mathrm{mg} / \mathrm{dL})$ & 161 & $152(108-215,5)$ \\
PCR ultra-sensível $(\mathrm{mg} / \mathrm{dL})$ & 70 & $0,33(0,12-0,57)$ \\
Uréia $(\mathrm{mg} / \mathrm{dL})$ & 163 & $30(24-35)$ \\
Creatinina $(\mathrm{mg} / \mathrm{dL})$ & 162 & $0,8(0,7-1,0)$ \\
AST $(\mathrm{U} / \mathrm{L})$ & 151 & $20(17-27)$ \\
ALT (U/L) & 149 & $20(16-29)$ \\
GGT (U/L) & 99 & $31(22-59)$
\end{tabular}

IQ: intervalo interquartil; AST: aspartato aminotransferase;ALT: aspartato alaninotransferase, GGT: gamaglutamiltransferase; PCR: proteína $C$ reativa.

\subsection{PEROXIDAÇÃO LIPÍDICA E CAPACIDADE ANTIOXIDANTE TOTAL}

A peroxidação lipídica foi avaliada, em amostras de soro, pelo ensaio de TBARS e a capacidade antioxidante total, nas mesmas amostras, pelo ensaio FRAP. Nesta análise, foram incluídos os 165 pacientes diabéticos e 130 controles. As características demográficas e clínicas destes sujeitos estão apresentadas na Tabela 6 e 7.

Os casos e controles não diferiram em relação à idade, porém a proporção de indivíduos do sexo masculino foi significativamente maior no grupo controle, assim como a frequência de maior nível de escolaridade.

O IMC foi significativamente superior no grupo de sujeitos com DM2. Em concordância, a frequência de obesidade foi superior entre os diabéticos tipo 2, em relação aos controles (Tabela 6). 
Tabela 6. Características demográficas e clínicas dos diabéticos tipo $2(n=165)$ e controles $(n=130)$.

\begin{tabular}{|c|c|c|c|c|c|}
\hline \multirow[b]{2}{*}{ Variável } & \multicolumn{2}{|c|}{ Casos } & \multicolumn{2}{|c|}{ Controles } & \\
\hline & Mediana (IQ) & $\mathbf{N}(\%)$ & Mediana (IQ) & $\mathbf{N}(\%)$ & \\
\hline Sexo masculino & & $40(24,2)$ & & $90(69,2)$ & * \\
\hline Idade (anos) & $49(46-53)$ & & $46(43-49)$ & & \\
\hline \multicolumn{6}{|l|}{ Escolaridade } \\
\hline Analfabeto & & $0(0)$ & & $1(0,8)$ & ** \\
\hline Fundamental incompleto & & $66(40)$ & & $12(9,2)$ & \\
\hline Fundamental completo & & $42(25,4)$ & & $10(7,7)$ & \\
\hline Médio incompleto & & $11(6,7)$ & & $4(3,1)$ & \\
\hline Médio completo & & $36(21,8)$ & & $41(31,5)$ & \\
\hline Superior incompleto & & $1(0,6)$ & & $20(15,4)$ & \\
\hline Superior completo & & $9(5,5)$ & & $31(23,8)$ & \\
\hline Pós-graduação & & $0(0)$ & & $11(8,5)$ & \\
\hline PAS (mmHg) & $130(120-40)$ & & $126(119-135)$ & & \\
\hline PAD (mmHg) & $80(80-90)$ & & $85(76-92)$ & & \\
\hline IMC $\left(\mathrm{kg} / \mathrm{m}^{2}\right)$ & $30(26,2-35,2)$ & & $\begin{array}{c}27,2(24,7- \\
29,6)\end{array}$ & & *** \\
\hline \multicolumn{6}{|l|}{ Estado nutricional } \\
\hline Baixo peso & & $2(1,2)$ & & $0(0)$ & * \\
\hline Eutrófico & & $31(18,8)$ & & $34(26,2)$ & \\
\hline Sobrepeso & & $49(29,7)$ & & $67(51,5)$ & \\
\hline Obesidade & & $83(50,3)$ & & $29(22,3)$ & \\
\hline
\end{tabular}


A concentração de TBARS foi significativamente maior no grupo casos, em relação ao grupo controle (Figura 9).

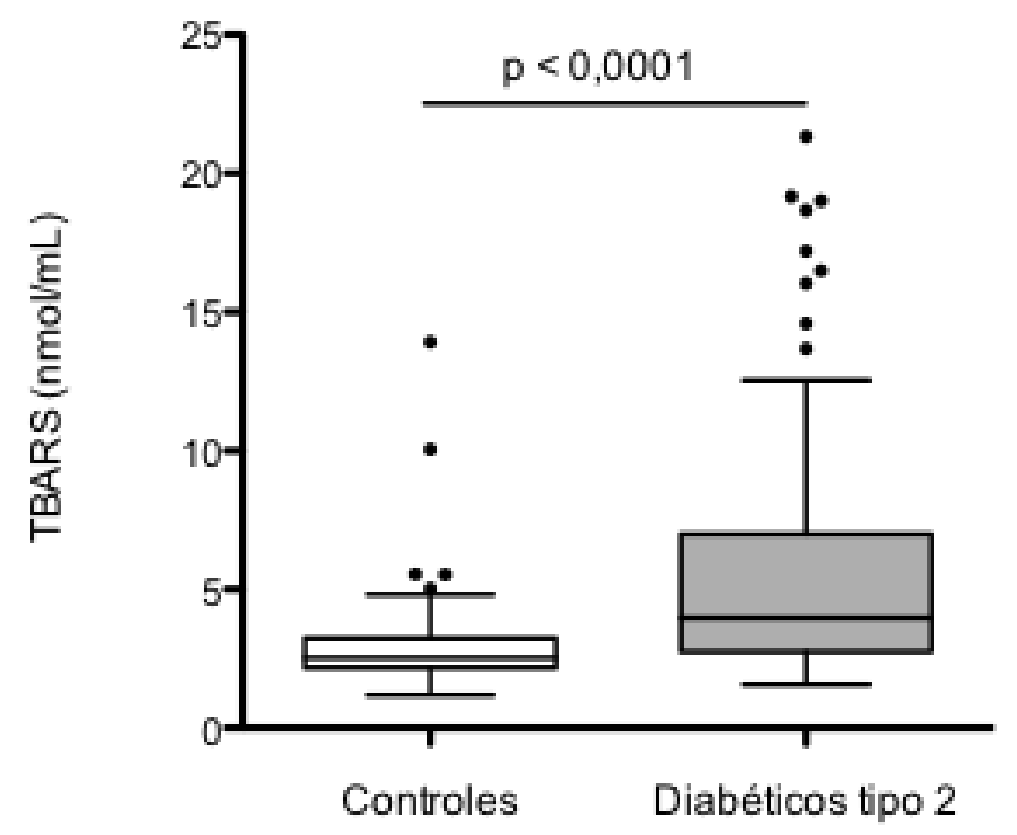

Figura 9 Concentração de TBARS nos diabéticos tipo 2 e controles com tolerância normal à glicose (teste de Mann-Whitney).

Para avaliação da capacidade antioxidante total no soro dos sujeitos de estudo, foi inicialmente elaborada uma curva padrão com concentrações crescentes de Trolox $(50,100,200,400,800$ e 1000( $\mu \mathrm{M})$.A representação gráfica da concentração de Trolox em função da absorbância de cada uma das concentrações está apresentada na Figura 10. 


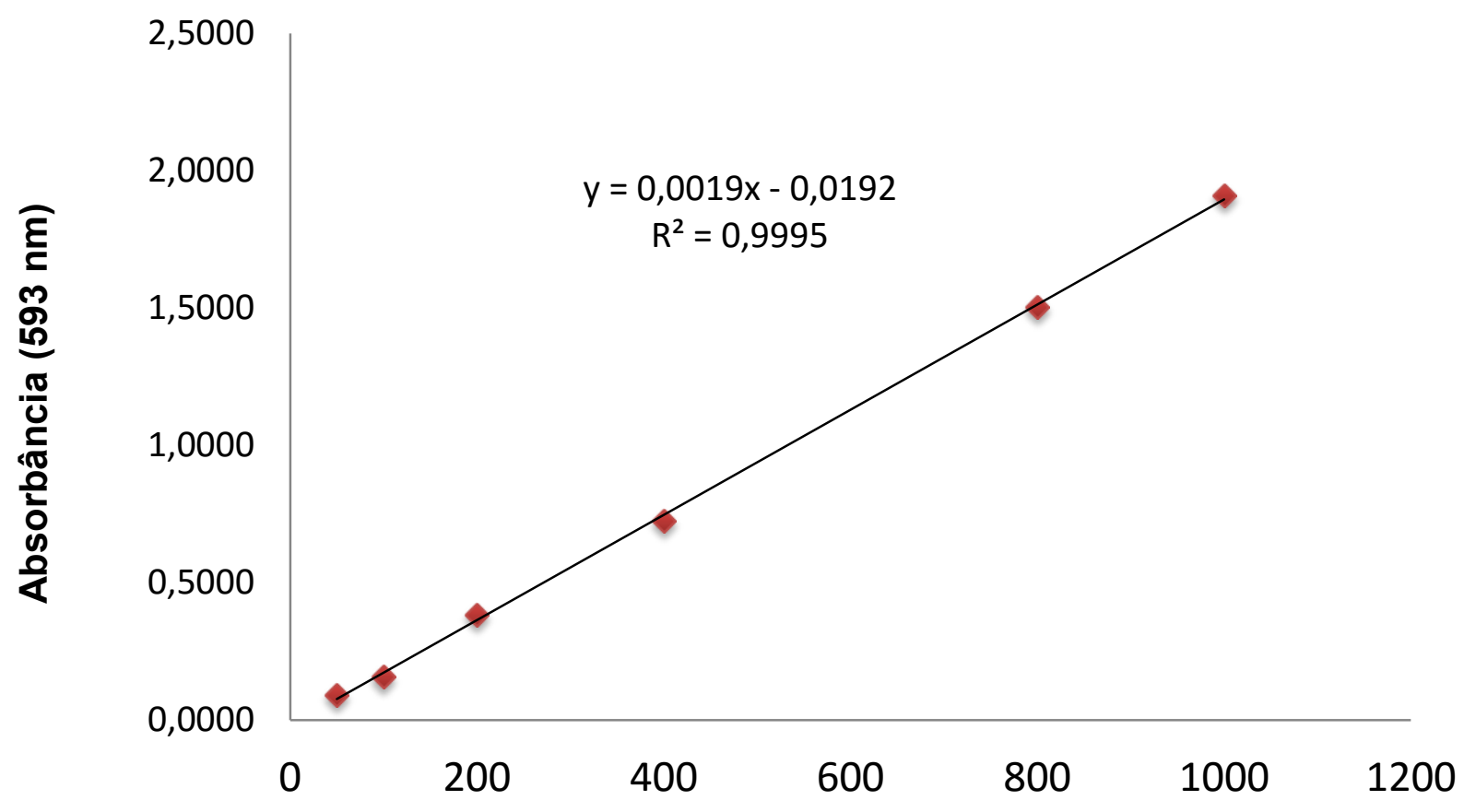

Trolox $[\mu \mathrm{M}]$

Figura 10 Representação gráfica da concentração de Trolox em função da absorbância da amostra e regressão linear para obtenção da equação da reta e determinação da capacidade antioxidante total nas amostras dos sujeitos do estudo.

Foi observada redução significativa da capacidade antioxidante total no soro dos diabéticos tipo 2, em comparação com os controles (Figura 11A). Em concordância, foi observada redução da relação FRAP/TBARS nos diabéticos, em relação aos controles (Figura 11B). 
A

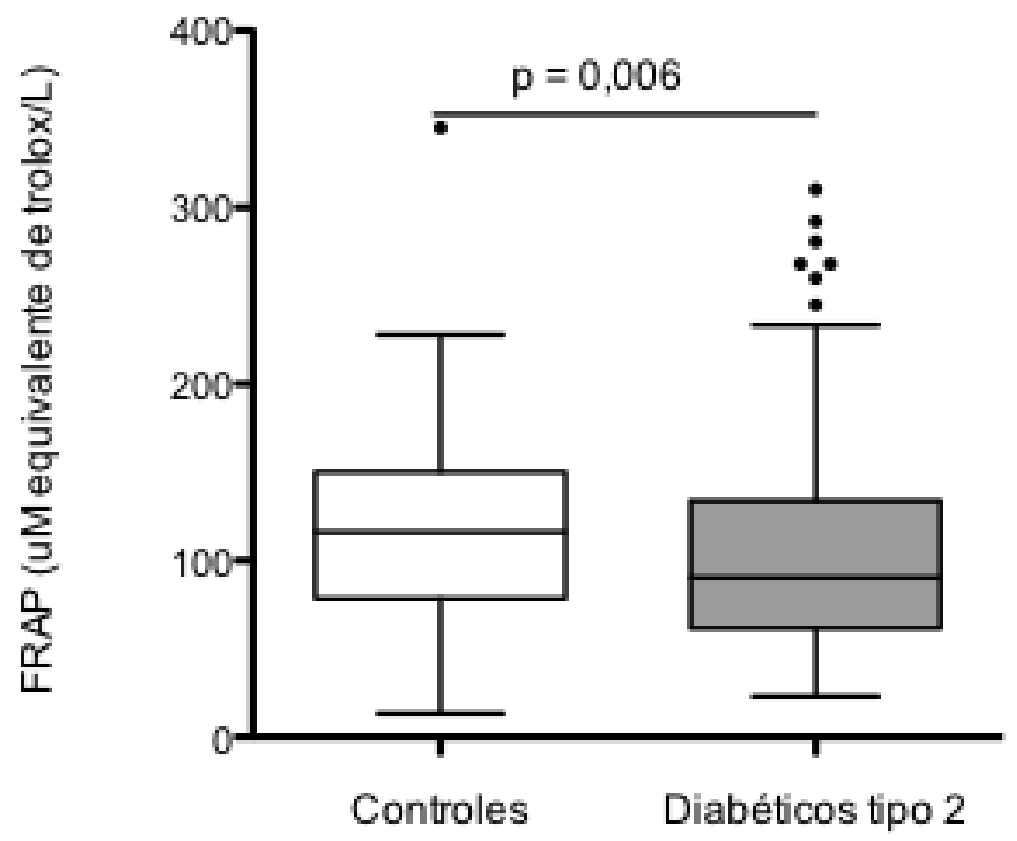

B

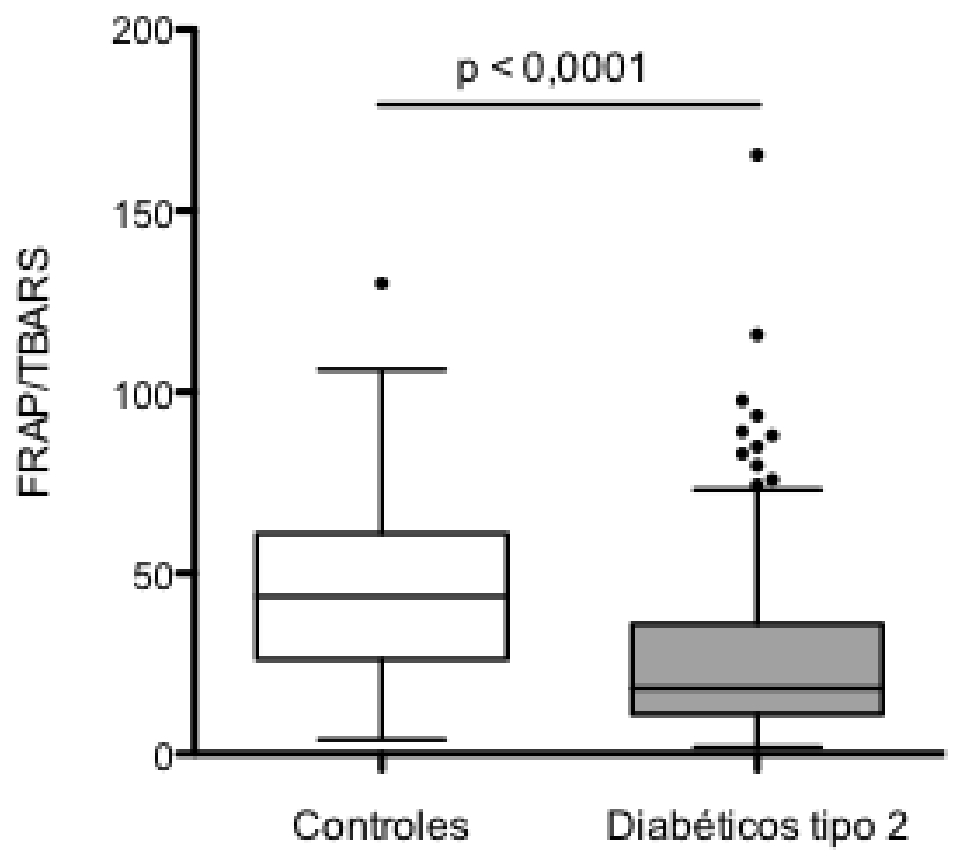

Figura 11 Capacidade antioxidante total (A), analisada pelo ensaio FRAP, e relação FRAP/TBARS (B) nos diabéticos tipo 2 e controles com tolerância normal (teste de Mann-Whitney). 
Considerando a diferença de distribuição de sexo no grupo de diabéticos tipo 2 e nos controles, a concentração de TBARS foi expressa de acordo com o sexo.

Não foram observadas diferenças entre os sexos com relação a esta variável, porém o aumento da concentração de TBARS se manteve entre homens e mulheres, quando comparados aos sujeitos do mesmo sexo, no grupo controle (Figura 12).

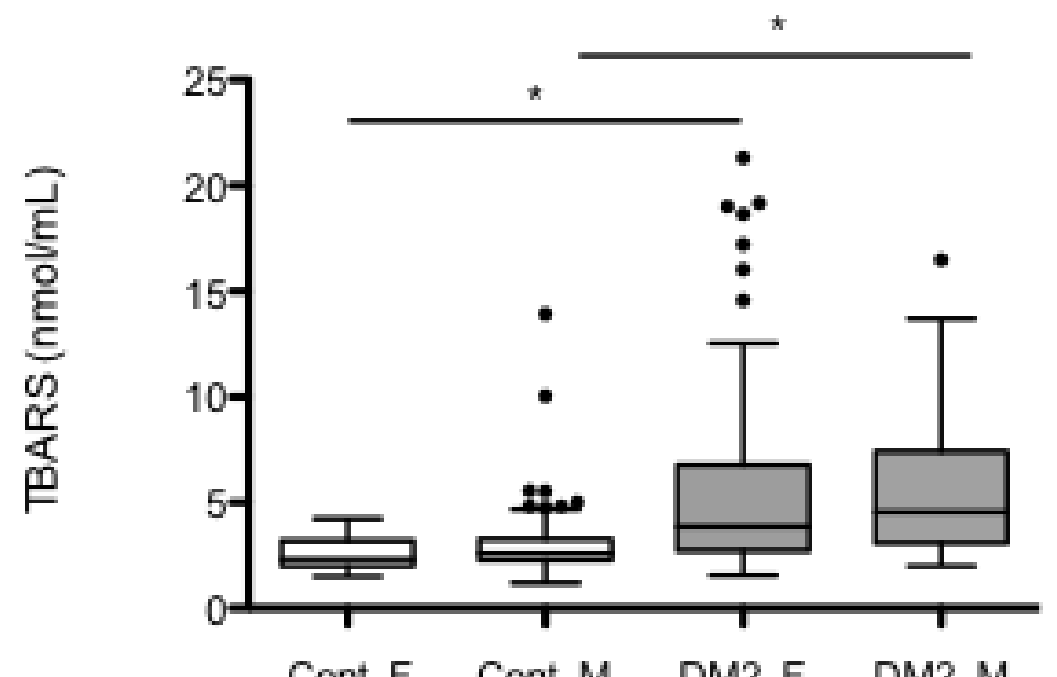

Figura 12 Concentração de TBARS no sexo feminino e masculino, nos diabéticos tipo 2 e controles com tolerância normal à glicose ( ${ }^{*} p<0,05$, teste de Kruskal-Wallis seguido do pós-teste de Dunn). Cont: grupo controle; DM2: diabéticos tipo 2; F: sexo feminino; M:masculino.

A capacidade antioxidante total também foi avaliada segundo o sexo, porém não foram observadas diferenças (Figura 12). Nesta análise, não foram também observadas as diferenças entre os casos e controles, descritas anteriormente (Figura 13). 


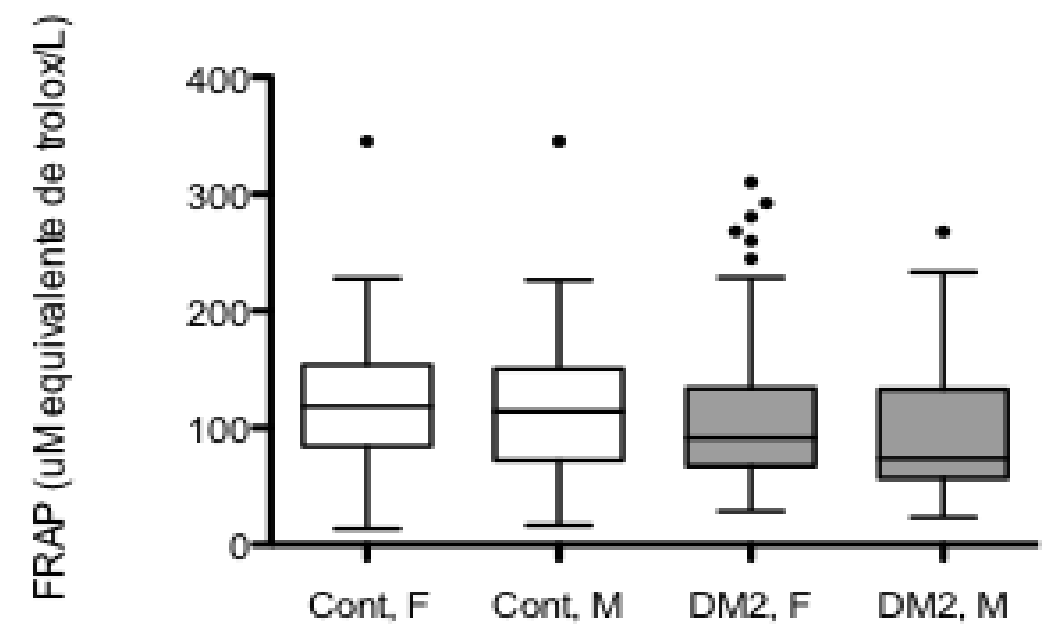

Figura 13 Capacidade antioxidante total (FRAP) no sexo feminino e masculino, nos diabéticos tipo 2 e controles com tolerância normal à glicose. Cont: grupo controle; DM2: diabéticos tipo 2; F: sexo feminino; M: sexo masculino.

A concentração de TBARS foi analisada também segundo o IMC, considerando a diferença de estado nutricional, segundo o IMC, entre o indivíduos com DM2 e os controles. Nesta análise, não houve, em cada grupo, diferença da concentração de TBARS segundo o IMC, porém as diferenças entre o grupo de diabéticos tipo 2 e o grupo controle se mantiveram em cada categoria de estado nutricional (Figura 14).

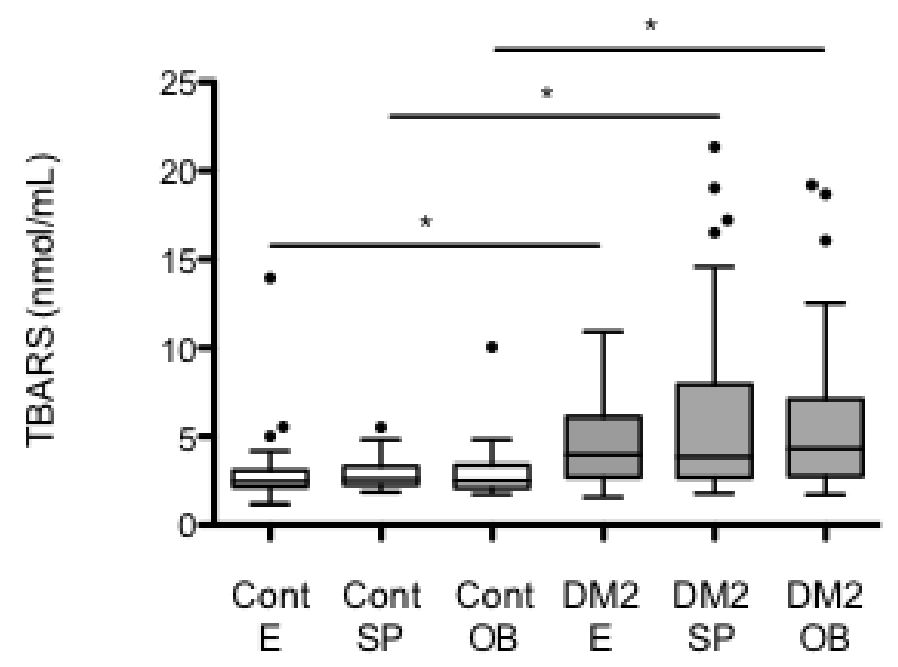

Figura 14 Concentração de TBARS, segundo o IMC, nos diabéticos tipo 2 e controles com tolerância normal à glicose ( ${ }^{*} p<0,05$, teste de Kruskal-Wallis seguido do pós-teste de Dunn). Cont: grupo controle; DM2: diabéticos tipo 2; E: eutrófico; SP: sobrepeso; OB: obeso. 
Diferentemente, quando foi analisada a capacidade antioxidante segundo o IMC, a diferença entre os casos e os controles não mais foi observada, embora tenha sido verificada tendência de redução em todas as categorias de IMC no grupo caso em relação ao grupo controle. Além disso, não foram observadas diferenças deste marcador segundo o IMC, em cada grupo (Figura 15).

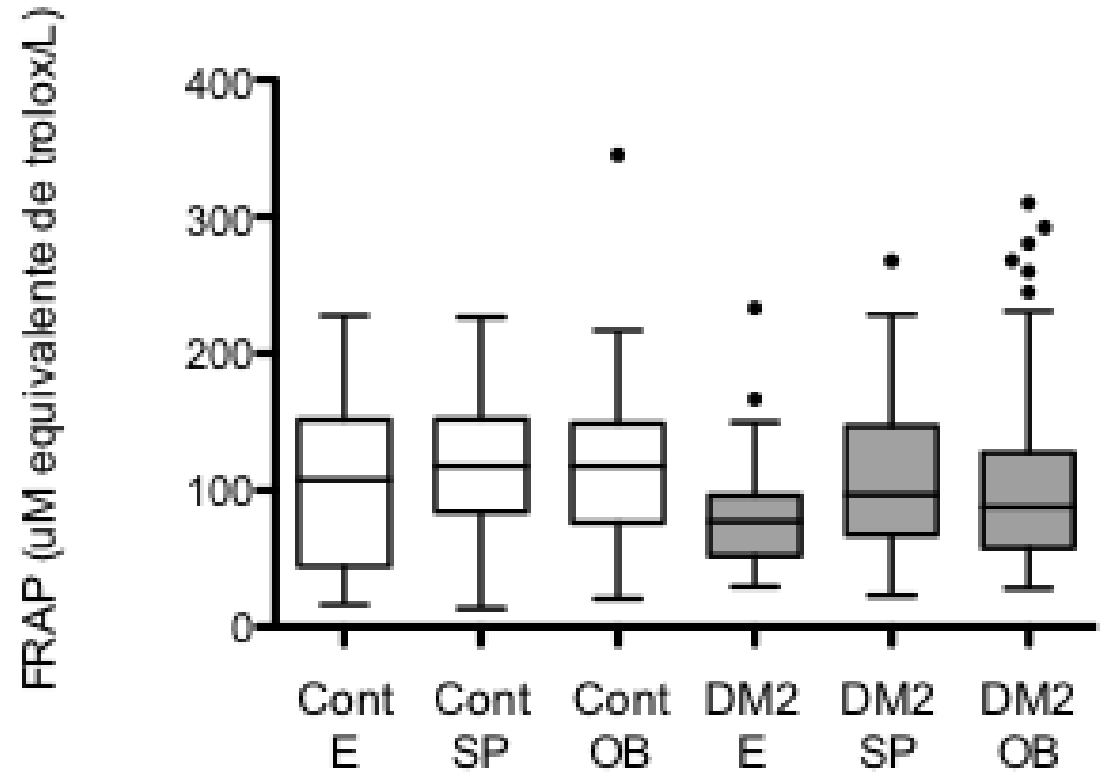

Figura 15 Concentração da capacidade antioxidante total, segundo o IMC, nos diabéticos tipo 2 e controles com tolerância normal à glicose $\left({ }^{*} p<0,05\right.$, teste de Kruskal-Wallis seguido do pós-teste de Dunn). Cont: grupo controle; DM2: diabéticos tipo 2; E:eutrófico.

Para cada um dos grupos, foi também avaliada a correlação entre concentração de TBARS no soro e a capacidade antioxidante total no soro e variáveis clínicas e relacionadas ao controle metabólico, incluindo idade, tempo de diagnóstico do DM2, PAS, PAD, IMC, CA, glicemia de jejum, glicemia pós-prandial, hemoglobina glicada, colesterol total, colesterol LDL, colesterol HDL, triglicerídeo, PCR ultra-sensível, ureia, creatinina e enzimas hepáticas.

Entre os diabéticos tipo 2, foi observada correlação negativa entre a concentração de TBARS e a concentração sérica de colesterol LDL (coeficiente de correlação de Spearman de $-0,18, p=0,02$ ) e correlação positiva entre a capacidade 
antioxidante total e o tempo de diagnóstico de DM2 (coeficiente de correlação de Spearman de $0,2, p=0,01$ ), hemoglobina glicada (coeficiente de correlação de Spearman de $0,25, p=0,003$ ) e triglicerídeo (coeficiente de correlação de Spearman de $0,19, p=0,01)$.

Entre os sujeitos do grupo controle, não foi observada correlação da concentração sérica de TBARS e nenhuma das variáveis testadas. Foi observada correlação positiva entre a capacidade antioxidante total em amostra de soro e a idade (coeficiente de correlação de Spearman de 0,47, p < 0,0001).

\subsection{COMPRIMENTO RELATIVO DOS TELÔMEROS DE LEUCÓCITOS DO SANGUE PERIFÉRICO EM DIABÉTICOS TIPO 2}

Para determinação do comprimento relativo dos telômeros, as amostras de DNA dos sujeitos no grupo caso (diabéticos tipo 2) e controles (tolerância normal à glicose) foram submetidas a amplificação da sequência telomérica e de sequência do gene de cópia única (36B4) simultaneamente, em duas placas de 96 poços, em que a posição de cada amostra nas duas placas era correspondente.

Em cada placa foram, ainda, amplificadas 6 concentrações de uma amostra referência de DNA, utilizada para o cálculo relativo do comprimento dos telômeros (razão T/S). A eficiência de amplificação dos iniciadores, para cada uma das reações realizadas, assim como o coeficiente de regressão linear após estabelecimento da curva padrão considerando a amostra referência, estão apresentados na Tabela 7. 
Tabela 7 Eficiência de amplificação e coeficiente de regressão linear após elaboração das curvas-padrão.

\begin{tabular}{ccccc}
\hline $\begin{array}{c}\text { Reações } \\
\text { PCRq }\end{array}$ & \multicolumn{2}{c}{ Sequência telomérica } & \multicolumn{2}{c}{ 36B4 } \\
Eficiência (\%) & $\mathbf{R}^{\mathbf{2}}$ & Eficiência (\%) & $\mathbf{R}^{\mathbf{2}}$ \\
\hline 1 & 97,2 & 0,99 & 105,4 & 0,94 \\
2 & 99,1 & 0,99 & 97,4 & 0,99 \\
3 & 98,0 & 0,99 & 90,9 & 0,99 \\
4 & 97,2 & 0,98 & 109,2 & 0,92 \\
5 & 95,6 & 0,99 & 98,1 & 0.93 \\
6 & 93,5 & 0,99 & 105,5 & 0,97 \\
7 & 92,3 & 0,98 & 103,9 & 0,96 \\
8 & 93,4 & 0,94 & 96,9 & 0,95 \\
9 & 87,8 & 0,91 & 106,9 & 0,96 \\
10 & 90,3 & 0,96 & 104,7 & 0,96 \\
\hline
\end{tabular}

Para avaliar a especificidade da amplificação, foi realizada a curva de dissociação (ou desnaturação) ao final da reação de amplificação. Esta análise confirmou produto único e estreito de amplificação na reação de amplificação de sequência de 36B4 (Figura 16A). Como esperado, a curva de dissociação do produto de amplificação na reação da sequência telomérica foi sugestiva de mais de um produto de amplificação (Figura 16 B).

A

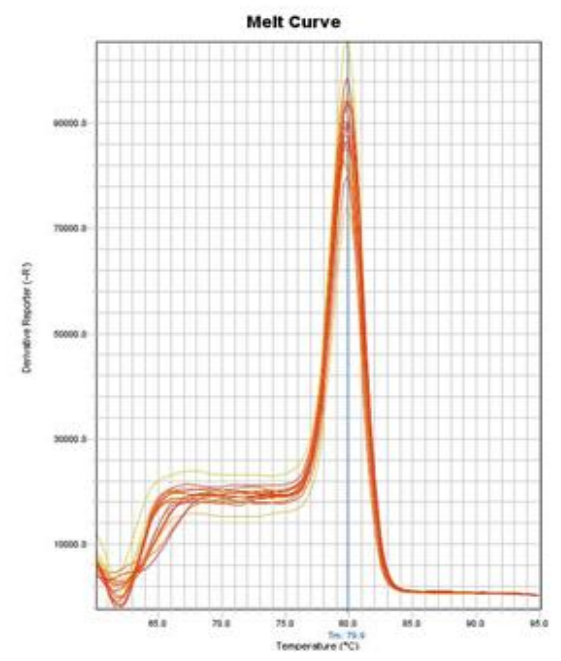

B

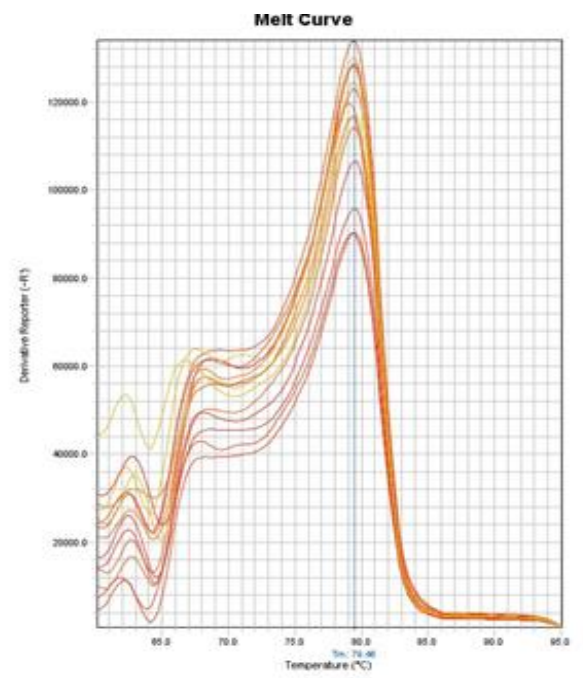

Figura 16 Curvas de dissociação do produto de amplificação da reação conduzida para amplificação (A) de sequência do gene de cópia única (36B4) e (B) da sequência telomérica. 
As curvas padrão para o Telômero e 36B4 são apresentadas na Figura 17 (A e B).

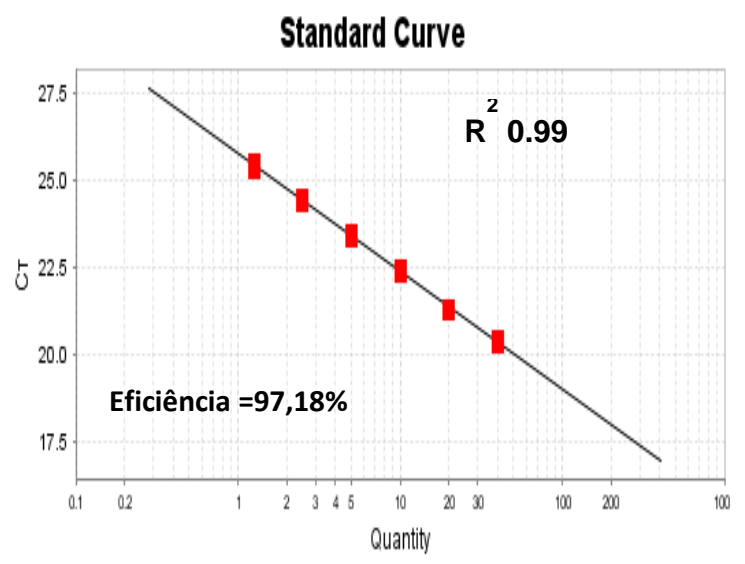

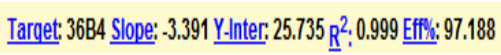

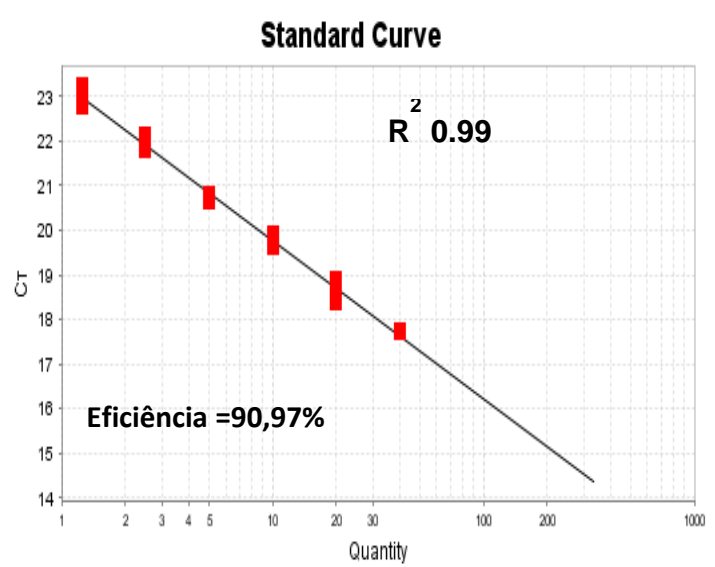

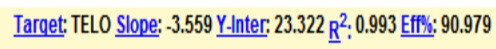

Figura 17 Curvas padrão das reações de amplificação (A) de sequência do gene de copia única (36B4) e (B) da sequência telomérica na amostra referência de DNA. Eficiência e coeficiente de correlação após análise e estabelecimento da curva padrão para cada sequência.

\subsubsection{Comprimento relativo dos telômeros em diabéticos tipo 2}

$\mathrm{Na}$ análise do comprimento relativo dos telômeros, foram incluídos os 165 pacientes diabéticos e 158 controles com tolerância normal à glicose. As características demográficas e clínicas destes sujeitos estão apresentadas na Tabela 8.

Os casos e controles não diferiram em relação à idade, porém a proporção de indivíduos do sexo masculino foi significativamente maior no grupo controle, assim como a frequência de maior nível de escolaridade. O IMC foi significativamente superior no grupo de sujeitos com DM2. Em concordância, a frequência de obesidade foi superior entre os diabéticos tipo 2 , em relação aos controles (Tabela 8). 
Tabela 8. Características demográficas e clínicas dos diabéticos tipo $2(n=165)$ e controles $(n=158)$.

\begin{tabular}{|c|c|c|c|c|c|}
\hline \multirow[b]{2}{*}{ Variável } & \multicolumn{2}{|c|}{ Casos } & \multicolumn{2}{|c|}{ Controles } & \\
\hline & Mediana (IQ) & $\mathbf{N}(\%)$ & Mediana (IQ) & $\mathbf{N}(\%)$ & \\
\hline Sexo masculino & & $40(24,2)$ & & $\begin{array}{c}111 \\
(70,3)\end{array}$ & * \\
\hline Idade (anos) & $49(46-53)$ & & $49(46-53)$ & & \\
\hline \multicolumn{6}{|l|}{ Escolaridade } \\
\hline Analfabeto & & $0(0)$ & & $0(0)$ & ** \\
\hline Fundamental incompleto & & $66(40)$ & & $9(5,7)$ & \\
\hline Fundamental completo & & $42(25,4)$ & & $12(7,6)$ & \\
\hline Médio incompleto & & $11(6,7)$ & & $1(0,6)$ & \\
\hline Médio completo & & $36(21,8)$ & & $83(52,5)$ & \\
\hline Superior incompleto & & $1(0,6)$ & & $12(7,6)$ & \\
\hline Superior completo & & $9(5,5)$ & & $35(22,2)$ & \\
\hline Pós-graduação & & $0(0)$ & & $6(3,8)$ & \\
\hline PAS $(\mathrm{mmHg})$ & $130(120-40)$ & & $130(120-136)$ & & \\
\hline PAD (mmHg) & $80(80-90)$ & & $85(78-92)$ & & \\
\hline $\operatorname{IMC}\left(\mathrm{kg} / \mathrm{m}^{2}\right)$ & $30(26,2-35,2)$ & & $27,3(24,4-30,2)$ & & $\star \star \star \star ~$ \\
\hline \multicolumn{6}{|l|}{ Estado nutricional } \\
\hline Baixo peso & & $2(1,2)$ & & $0(0)$ & * \\
\hline Eutrófico & & $31(18,8)$ & & $44(27,8)$ & \\
\hline Sobrepeso & & $49(29,7)$ & & $74(46,8)$ & \\
\hline Obesidade & & $83(50,3)$ & & $40(25,4)$ & \\
\hline
\end{tabular}

Mediana-IQ: intervalo interquartil; $\mathrm{N}$ : frequência absoluta.

${ }^{*} p<0,0001$ (teste exato de Fisher); ${ }^{* *} p<0,0001$ (teste do qui quadrado);

${ }^{* \star *} p<0,0001$ (teste de Mann-Whitney);

\subsubsection{Comparação de características demográficas, clínicas e bioquímicas dos diabéticos tipo $2 \mathrm{com}$ valores de T/S relativo considerados discrepantes e não discrepantes}

Foi observado que os 11 pacientes com valores T/S relativos considerados discrepantes apresentavam maior nível de escolaridade, maior frequência de prática de atividade física, menor mediana do tempo de diagnóstico, glicemia de jejum, hemoglobina glicada e PCR ultrassensível. Não foram observadas diferenças com relação à idade, sexo, renda mensal, frequência de tabagismo, etilismo ou alteração da fundoscopia, esquema de tratamento farmacológico do DM, frequência de HAS, dislipidemia ou hipotireoidismo, mediana da PAS ou PAD, mediana do IMC, estado nutricional segundo o IMC, CA, concentração sérica de colesterol total, colesterol LDL, 
colesterol HDL, triglicerídeos, uréia, creatinina, enzimas hepáticas, TBARS ou capacidade antioxidante total no soro. 
Tabela 9 Características demográficas, clínicas e bioquímicas de diabéticos tipo $2 \mathrm{com}$ valores de T/S relativo discrepantes (outliers) e não discrepantes.

\begin{tabular}{|c|c|c|c|c|c|c|c|c|}
\hline \multirow[b]{2}{*}{ Variável } & \multicolumn{2}{|c|}{ Outliers } & \multicolumn{2}{|c|}{ Não outliers } & \multirow{2}{*}{$\begin{array}{l}\text { Outliers vs } \\
\text { não outliers }\end{array}$} & \multicolumn{2}{|c|}{ Controles } & \multirow{2}{*}{$\begin{array}{c}\text { Outliers } \\
\text { vs } \\
\text { controles }\end{array}$} \\
\hline & Mediana (IQ) & $\mathbf{N}(\%)$ & Mediana (IQ) & $\mathbf{N}(\%)$ & & Mediana (IQ) & $\mathbf{N}(\%)$ & \\
\hline Sexo masculino/feminino & $1 / 10(70,3)$ & & & $39 / 115$ & $p>0,05$ & & $111(70,3)$ & $p<0,0001$ \\
\hline Idade (anos) & $48(45-49)$ & & $49,5(46-53)$ & & $p>0,05$ & $49(46-53)$ & & $p>0,05$ \\
\hline \multicolumn{9}{|l|}{ Escolaridade } \\
\hline Analfabeto & & $0(0)$ & & $0(0)$ & $p=0,031$ & $0(0)$ & & $p>0,05$ \\
\hline $\begin{array}{l}\text { Fundamental } \\
\text { incompleto }\end{array}$ & & $3(27,3)$ & & $63(40,9)$ & & $9(5,7)$ & & \\
\hline Fundamental completo & & $1(9,1)$ & & $41(26,6)$ & & $12(7,6)$ & & \\
\hline Médio incompleto & & $0(0)$ & & $11(7,1)$ & & $1(0,6)$ & & \\
\hline Médio completo & & $6(54,5)$ & & $30(19,5)$ & & $83(52,5)$ & & \\
\hline Superior incompleto & & $0(0)$ & & $1(0,7)$ & & $12(7,6)$ & & \\
\hline Superior completo & & $1(9,1)$ & & $8(5,2)$ & & $35(22,2)$ & & \\
\hline Pós-graduação & & $0(0)$ & & $0(0)$ & & $6(3,8)$ & & \\
\hline
\end{tabular}


Tabela 9 (continuação). Características demográficas, clínicas e bioquímicas de diabéticos tipo 2 com valores de T/S relativo discrepantes (outliers) e não discrepantes.

\begin{tabular}{|c|c|c|c|c|c|c|c|c|}
\hline \multirow[b]{2}{*}{ Variável } & \multicolumn{2}{|c|}{ Outliers } & \multicolumn{2}{|c|}{ Não outliers } & \multirow{2}{*}{$\begin{array}{c}\text { Outliers vs } \\
\text { não } \\
\text { outliers }\end{array}$} & \multicolumn{2}{|c|}{ Controles } & \multirow{2}{*}{$\begin{array}{c}\text { Outliers } \\
\text { vs }\end{array}$} \\
\hline & $\begin{array}{l}\text { Mediana } \\
\text { (IQ) }\end{array}$ & $\mathbf{N}(\%)$ & $\begin{array}{l}\text { Mediana } \\
\text { (IQ) }\end{array}$ & N (\%) & & $\begin{array}{l}\text { Mediana } \\
\text { (IQ) }\end{array}$ & $\mathbf{N}(\%)$ & \\
\hline Renda mensal $\left(\mathrm{SM}^{\mathrm{a}}\right)$ & & & & & $p>0,05$ & & & \\
\hline 1 a 2,9 & & $7(63,6)$ & & $106(68,8)$ & & & & \\
\hline 3 a 4,9 & & $3(27,3)$ & & $44(28,6)$ & & & & \\
\hline 5 a 6,9 & & $0(0)$ & & $2(1,3)$ & & & & \\
\hline 7 ou mais & & $1(9,1)$ & & $2(1,3)$ & & & & \\
\hline Tabagismo & & & & & $p>0,05$ & & & \\
\hline Nunca & & $10(90,9)$ & & $101(65,6)$ & & & & \\
\hline Anterior & & $1(9,1)$ & & $7(4,5)$ & & & & \\
\hline Atual & & $0(0)$ & & $46(29,9)$ & & & & \\
\hline Etilismo & & & & & $p>0,05$ & & & \\
\hline Nunca & & $11(100)$ & & $119(77,3)$ & & & & \\
\hline Anterior & & $0(0)$ & & $12(7,8)$ & & & & \\
\hline Atual & & $0(0)$ & & $23(14,9)$ & & & & \\
\hline
\end{tabular}


Tabela 9 (continuação). Características demográficas, clínicas e bioquímicas de diabéticos tipo 2 com valores de T/S relativo discrepantes (outliers) e não discrepantes.

\begin{tabular}{|c|c|c|c|c|c|c|c|c|}
\hline \multirow[b]{2}{*}{ Variável } & \multicolumn{2}{|c|}{ Outliers } & \multicolumn{2}{|c|}{ Não outliers } & \multirow{2}{*}{$\begin{array}{l}\text { Outliers vs } \\
\text { não outliers }\end{array}$} & \multicolumn{2}{|c|}{ Controles } & \multirow{2}{*}{$\begin{array}{l}\text { Outliers vs } \\
\text { controles }\end{array}$} \\
\hline & Mediana (IQ) & $\mathbf{N}(\%)$ & Mediana (IQ) & $\mathbf{N}(\%)$ & & Mediana (IQ) & $\mathbf{N}(\%)$ & \\
\hline Prática de atividade física & & $10(90,9)$ & & $57(37,0)$ & $p=0,0006$ & & & \\
\hline $\begin{array}{l}\text { Tempo de diagnóstico } \\
\text { (anos) }\end{array}$ & $1(0-1)$ & & $2(1-5)$ & & $p=0,0037$ & & & \\
\hline Alteração de fundoscopia & & $2(18,2)$ & & $21(13,6)$ & $p>0,05$ & & & \\
\hline Tratamento do DM2 & & & & & $p>0,05$ & & & \\
\hline Metformina & 10 & & 146 & & & & & \\
\hline Sulfonilureia & 0 & & 16 & & & & & \\
\hline Insulina & 1 & & 29 & & & & & \\
\hline Comorbidades & & & & $P>0,05$ & & & & \\
\hline Dislipidemia & 5 & & 53 & & & & & \\
\hline HAS & 2 & & 87 & & & & & \\
\hline Hipotireoidismo & 0 & & 13 & & & & & \\
\hline PAS $(\mathrm{mmHg})$ & $130(120-140)$ & & $130(120-140)$ & & $p>0,05$ & $130(120-136)$ & & $p>0,05$ \\
\hline PAD (mmHg) & $80(80-90)$ & & $80(80-90)$ & & $p>0,05$ & $85(78-92)$ & & $p>0,05$ \\
\hline
\end{tabular}

Mediana-IQ: intervalo interquartil; $\mathrm{N}$ : frequência absoluta. 
Tabela 9 (continuação). Características demográficas, clínicas e bioquímicas de diabéticos tipo 2 com valores de T/S relativo discrepantes (outliers) e não discrepantes.

\begin{tabular}{|c|c|c|c|c|c|c|c|c|}
\hline \multirow[b]{2}{*}{ Variável } & \multicolumn{2}{|c|}{ Outliers } & \multicolumn{2}{|c|}{ Não outliers } & \multirow{2}{*}{$\begin{array}{l}\text { Outliers vs } \\
\text { não outliers }\end{array}$} & \multicolumn{2}{|c|}{ Controles } & \multirow{2}{*}{$\begin{array}{c}\text { Outliers } \\
\text { vs } \\
\text { controles }\end{array}$} \\
\hline & Mediana (IQ) & $\mathbf{N}(\%)$ & $\begin{array}{l}\text { Mediana } \\
\text { (IQ) }\end{array}$ & $\mathbf{N}(\%)$ & & Mediana (IQ) & $\mathbf{N}(\%)$ & \\
\hline IMC $\left(\mathrm{kg} / \mathrm{m}^{2}\right)$ & $34,1(23,9-39,3)$ & & $\begin{array}{c}29,94 \\
(26,34- \\
35,12)\end{array}$ & & $p>0,05$ & $27,3(24,4-30,2)$ & & $p>0,05$ \\
\hline Estado nutricional & & & & & $p>0,05$ & & & $p>0,05$ \\
\hline Baixo peso & & $0(0)$ & & $2(1,3)$ & & $0(0)$ & & \\
\hline Eutrófico & & $3(27,3)$ & & $28(18,2)$ & & $44(27,8)$ & & \\
\hline Sobrepeso & & $2(18,2)$ & & $47(30,5)$ & & $74(46,8)$ & & \\
\hline Obesidade grau I & & $2(18,2)$ & & $38(24,7)$ & & 33 & & \\
\hline Obesidade grau II & & $3(27,3)$ & & $26(16,9)$ & & 6 & & \\
\hline Obesidade grau III & & $1(9,1)$ & & $13(8,4)$ & & 1 & & \\
\hline \multicolumn{9}{|l|}{$\mathrm{CA}(\mathrm{cm})$} \\
\hline Sexo feminino & $\begin{array}{c}99,5(93,8- \\
110,5)\end{array}$ & & $\begin{array}{c}102,0(94,0- \\
117,0)\end{array}$ & & $p>0,05$ & & & \\
\hline Sexo masculino & 139 & & $118(95-118)$ & & NA & & & \\
\hline GJ & $103(95-123)$ & & $\begin{array}{c}114(102- \\
143,3)\end{array}$ & & $p=0,048$ & & & \\
\hline
\end{tabular}


Tabela 9 (continuação). Características demográficas, clínicas e bioquímicas de diabéticos tipo 2 com valores de T/S relativo discrepantes (outliers) e não discrepantes.

\begin{tabular}{|c|c|c|c|c|c|c|c|c|}
\hline \multirow[b]{2}{*}{ Variável } & \multicolumn{2}{|l|}{ Outliers } & \multicolumn{2}{|c|}{ Não outliers } & \multirow{2}{*}{$\begin{array}{l}\text { Outliers vs } \\
\text { não outliers }\end{array}$} & \multicolumn{2}{|c|}{ Controles } & \multirow{2}{*}{$\begin{array}{c}\text { Outliers } \\
\text { vs } \\
\text { controles }\end{array}$} \\
\hline & Mediana (IQ) & $\mathbf{N}(\%)$ & Mediana (IQ) & $\mathbf{N}(\%)$ & & Mediana (IQ) & $\begin{array}{c}\mathbf{N} \\
(\%)\end{array}$ & \\
\hline \multirow[t]{2}{*}{ GPP } & 138 & & $144(120,5-191)$ & & NA & & & \\
\hline & $\mathrm{N}=1$ & & $N=53$ & & & & & \\
\hline $\mathrm{HbA1c}$ & $6,1(5,7-6,2)$ & & $6,5(5,9-7,4)$ & & $p=0,019$ & & & \\
\hline \multirow[t]{2}{*}{ CT } & $202(182-233)$ & & $192,5(159-215,5)$ & & $p>0,05$ & & & \\
\hline & $N=11$ & & $N=150$ & & & & & \\
\hline \multirow[t]{2}{*}{ LDL } & $121(105,5-167,5)$ & & $110(92-138,3)$ & & $p>0,05$ & & & \\
\hline & $\mathrm{N}=10$ & & $\mathrm{~N}=142$ & & & & & \\
\hline \multirow[t]{2}{*}{ HDL } & $47(40-48)$ & & $40,5(34-49,0)$ & & $p>0,05$ & & & \\
\hline & $\mathrm{N}=11$ & & $N=150$ & & & & & \\
\hline \multirow[t]{2}{*}{ TG } & $184(131-194)$ & & $149(106-216,8)$ & & $p>0,05$ & & & \\
\hline & $\mathrm{N}=11$ & & $N=150$ & & & & & \\
\hline \multirow[t]{2}{*}{ PCR US } & $0,12(0,09-0,46)$ & & $0,35(0,15-0,82)$ & & $p=0,045$ & & & \\
\hline & $\mathrm{N}=8$ & & $\mathrm{~N}=62$ & & & & & \\
\hline
\end{tabular}


Tabela 9 (continuação). Características demográficas, clínicas e bioquímicas de diabéticos tipo 2 com valores de T/S relativo discrepantes (outliers) e não discrepantes.

\begin{tabular}{|c|c|c|c|c|c|c|c|c|}
\hline \multirow[b]{2}{*}{ Variável } & \multicolumn{2}{|l|}{ Outliers } & \multicolumn{2}{|c|}{ Não outliers } & \multirow{2}{*}{$\begin{array}{l}\text { Outliers vs } \\
\text { não outliers }\end{array}$} & \multicolumn{2}{|c|}{ Controles } & \multirow{2}{*}{$\begin{array}{c}\text { Outliers vs } \\
\text { controles }\end{array}$} \\
\hline & Mediana (IQ) & $\mathbf{N}(\%)$ & Mediana (IQ) & $\mathbf{N}(\%)$ & & Mediana (IQ) & $\mathbf{N}(\%)$ & \\
\hline \multirow[t]{2}{*}{ Uréia } & $30(24-37)$ & & 30 (24-35) & & $p>0,05$ & & & \\
\hline & $\mathrm{N}=11$ & & $N=152$ & & & & & \\
\hline Creatinina & $0,85(0,80-1,05)$ & & $0,8(0,7-1,0)$ & & $p>0,05$ & & & \\
\hline \multirow[t]{2}{*}{ TGO } & $17,5(16-20,75)$ & & $21(17-27)$ & & $p>0,05$ & & & \\
\hline & $\mathrm{N}=10$ & & $\mathrm{~N}=141$ & & & & & \\
\hline \multirow[t]{2}{*}{ TGP } & $20(13,5-30)$ & & $20,5(16-28,8)$ & & $p>0,05$ & & & \\
\hline & $\mathrm{N}=9$ & & $N=140$ & & & & & \\
\hline FRAP & $71,0(46,2-95,9)$ & & $\begin{array}{c}90,0(62,3- \\
135,4)\end{array}$ & & $p>0,05$ & & & \\
\hline
\end{tabular}


O comprimento relativo dos telômeros ( $\mathrm{T} / \mathrm{S}$ relativo) foi significativamente superior no grupo de diabéticos tipo 2 em relação ao grupo controle (Figura 18A). Quando os 11 sujeitos com valores discrepantes (outliers) de T/S relativo foram excluídos da análise, não foi observada diferença entre o grupo de diabéticos tipo 2 e o controle (Figura 18B). O coeficiente de variação do T/S relativo, calculado pela divisão do desvio padrão pela média do $\mathrm{T} / \mathrm{S}$ relativo da amostra referência na quantidade de 20 ng, foi de $5,63 \%$.

A

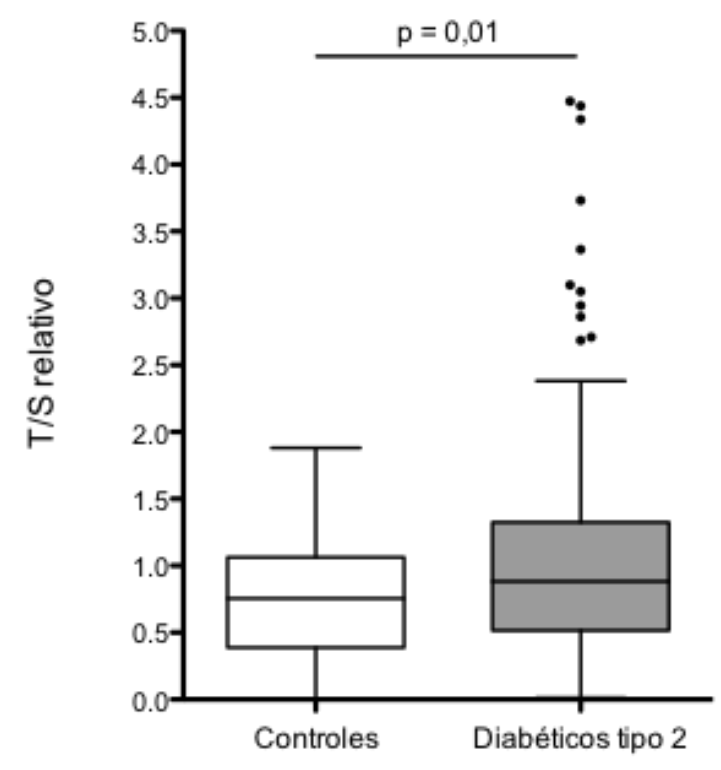

B

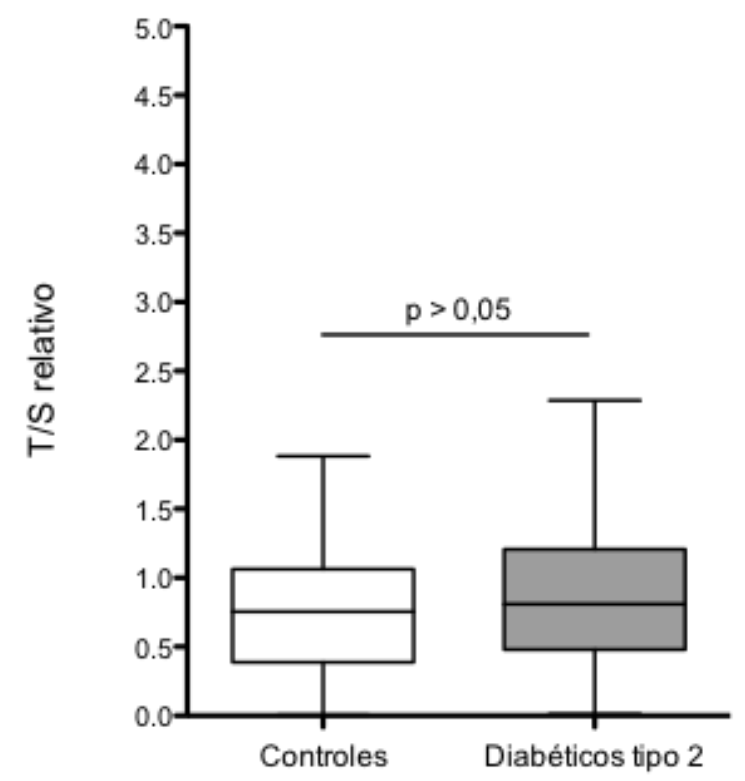

Figura 18 Comprimento relativo dos telômeros (T/S relativo) nos diabéticos tipo 2 e grupo controle, sem (A) e com (B) exclusão dos outliers. Teste de Mann-Whitney.

Considerando a diferença de sexo entre os diabéticos tipo 2 e os sujeitos no grupo controle, a análise do T/S relativo foi realizada de acordo com o sexo. Não foi observada diferença do T/S relativo entre os sexos masculino e feminino, nos dois grupos (Figura 19). 


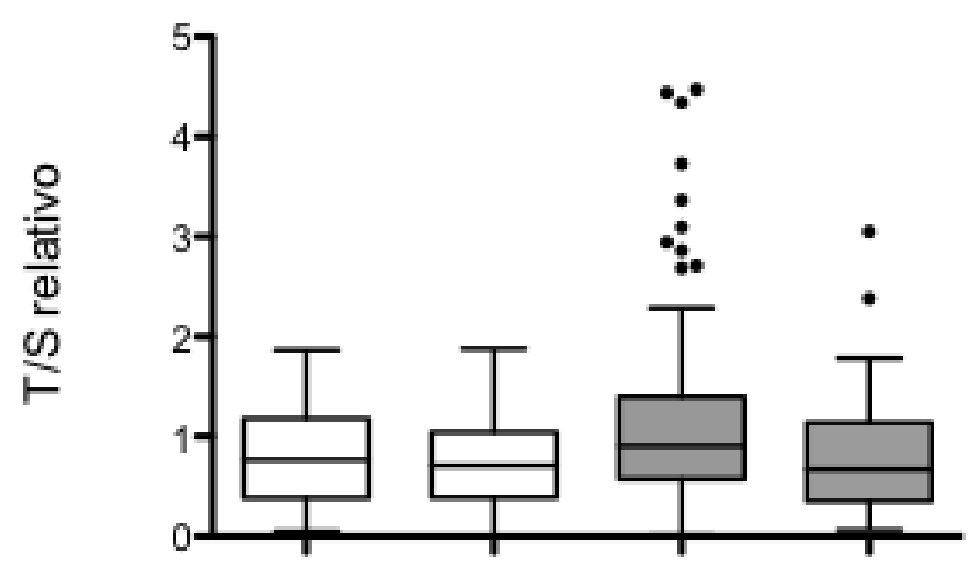

Cont, $\mathrm{F} \quad$ Cont, $\mathrm{M} \quad \mathrm{DM} 2, \mathrm{~F} \quad \mathrm{DM} 2, \mathrm{M}$

Figura 19 Comprimento relativo dos telômeros (T/S relativo), no sexo feminino e masculino, nos diabéticos tipo 2 e controles com tolerância normal à glicose. Cont: grupo controle; DM2: diabéticos tipo 2; F: sexo feminino; M: sexo masculino.

Também não foi observada diferença do T/S relativo, em cada grupo, de acordo com o estado nutricional, definido pelo valor do IMC (Figura 20).

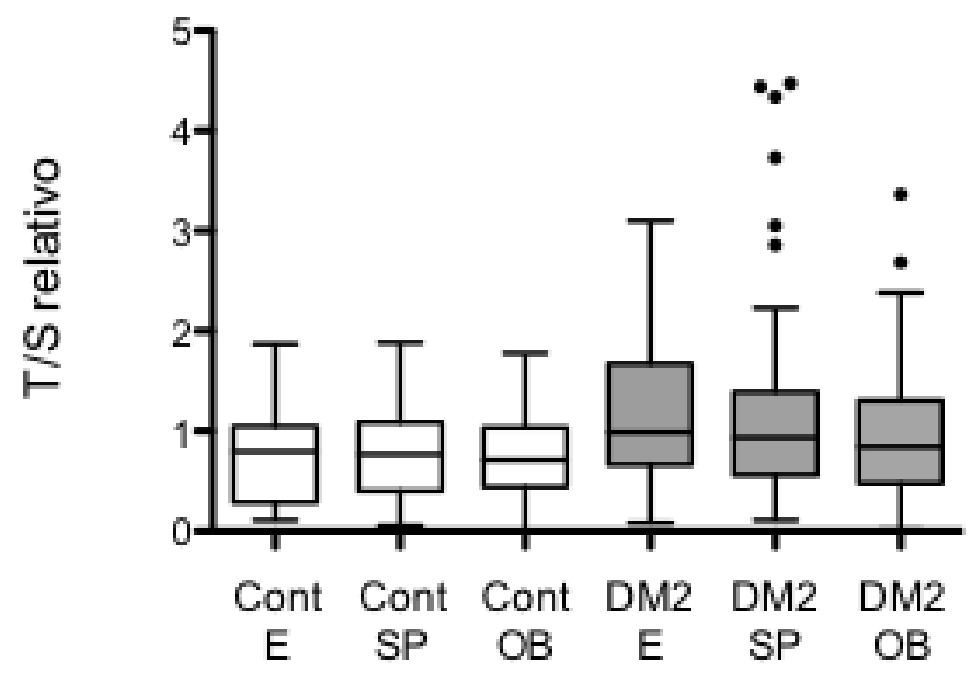

Figura 20 Comprimento relativo dos telômeros (T/S relativo), segundo o IMC, nos diabéticos tipo 2 e controles com tolerância normal à glicose. Cont: grupo controle; DM2: diabéticos tipo 2; E: eutrófico; SP: sobrepeso; OB: obesidade.

Não foi observada, nos dois grupos, diferença do T/S relativo de acordo com o nível de escolaridade. 


\subsubsection{Comprimento relativo dos telômeros em diabéticos tipo 2 e variáveis clínicas e bioquímicas}

O comprimento relativo dos telômeros, no grupo de diabéticos tipo 2, foi comparado entre o subgrupo com fundoscopia alterada (retinopatia diabética) e fundoscopia normal. Não foi observada diferença entre os grupos (Figura 21).

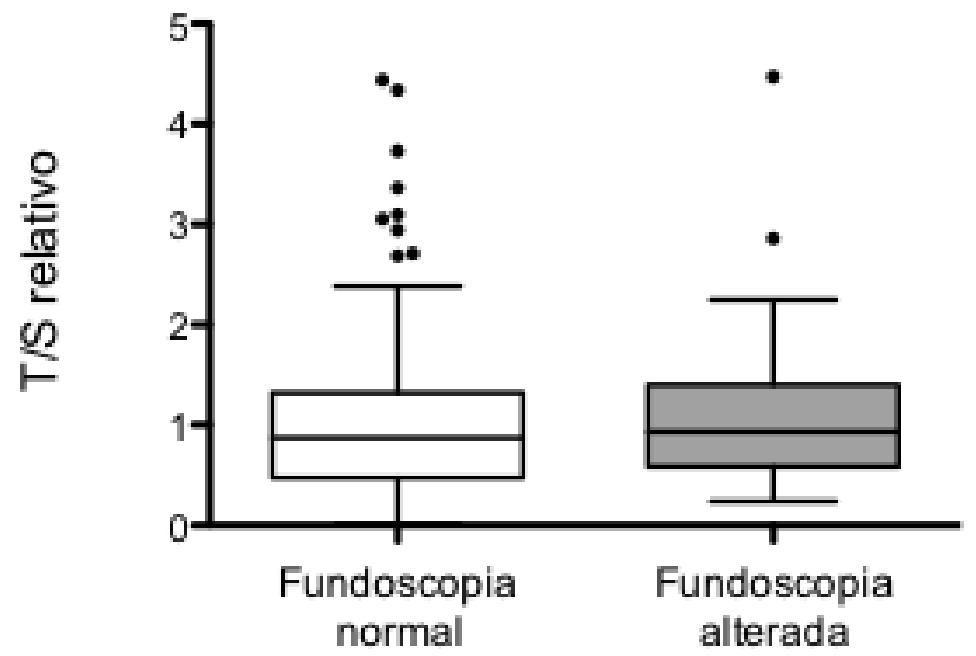

Figura 21 Comprimento relativo dos telômeros (T/S relativo), segundo a presença de retinopatia diabética. Teste de Mann-Whitney.

Foi também avaliada a correlação entre o comprimento relativo dos telômeros e variáveis clínicas, bioquímicas relacionadas ao controle metabólico e a $\mathrm{EO}$, incluindo idade, tempo de diagnóstico do DM2, PAS, PAD, IMC, CA, glicemia de jejum, glicemia pós-prandial, hemoglobina glicada, colesterol total, colesterol LDL, colesterol HDL, triglicerídeo, PCR ultra-sensível, ureia, creatinina, enzimas hepáticas, concentração sérica de TBARS e capacidade antioxidante total.

Observou-se a correlação negativa entre o comprimento relativo dos telômeros e o tempo de diagnóstico do DM2 (Figura 22), o valor da glicemia de jejum (Figura 23A), o valor da hemoglobina glicada (Figura 23B) e a capacidade antioxidante total (Figura 
24A). Foi observada correlação positiva entre o comprimento relativo dos telômeros e a concentração sérica de TBARS (Figura 24B).

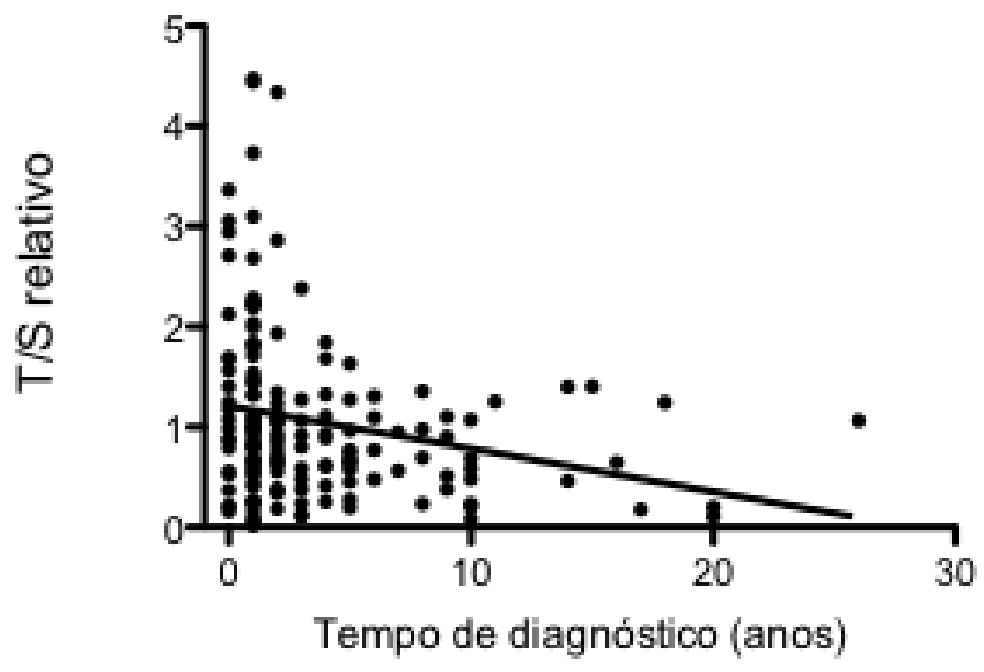

Figura 22 Correlação entre o comprimento relativo dos telômeros e o tempo de diagnóstico de DM2, nos diabéticos tipo $2\left(r^{2}\right.$ Spearman $\left.-0,25, p=0,0015\right)$.

A

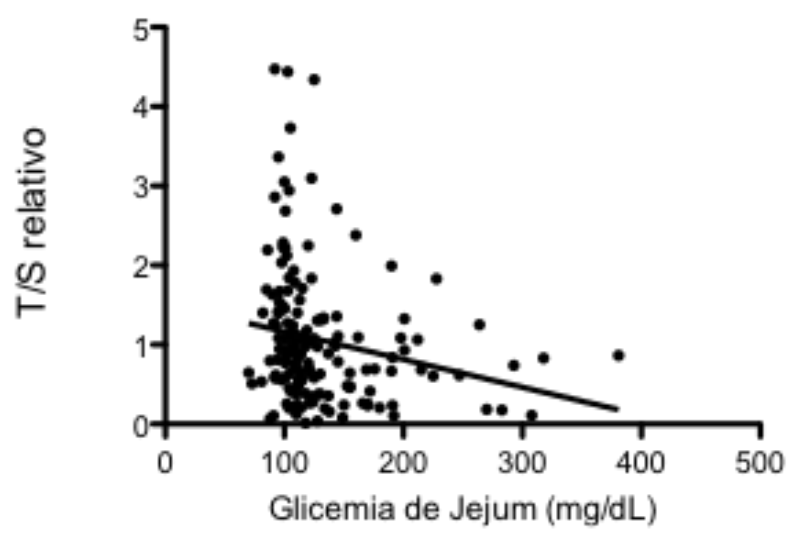

B

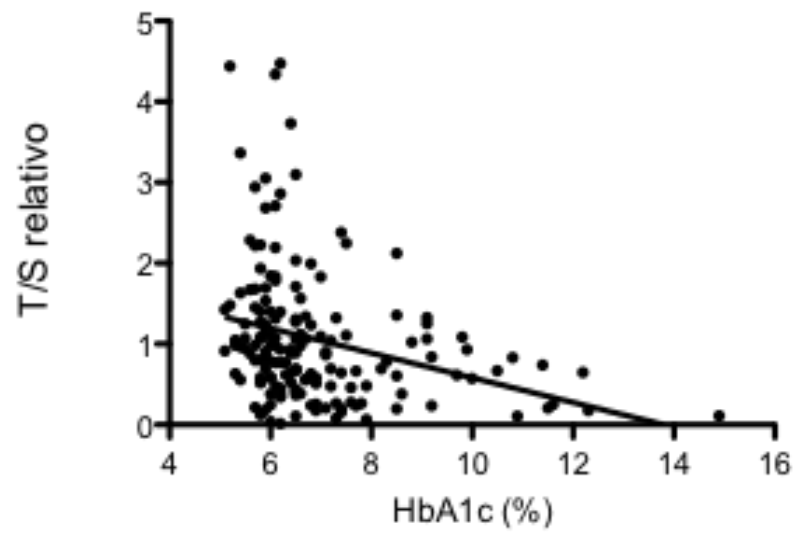

Figura 23 Correlação entre o comprimento relativo dos telômeros e $(A)$ a glicemia de jejum $\left(r^{2}\right.$ Spearman -0,26, $p=0,0004)$ e $(B)$ a hemoglobina glicada $\left(r^{2}\right.$ Spearman $\left.-0,35, p<0,0001\right)$, nos diabéticos tipo 2. 
A

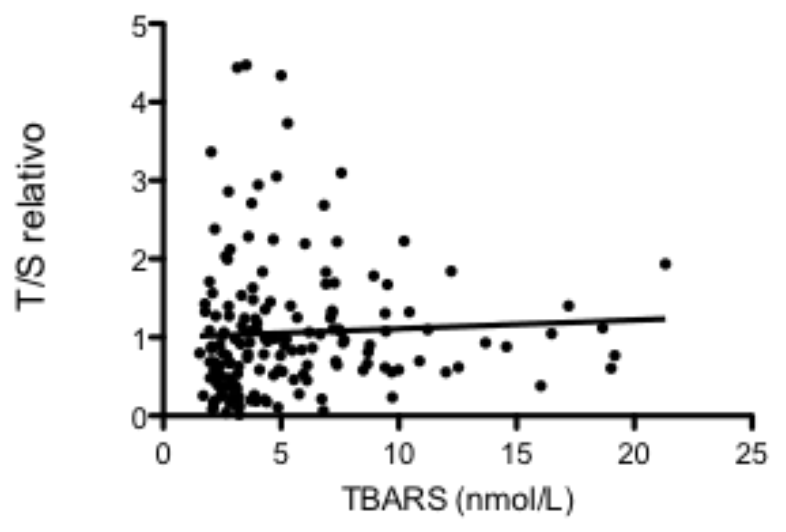

B

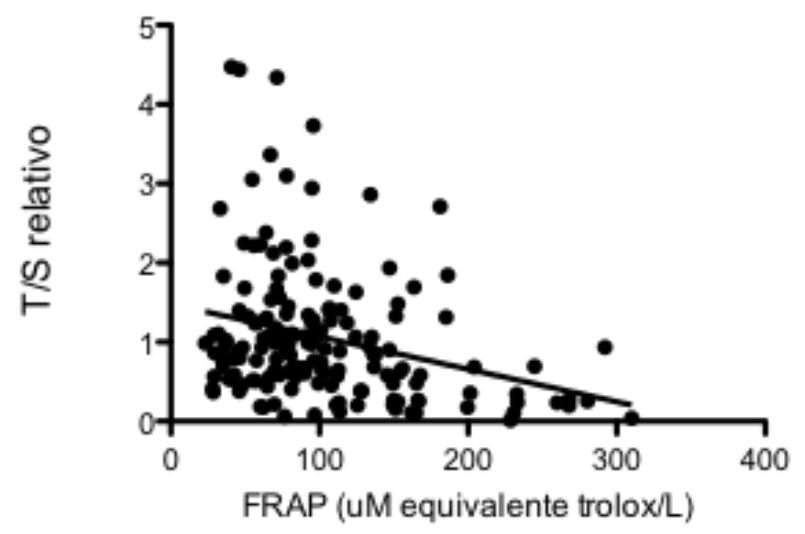

Figura 24 Correlação entre o comprimento relativo dos telômeros e $(A)$ a concentração sérica de TBARS $\left(r^{2}\right.$ Spearman $\left.+0,19, p=0,02\right)$ e $(B)$ a capacidade antioxidante total no soro $\left(r^{2}\right.$ Spearman $-0,28, p<0,0002)$, nos diabéticos tipo 2 .

\subsubsection{Comprimento relativo dos telômeros em indivíduos com tolerância normal à glicose e variáveis clínicas}

Entre os sujeitos do grupo controle, foi avaliada a correlação entre o comprimento relativo dos telômeros e a idade, IMC, PAS e PAD. Foi observada correlação negativa entre o comprimento relativo dos telômeros e a idade (Figura 25), em contraste com os diabéticos tipo 2 , em que não foi verificada correlação entre a idade e o comprimento dos telômeros.

A correlação entre o comprimento relativo dos telômeros e a concentração sérica de TBARS ou capacidade antioxidante total no soro não foi analisada porque os sujeitos que compuseram as duas investigações não foram os mesmos. 


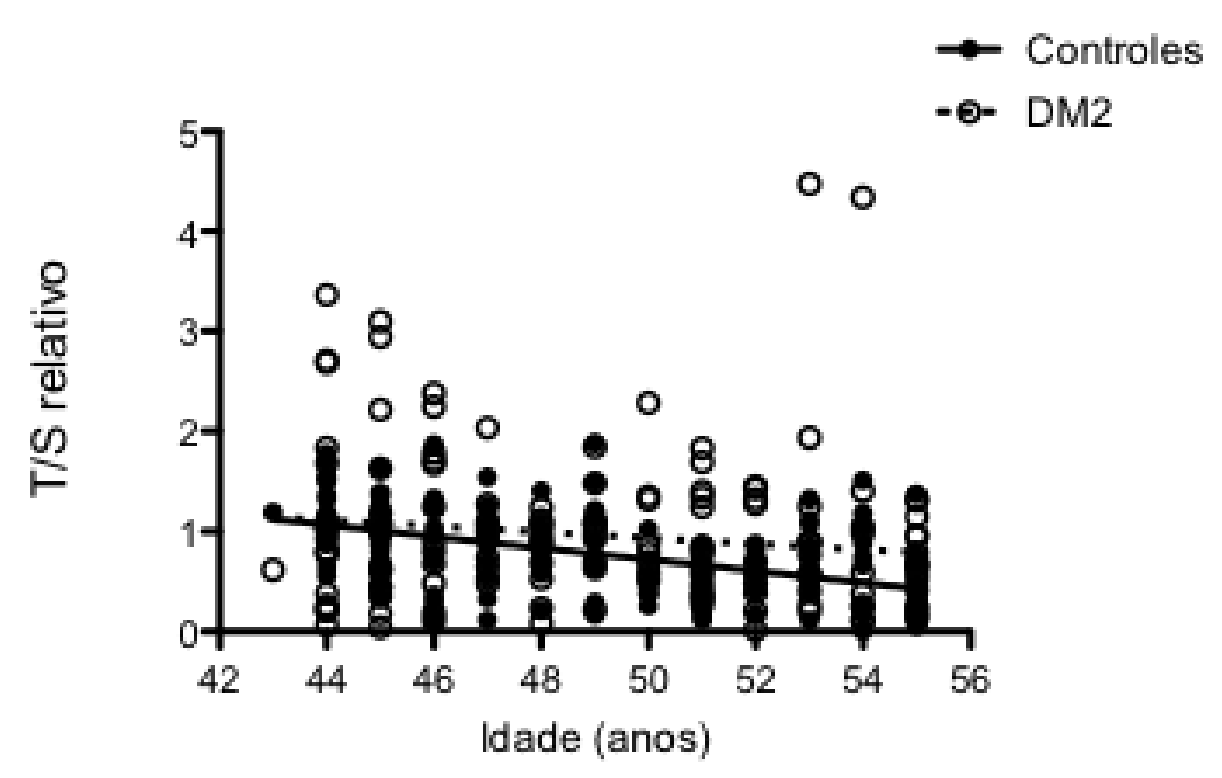

Figura 25 Correlação entre o comprimento relativo dos telômeros e a idade nos diabéticos tipo $2\left(r^{2}\right.$ Spearman -0,05, $p=0,53$ ) e nos sujeitos do grupo controle $\left(r^{2}\right.$ Spearman $-0,51$ e $\left.p<0,0001\right)$. 


\subsection{DISCUSSÃO}

Os estudos prévios que investigaram a associação entre o comprimento dos telômeros dos leucócitos do sangue periférico e o DM2, em sua maioria, sugerem que a doença esteja associada a menor comprimento dos telômeros e atribuem este achado, entre outros fatores, à idade e ao EO. Este, por sua vez, é atribuído a várias anormalidades, incluindo hiperglicemia, resistência à insulina, hiperinsulinemia e dislipidemia $(45,126,288)$. Cada um destes fatores contribui para aumento da produção de superóxido mitocondrial em células endoteliais e no miocárdio, além de inflamação tecidual. Somados a outros fatores, como polimorfismos em proteínas de desacoplamento mitocondriais (UCP) e polimorfismos de genes cujos produtos estão envolvidos na regulação do comprimento dos telômeros, estes aspectos poderiam contribuir para as alterações do comprimento dos telômeros relacionada ao DM2 (289).

A faixa etária dos diabéticos tipo 2 estudados foi de 43 a 55, semelhante à de estudos prévios (290). Houve, ainda, predomínio do sexo feminino $(75,8 \%)$ e baixo grau de escolaridade. No caso do DM2, cujo tratamento que envolve mudanças no estilo de vida e educação a respeito da doença, a escolaridade é aspecto importante para o tratamento e também para o acesso às informações e atenção com a saúde (291).

A maioria dos pacientes apresentou diagnóstico recente do DM2, entre 1 e 5 anos. A frequência de complicações do diabetes e também de comorbidades aumenta ao longo dos anos, em especial das complicações vasculares crônicas $(77,292)$. Embora neste estudo o tempo de diagnóstico tenha sido pequeno, foi possível observar a presença de algumas comorbidades mas e também de EO. Estudos indicam que grandes variações da glicemia estão associadas ao desenvolvimento de EO que, por sua vez, desempenha papel fundamental na progressão e desenvolvimento do DM e de e suas complicações (293) como foi descrito por Morsi e colaboradores (2016) (294) e Tiwari (2013) (295). As complicações agudas incluem a hipoglicemia, o estado hiperglicêmico hiperosmolar e a cetoacidose diabética. As crônicas são a retinopatia, nefropatia, neuropatia, cardiopatia isquêmica, doença cerebrovascular e vascular periférica $(56,296,297)$ 
Existem várias características que podem influenciar o comprimento dos telômeros, incluindo idade, estado nutricional, nível de escolaridade, estresse oxidativo, depressão, fatores relacionados ao estilo de vida e fatores genéticos, e no nosso estudo o pareamento foi realizado somente com relação à idade. Entretanto, não foi observada diferença do CT em relação ao sexo, estado nutricional ou nível de escolaridade nos dois grupos, sugerindo que estes aspectos, diferentes entre diabéticos e controles, não tenham contribuído para a diferença encontrada.

O tratamento do DM2 pode ser realizado com diferentes classes de medicamentos. No presente estudo, observou-se que 0 medicamento mais freqüentemente utilizado foi a biguanida metformina, seguida dos secretagogos sulfonilureias e da insulina. De acordo com a Sociedade Brasileira de Diabetes, a metformina é o medicamento de escolha na fase inicial do DM2, considerando os mecanismos fisiopatológicos da doença, em especial a resistência à insulina, e características frequentes do paciente, como obesidade e hiperglicemia menos acentuada, quando comparada à outra forma mais prevalente da doença, o DM1 (SBD. 2015). É possível que o tipo de tratamento do DM2 possa influenciar o CT é tratamento do diabetes. A maioria dos diabéticos incluídos no nosso estudo utilizava a metformina, e um estudo prévio mostrou que o tratamento de diabéticos tipo 2 recém diagnosticados com metformina durante dois meses também resultou em aumento do CT (298). Du e cols (2013) (22) constataram que houve aumento do CT em resposta ao tratamento, durante 2 meses, com outro anti-hiperglicemiante, a sitagliptina, em pré-diabéticos.

Entre as comorbidades, a hipertensão arterial sistêmica foi a mais frequente, seguida da dislipidemia. A maioria dos pacientes referiu ser sedentária, em concordância com os resultados de outros estudos envolvendo pacientes com DM2 (255, 299, 300). De acordo com a Sociedade Brasileira de Diabetes, e também com dados de outros estudos, a grande parte dos portadores de DM2 apresenta obesidade, hipertensão arterial e dislipidemia, e é sedentária $(59,126,301)$. Embora a frequência de hipertensão arterial nos pacientes estudados tenha sido elevada, a mediana da PAS e da PAD foi normal, sugerindo bom controle da doença. A maioria dos pacientes apresentou estado nutricional compatível com sobrepeso e obesidade graul, em concordância com o que é descrito na literatura $(59,301,302)$. 
Com relação aos dados de depressão pessoal e familiar apenas $8,38 \%$ dos pacientes com DM2 foram diagnosticados e seguem tratamento com uso de Fluoxetina. De acordo com Barbé-Tuana FM e cols (2016) telomeros mais curtos foram associados com a presença de desordem bipolar embora estudos adicionais usando desenhos longitudinais a possibilidade de incluir parentes que não apresentam a doença permitirá xxplorar outros traços hereditários. Em um estudo recente Wium-Andersen e cols(2016) (303) mostramram que telômeros mais curtos estão associados com a depressão transversalmente e não de forma prospectiva assim como em pacientes com esquizofrenia, indicam que um perfil de envelhecimento acelerado patológico poderia estar presente embora estudos adicionais sejamo necessários para confirmar o tamanho do telomero como endofenótipo potencial, especialmente em população de risco (304)

No presente estudo, as medianas da glicemia de jejum e pós-prandial foram discretamente superiores às metas de controle glicêmico para o paciente diabético $(<$ $100 \mathrm{mg} / \mathrm{dL}$ para a glicemia de jejum e $<140 \mathrm{mg} / \mathrm{dL}$ para glicemia pós-prandial) e a mediana da hemoglobina glicada foi indicativa de controle glicêmico adequado $(5,57$, $59,305)$. O resultado das variáveis relacionadas ao perfil lipídico, no entanto, indicou aumento da concentração sérica de LDL e triglicerídeo, acima das metas de controle de colesterol LDL $(<100 \mathrm{mg} / \mathrm{dL})$ e triglicerídeo (meta $<150 \mathrm{mg} / \mathrm{dL})(306,307)$. Estes dois aspectos, além da diminuição da lipoproteína de alta densidade (HDL), hipertensão arterial sistêmica e excesso de peso, contribuem para o EO, disfunção endotelial e aumento do risco cardiovascular. Estas alterações bioquímicas são apontadas como fatores prévios no desenvolvimento de complicações tanto micro quanto macrovasculares do DM $(59,92,126,308,309)$.

Considera-se que a normalização da atividade dos marcadores de EO, como enzimas, substâncias reativas do ácido tiobarbitúrico (TBARS) e radicais livres representa forma eficaz de reduzir os efeitos nocivos das ERO $(121,254,310)$. Os subprodutos da peroxidação de lípideos, tais como dienos conjugados e de malondialdeído (MDA), são aumentadas em pacientes com obesidade, síndrome metabólica e DM2. Carboidratos, lipídeos, proteínas e DNA são os alvos de biomoléculas de modificação de estresse oxidativo em geral como o principal de dano 
celular induzida ROS (311). Há evidência clínica e experimental do aumento do EO em ambos os tipos de diabetes, DM1 e DM2, inclusive em suas fases precoces $(168,169)$. Conforme estudos de D'Souza (2016) (312), Palem (2015) (140) e Tiwari $(295,313)$.

A concentração sérica de TBARS, no presente estudo, foi significativamente maior nos pacientes com DM2, em relação ao grupo controle, o que corrobora com outras investigações $(172,314,315)$. O aumento da concentração sérica de TBARS se manteve entre homens e mulheres, quando comparados aos sujeitos do mesmo sexo, no grupo controle, também em concordância com estudos prévios (166, 294, 316). A capacidade antioxidante total, avaliada pelo FRAP, foi significativamente menor nos pacientes diabéticos tipo 2, em comparação com os controles. Em concordância, foi observada redução da relação FRAP/TBARS nos diabéticos, em relação aos controles.

A diferença da capacidade antioxidante total no soro, entre diabéticos e controles, se manteve quando foram considerados separadamente os sexos feminino e masculino. Em investigação realizada em população do norte da Índia, os resultados foram semelhantes aos do presente estudo (173), assim como descrito por Rizvi (2007) e Pandley (2010) (166, 317), sem diferença de sexo(166).

O EO, nos pacientes com DM2, é atribuído a diversas alterações, incluindo aumento da concentração plasmática de glicose e ácidos graxos e resposta inflamatória sistêmica $(311,318)$. O EO resulta em danos celulares que estão associados ao caráter progressivo do DM2 e redução das funções celulares $(319,320)$.

A análise da concentração sérica de TBARS de acordo com o IMC, no presente estudo, indicou que não houve variação do TBARS com relação ao IMC. Além disso, em cada categoria de estado nutricional, a diferença entre os diabéticos e os controles tenha se mantido. Entretanto, de acordo com a literatura, o EO e IMC estão correlacionados, uma vez que indivíduos com sobrepeso e obesidade apresentaram elevação da concentração sérica de marcadores inflamatórios e de EO, além de indicadores de defesa antioxidante mais baixo quando comparados a indivíduos eutróficos $(321,322)$. Também não foi observada alteração da concentração sérica de TBARS segundo o estado nutricional nos sujeitos do grupo controle.

Entre os diabéticos tipo 2, houve correlação positiva entre a capacidade antioxidante total e o tempo de diagnóstico de DM2, a idade, o valor da hemoglobina 
glicada e concentração sérica de triglicerídeo. A relação entre capacidade antioxidante total, EO e idade ainda não é bem definida (109, 323, 324). Nossos resultados indicam que o a presença de DM2, idade avançada e aumento da concentração sérica de triglicerídeos poderia sugerir diminuição da capacidade antioxidante total e aumento da lipoperoxidação.

Entre os sujeitos do grupo controle, não foi observada correlação da concentração sérica de TBARS em nenhuma das variáveis testadas. Estudos recentes indicam que os valores do FRAP foram associados com elevação da concentração de glicose em jejum, sugerindo associação de nível mais elevado de defesa antioxidante com hiperglicemia, como compensação e posterior produção de da produção de ROS (325).

Supervisionar as defesas antioxidantes pode ser importante na prática clínica. Uma vez que o aumento da defesa antioxidante pode aliviar o EO, a suplementação com antioxidantes tem sido considerada terapia atrativa. Esta abordagem foi avaliada em numerosos ensaios clínicos que avaliaram o efeito da suplementação com antioxidantes sobre o risco de diabetes, controle glicêmico e o desenvolvimento de complicações crônicas. No entanto, os resultados destes estudos são contraditórios e não permitem tirar conclusões consistentes (325-327).

Estudos recentes sugerem a associação entre DM2, EO e comprimento dos telômeros. Para realizar a medida do tamanho médio dos telômeros, várias técnicas foram desenvolvidas. O "padrão ouro" para a obtenção dessa medida ainda continua sendo o TRF. De acordo com Cawthon (2002), a técnica de PCR quantitativa relativa é adequada para estudos epidemiológicos, sendo reprodutível e com alta credibilidade (260, 264, 328). De fato, é uma das mais frequentemente utilizadas (12, 30, 45, 245 , 255). A PCR quantitativa relativa para a medida do comprimento dos telômeros foi escolhida por ser amplamente utilizada em diversos estudos principalmente na pesquisa clínica e por detectar especificamente a região telomérica (a sequência de nucleotideos- TTAGGG) $(263,328)$.

Atualmente o PCR digital ( $\mathrm{APCR}$ ) vem sendo bastante utilizado para testar as sequencias dos iniciadores sendo possivel prever erros e dimeros. Esta tecnica utiliza estatísticas de Poisson para quantificar o DNA e permite: a detecção de alelos raros, a 
verificação dos níveis relativos de expressão, a identificação de CNVs(variação do número de cópias)e a análise quantitativa de produtos de $\operatorname{PCR}(329,330)$,

Alguns estudos não encontraram associação entre o comprimento dos telômeros e o DM2 (22, 244, 331-333). No presente estudo o comprimento relativo dos telômeros (T/S relativo) foi significativamente superior no grupo de diabéticos tipo 2 em relação ao grupo controle em primeira análise. Em análise posterior, em que foram excluídos os pacientes com valores discrepantes (outliers) de T/S relativo, não foi observada diferença entre o grupo de diabéticos tipo 2 e o controle. Em estudo populacional realizado na China, não foi encontrada nenhuma relação entre tamanho do telômero e o DM2 ou sua duração duração do DM2 (240). Em estudo tipo caso-controle aninhado, realizado a partir de dados do estudo multiétnico observacional de Coorte Iniciativa em Saúde da Mulher (Women's Health Initiative Observational Study Cohort, WHI-OS), conduzido nos Estados Unidos da América $(46,334)$, e em estudo envolvendo a população finlandesa analisada no Estudo de Prevenção em Diabetes (Diabetes Prevention Study) (47), também não foi encontrada associação entre o comprimento relativo dos telômeros e o DM2.

Entretanto, diversos estudos têm relatado associação positiva entre o comprimento dos telômeros e o DM2, conforme descrito por Shen e Cols (2012) (240) e Ma (2013) (24). Telômeros mais curtos têm sido demonstrados em pacientes com DM2 e este achado tem sido correlacionado com o a duração da doença (335-337).

No presente estudo, foi realizada análise entre o comprimento relativo dos telômeros e IMC, grau de escolaridade e sexo para ambos os grupos. Não houve diferença significativa do T/S relativo, não tendo sido observadas diferenças. Entretanto, Ma e cols (2013)(24) mostraram associação significativa entre a presença de DM2 e razão T/S ajustada para idade, sexo, IMC, e tabagismo.

No presente estudo, foi avaliada a correlação entre o comprimento relativo dos telômeros e variáveis clínicas, bioquímicas e antropometricas relacionadas ao controle metabólico e a EO, incluindo idade, tempo de diagnóstico do DM2, PAS, PAD, IMC, CA, glicemia de jejum, glicemia pós-prandial, hemoglobina glicada, colesterol total, colesterol LDL, colesterol HDL, triglicerídeo, PCR ultra-sensível, ureia, creatinina, enzimas hepáticas, concentração sérica de TBARS e capacidade antioxidante total. Foi 
observada correlação positiva entre o comprimento relativo dos telômeros e a concentração sérica de TBARS e antioxidante total. Para as demais variáveis citadas anteriormente, não houve diferença significativa para o T/S relativo. Estudos prévios (145) também encontraram correlação positiva entre o comprimento relativo dos telômeros e a concentração sérica de TBARS. Em um estudo similiar, Monickaraj e colaboradores (52) observaram que o comprimento dos telômeros foi positivamente correlacionado com adiponectina, HDL e DNAmt. $\mathrm{Na}$ análise de regressão, os autores observaram que telômeros mais curtos mostraram associação significativa com a presença de DM2, após o ajuste para a circunferência abdominal, resistência à insulina, triglicerídeos, HDL, adiponectina, DNAmt e TBARS.

O comprimento dos telômeros foi associado, em estudos preliminares, ao prognóstico de pacientes com DM2. Em uma investigação recente envolvendo 568 pacientes com DM2, foi observado que o tempo de duração da doença e o comprimento dos telômeros de leucócitos do sangue periférico, correlacionou-se com o risco de mortalidade. A Idade, sexo, creatinina, duração do diabetes e o tamanho dos telômeros foram significativamente diferentes entre os pacientes com DM2 que estavam no seguimento. $\mathrm{Na}$ análise de regressão de Cox ajustada para as variáveis o tamanho do telômero foi mais curto com os pacientes de idade mais avançada e maior duração da doença aumentaram significativamente o risco de mortalidade (45).

Em outros estudos, no entanto, a associação entre comprimento dos telômeros e presença de DM2 ou seu prognóstico não foi observada. No presente estudo, não foi observada associação entre o comprimento dos telômeros e leucócitos do sangue periférico e a retinopatia diabética, uma das principais complicações crônicas da doença. Embora tenham sido observadas algumas cormobidades (HAS, Dislipidemia e Hipotireoidismo)e por apresentarem tempo de doença relativamente curto, glicemia e hemoglobina glicada sob controle, não foi possível observar características fenotípicas de cronicidade, não apresentando os telômeros menores como previsto em alguns estudos.

Além disso, é possível que a ocorrência de resultados contraditórios com a literatura deva-se a diferentes métodos empregados para a determinação do comprimento dos telômeros tais como: número de indivíduos participantes, tempo de 
diagnóstico, pareamento e ajuste por idade e sexo, grupo populacional, características clinicas e bioquímicas dos grupos observados, tratamento da doença, estilo de vida, estado nutricional e metodologia para a medida dos telômeros.

Nos estudos prospectivos realizados por You e cols (2012)(238) e Hovatta e cols (244)(2012), prospectivos, não foi observada associação do CT e risco de desenvolvimento de DM2. Hovatta e cols(2012)(244), por exemplo, verificaram aumento do CT em diabéticos e não diabéticos, após seguimento médio de 4,5 anos, independentemente da intervenção a que o sujeito foi submetido, não houve associação CT e risco de desenvolvimento de DM2. Nossos resultados, assim como os dos estudos que não observaram a associação, podem refletir a complexidade da dinâmica dos telômeros e os vários fatores capazes de influenciá-lo (338). Por esses aspectos, pode ser difícil estabelecer com segurança o CT com uma medida em um único ponto no tempo.

Este estudo apresentou algumas limitações que poderiam influenciar o comprimento dos telômeros e desta forma ter influenciado nossos resultados foram: tempo de coleta, diferença entre o número dos participantes com relação ao sexo,. e características clínicas não disponíveis dos sujeitos considerados controles. Embora a doação de sangue requeira bom estado de saúde, é possível que estes indivíduos apresentassem alterações metabólicas leves, não consideradas proibitivas para a doação e não identificadas na avaliação do doador e a padronização da técnica.

O comprimento dos telómeros está relacionado com o tempo de vida e tem sido proposto como biomarcador de envelhecimento e a importância potencial da biologia dos telômeros em DM2 (339, 340). Entretanto, a complexa dinâmica do comprimento dos telômeros e a varidade de fatores que podem influênciá-la, limita a interpretação de estudos em que estas variáveis não são consideradas na análise dos resultados. 


\subsection{CONCLUSÕES}

Com base nos resultados do presente estudo, foi possível concluir que:

- Os diabéticos tipo 2 estudados, em comparação com os controles com tolerância normal à glicose, apresentaram aumento da concentração sérica de TBARS e redução da capacidade antioxidante total no soro, independentemente do sexo e do estado nutricional segundo o IMC.

- Nos diabéticos tipo 2, foi observada correlação positiva entre a concentração sérica de TBARS e a concentração sérica de colesterol LDL.

- Nos diabéticos tipo 2, foi observada correlação positiva entre a capacidade antioxidante total e o tempo de diagnóstico do DM2, hemoglobina glicada e concentração sérica de triglicerídeos.

- Nos controles com tolerância normal à glicose, foi observada correlação positiva entre a capacidade antioxidante total e a idade.

- A mediana do comprimento relativo dos telômeros (T/S relativo) foi superior nos diabéticos tipo 2, em relação ao controle, porém não foi observada diferença quando excluídos os valores discrepantes (outliers) no grupo de diabéticos. Em ambos os grupos, não houve variação do comprimento relativo dos telômeros de acordo com o peso, estado nutricional segundo o IMC ou nível de escolaridade.

- Nos diabéticos tipo 2, não foi observada associação entre o comprimento relativo dos telômeros e a presença de retinopatia diabética.

- Nos diabéticos tipo 2, foi observada correlação negativa entre o comprimento relativo dos telômeros e o tempo de diagnóstico do DM2, glicemia de jejum, hemoglobina glicada e capacidade antioxidante total no soro, e correlação negativa com a concentração sérica de TBARS.

- Nos controles com tolerância normal à glicose, foi observada correlação negativa entre o comprimento relativo dos telômeros e a idade. 


\section{REFERÊNCIAS}

1. Ismail A, Suddin LS, Sulong S, Ahmed Z, Kamaruddin NA, Sukor N. Profiles and Factors Associated with Poor Glycemic Control Among Inpatients with Diabetes Mellitus Type 2 as a Primary Diagnosis in a Teaching Hospital. Indian journal of community medicine : official publication of Indian Association of Preventive \& Social Medicine. 2016;41(3):208-12.

2. King H, Aubert RE, Herman WH. Global burden of diabetes, 1995-2025: prevalence, numerical estimates, and projections. Diabetes care. 1998;21(9):1414-31.

3. Guariguata L, Whiting DR, Hambleton I, Beagley J, Linnenkamp U, Shaw JE. Global estimates of diabetes prevalence for 2013 and projections for 2035. Diabetes Res Clin Pract. 2014;103(2):137-49.

4. Whiting DR, Guariguata L, Weil C, Shaw J. IDF diabetes atlas: global estimates of the prevalence of diabetes for 2011 and 2030. Diabetes Res Clin Pract. 2011;94(3):311-21.

5. IDF;. International Diabetes Federation, 2015. <http://www.idf.org/diabetesatlas >. 2015 [cited 2016 09/29.].6. Herder C, Roden M. Genetics of type 2 diabetes: pathophysiologic and clinical relevance. Eur J Clin Invest. 2011;41(6):679-92.

7. Temelkova-Kurktschiev T, Stefanov T. Lifestyle and genetics in obesity and type 2 diabetes. Exp Clin Endocrinol Diabetes. 2011;120(1):1-6.

8. Porte D, Jr., Kahn SE. beta-cell dysfunction and failure in type 2 diabetes: potential mechanisms. Diabetes. 2001;50 Suppl 1:S160-3.

9. Rhodes CJ. Type 2 diabetes-a matter of beta-cell life and death? Science. 2005;307(5708):380-4.

10. Takiishi T, Van Belle T, Gysemans C, Mathieu C. Effects of vitamin D on antigenspecific and non-antigen-specific immune modulation: relevance for type 1 diabetes. Pediatr Diabetes. 2012;14(2):81-9.

11. Mathieu C, van Etten E, Gysemans C, Decallonne B, Bouillon R. Seasonality of birth in patients with type 1 diabetes. Lancet. 2002;359(9313):1248. 
12. Masi S, D'Aiuto F, Cooper J, Salpea K, Stephens JW, Hurel SJ, et al. Telomere length, antioxidant status and incidence of ischaemic heart disease in type 2 diabetes. Int J Cardiol. 2016;216:159-64.

13. Nilsson PM, Lurbe E, Laurent $\mathrm{S}$. The early life origins of vascular ageing and cardiovascular risk: the EVA syndrome. Journal of hypertension. 2008;26(6):1049-57.

14. Giacco F, Brownlee M. Oxidative stress and diabetic complications. Circ Res. 2010;107(9):1058-70.

15. Liochev SI. Reactive oxygen species and the free radical theory of aging. Free Radic Biol Med. 2013;60:1-4.

16. Blasco M. Telomeres and human disease: ageing, cancer and beyond. Nat Rev Genet 2005;Aug;6(8)::611-22.

17. Harley $\mathrm{CB}$, Futcher $\mathrm{AB}$, Greider $\mathrm{CW}$. Telomeres shorten during ageing of human fibroblasts. Nature. 1990;345(6274):458-60.

18. de Lange T. Shelterin: the protein complex that shapes and safeguards human telomeres. Genes Dev. 2005;19(18):2100-10.

19. Demissie S, Levy D, Benjamin EJ, Cupples LA, Gardner JP, Herbert A, et al. Insulin resistance, oxidative stress, hypertension, and leukocyte telomere length in men from the Framingham Heart Study. Aging Cell. 2006;5(4):325-30.

20. Calado RT. Telomeres and marrow failure. Hematology Am Soc Hematol Educ Program. 2009:338-43.

21. Aalbers AM, Calado RT, Young NS, Zwaan CM, Wu C, Kajigaya S, et al. Telomere length and telomerase complex mutations in pediatric acute myeloid leukemia. Leukemia.

22. Du M, Prescott J, Cornelis MC, Hankinson SE, Giovannucci E, Kraft P, et al. Genetic predisposition to higher body mass index or type 2 diabetes and leukocyte telomere length in the Nurses' Health Study. PLoS One. 2013;8(2):e52240.

23. de Vos-Houben JM, Ottenheim NR, Kafatos A, Buijsse B, Hageman GJ, Kromhout $\mathrm{D}$, et al. Telomere length, oxidative stress, and antioxidant status in elderly men in Zutphen and Crete. Mech Ageing Dev. 2012;133(6):373-7. 
24. Ma D, Zhu W, Hu S, Yu X, Yang Y. Association between oxidative stress and telomere length in Type 1 and Type 2 diabetic patients. J Endocrinol Invest. 2013;36(11):1032-7.

25. Ping F, Li ZY, Lv K, Zhou MC, Dong YX, Sun $Q$, et al. DNA telomere length shortening can predict the incidence of non-alcoholic fatty liver disease in patients with type 2 diabetes mellitus. J Diabetes Investig. 2016.

26. Folli F, Corradi D, Fanti P, Davalli A, Paez A, Giaccari A, et al. The role of oxidative stress in the pathogenesis of type 2 diabetes mellitus micro- and macrovascular complications: avenues for a mechanistic-based therapeutic approach. Curr Diabetes Rev. 2011;7(5):313-24.

27. Correia-Melo C, Hewitt G, Passos JF. Telomeres, oxidative stress and inflammatory factors: partners in cellular senescence? Longevity \& healthspan. 2014;3(1):1.

28. Bakaysa SL, Mucci LA, Slagboom PE, Boomsma DI, McClearn GE, Johansson B, et al. Telomere length predicts survival independent of genetic influences. Aging Cell. 2007;6(6):769-74.

29. Kimura M, Hjelmborg JV, Gardner JP, Bathum L, Brimacombe M, Lu X, et al. Telomere length and mortality: a study of leukocytes in elderly Danish twins. Am J Epidemiol. 2008;167(7):799-806.

30. Salpea KD, Talmud PJ, Cooper JA, Maubaret CG, Stephens JW, Abelak K, et al. Association of telomere length with type 2 diabetes, oxidative stress and UCP2 gene variation. Atherosclerosis. 2009;209(1):42-50.

31. von Zglinicki T. Oxidative stress shortens telomeres. Trends in biochemical sciences. 2002;27(7):339-44.

32. Lu T, Finkel T. Free radicals and senescence. Exp Cell Res. 2008;314(9):191822.

33. Rai P, Onder TT, Young JJ, McFaline JL, Pang B, Dedon PC, et al. Continuous elimination of oxidized nucleotides is necessary to prevent rapid onset of cellular senescence. Proc Natl Acad Sci U S A. 2009;106(1):169-74. 
34. Stojkovic G, Makarova AV, Wanrooij PH, Forslund J, Burgers PM, Wanrooij S. Oxidative DNA damage stalls the human mitochondrial replisome. Sci Rep. 2016;6:28942.

35. Udomsinprasert W, Kitkumthorn N, Mutirangura A, Chongsrisawat V, Poovorawan Y, Honsawek S. Global methylation, oxidative stress, and relative telomere length in biliary atresia patients. Sci Rep. 2016;6:26969.

36. Kahl VF, Simon D, Salvador M, Branco Cdos S, Dias JF, da Silva FR, et al. Telomere measurement in individuals occupationally exposed to pesticide mixtures in tobacco fields. Environ Mol Mutagen. 2016;57(1):74-84.

37. Harte AL, da Silva NF, Miller MA, Cappuccio FP, Kelly A, O'Hare JP, et al. Telomere length attrition, a marker of biological senescence, is inversely correlated with triglycerides and cholesterol in South Asian males with type 2 diabetes mellitus. Exp Diabetes Res. 2012:895185.

38. Monickaraj F, Aravind S, Nandhini P, Prabu P, Sathishkumar C, Mohan V, et al. Accelerated fat cell aging links oxidative stress and insulin resistance in adipocytes. $\mathrm{J}$ Biosci.38(1):113-22.

39. Murillo-Ortiz B, Albarran-Tamayo F, Arenas-Aranda D, Benitez-Bribiesca L, Malacara-Hernandez JM, Martinez-Garza S, et al. Telomere length and type 2 diabetes in males, a premature aging syndrome. Aging Male.15(1):54-8.

40. Testa R, Olivieri F, Sirolla C, Spazzafumo L, Rippo MR, Marra M, et al. Leukocyte telomere length is associated with complications of type 2 diabetes mellitus. Diabet Med. 2011;28(11):1388-94.

41. Chen C, Chi HY, Yu ZH, Chen JL. [Effects of Chinese herbal medicine Shoushen Granule on telomere length and telomerase activity of peripheral white blood cells and vascular cells in rats with atherosclerosis]. Zhong Xi Yi Jie He Xue Bao.10(6):667-73.

42. Xiao F, Zheng X, Cui M, Shi G, Chen X, Li R, et al. Telomere dysfunction-related serological markers are associated with type 2 diabetes. Diabetes Care. 2011;34(10):2273-8.

43. Zhao J, Zhu Y, Lin J, Matsuguchi T, Blackburn E, Zhang Y, et al. Short leukocyte telomere length predicts risk of diabetes in american indians: the strong heart family study. Diabetes. 2013;63(1):354-62. 
44. Zhao J, Miao K, Wang H, Ding H, Wang DW. Association between telomere length and type 2 diabetes mellitus: a meta-analysis. PLoS One. 2013;8(11):e79993.

45. Bonfigli AR, Spazzafumo L, Prattichizzo F, Bonafe M, Mensa E, Micolucci L, et al. Leukocyte telomere length and mortality risk in patients with type 2 diabetes. Oncotarget. 2016.

46. Al-Attas OS, Al-Daghri NM, Alokail MS, Alkharfy KM, Alfadda AA, McTernan P, et al. Circulating leukocyte telomere length is highly heritable among families of Arab descent. BMC medical genetics.13:38.

47. Ahola K, Siren I, Kivimaki M, Ripatti S, Aromaa A, Lonnqvist J, et al. Work-related exhaustion and telomere length: a population-based study. PLoS One. 2012;7(7):e40186.

48. Cawthon RM. Telomere length measurement by a novel monochrome multiplex quantitative PCR method. Nucleic Acids Res. 2009;37(3):e21.

49. Petersen S, Saretzki G, von Zglinicki T. Preferential accumulation of singlestranded regions in telomeres of human fibroblasts. Exp Cell Res. 1998;239(1):152-60.

50. Nishikawa T, Edelstein D, Du XL, Yamagishi S, Matsumura T, Kaneda Y, et al. Normalizing mitochondrial superoxide production blocks three pathways of hyperglycaemic damage. Nature. 2000;404(6779):787-90.

51. Brownlee M. Biochemistry and molecular cell biology of diabetic complications. Nature. 2001;414(6865):813-20.

52. Monickaraj F, Aravind S, Gokulakrishnan K, Sathishkumar C, Prabu P, Prabu D, et al. Accelerated aging as evidenced by increased telomere shortening and mitochondrial DNA depletion in patients with type 2 diabetes. Mol Cell Biochem. 2012;365(1-2):343-50.

53. Salpea KD, Maubaret CG, Kathagen A, Ken-Dror G, Gilroy DW, Humphries SE. The effect of pro-inflammatory conditioning and/or high glucose on telomere shortening of aging fibroblasts. PLoS One. 2013;8(9):e73756.

54. Walsh SH, Grabowski P, Berglund M, Thunberg U, Thorselius M, Tobin G, et al. Telomere length and correlation with histopathogenesis in B-cell leukemias/lymphomas. Eur J Haematol. 2007;78(4):283-9. 
55. Diez Roux AV, Ranjit N, Jenny NS, Shea S, Cushman M, Fitzpatrick A, et al. Race/ethnicity and telomere length in the Multi-Ethnic Study of Atherosclerosis. Aging Cell. 2009;8(3):251-7.

56. American Diabetes A. 2. Classification and Diagnosis of Diabetes. Diabetes Care. 2016;39 Suppl 1:S13-22.

57. ADA. Diagnosis and Classification of Diabetes Mellitus. American Diabetes Association. Diabetes Care. 2013;36.

58. ADA. Diagnosis and classification of diabetes mellitus.American Diabetes Association. Diabetes Care. 2015; 38(Suppl):S8-S16.

59. SBD. SBdD. Diretrizes da Sociedade Brasileira de Diabetes Tratamento e acompanhamento do Diabetes mellitus. 2015.

60. Early interventions for diabetes and dysglycaemia. Surgery in the treatment of obesity and diabetes. Abstracts of the 5th International Congress on Prediabetes and the Metabolic Syndrome. Vienna, Austria. April 18-20, 2013. J Diabetes.5 Suppl 1:1215.

61. Chilelli NC, Burlina S, Lapolla A. AGEs, rather than hyperglycemia, are responsible for microvascular complications in diabetes: a "glycoxidation-centric" point of view. Nutrition, metabolism, and cardiovascular diseases : NMCD. 2013;23(10):913-9.

62. DeFronzo RA, Eldor R, Abdul-Ghani M. Pathophysiologic approach to therapy in patients with newly diagnosed type 2 diabetes. Diabetes Care. 2013;36 Suppl 2:S12738.

63. Gastaldelli A, Ferrannini E, Miyazaki Y, Matsuda M, DeFronzo RA. Beta-cell dysfunction and glucose intolerance: results from the San Antonio metabolism (SAM) study. Diabetologia. 2004;47(1):31-9.

64. Kucharska E. [Diabetes type 2--criteria concerning the recognition and prevention, as well as therapeutic targets in the light of research results and guidelines formulated by the American Diabetes Association in 2012]. Przegl Lek. 2013;70(6):4046.

65. Carrera Boada CA, Martínez-Moreno JM. Pathophysiology of diabetes mellitus type 2: beyond the duo "insulin resistance-secretion deficit". Nutr Hosp 2013;28 (Supl. 2):78-87). 
66. Ceriello A. Hyperglycaemia and the vessel wall: the pathophysiological aspects on the atherosclerotic burden in patients with diabetes. European journal of cardiovascular prevention and rehabilitation : official journal of the European Society of Cardiology, Working Groups on Epidemiology \& Prevention and Cardiac Rehabilitation and Exercise Physiology. 2010;17 Suppl 1:S15-9.

67. Padwal RS. Obesity, diabetes, and the metabolic syndrome: the global scourge. Can J Cardiol. 2014;30(5):467-72.

68. Murdolo G, Bartolini D, Tortoioli C, Piroddi M, luliano L, Galli F. Lipokines and oxysterols: Novel adipose-derived lipid hormones linking adipose dysfunction and insulin resistance. Free Radical Biology and Medicine. 2013;65:811-20.

69. Chen CT, Chen JY, Wang JH, Chang KC, Tseng PL, Kee KM, et al. Diabetes mellitus, metabolic syndrome and obesity are not significant risk factors for hepatocellular carcinoma in an HBV- and HCV-endemic area of Southern Taiwan. Kaohsiung J Med Sci. 2013;29(8):451-9.

70. Bullon P, Newman HN, Battino M. Obesity, diabetes mellitus, atherosclerosis and chronic periodontitis: a shared pathology via oxidative stress and mitochondrial dysfunction? Periodontol 2000. 2013;64(1):139-53.

71. Prevost G, Eas F, Kuhn JM. [Plasma testosterone, obesity, metabolic syndrome and diabetes]. Presse Med. 2013;43(2):186-95.

72. Campos J, Ramos A, Szego T, Zilberstein B, Feitosa H, Cohen R. The Role of Metabolic Surgery for Patients with Obesity Grade I Andclinically Uncontrolled Type 2 Diabetes. Arquivos brasileiros de cirurgia digestiva : $A B C D=$ Brazilian archives of digestive surgery. 2016;0:0.

73. Wild S, Roglic G, Green A, Sicree R, King H. Global prevalence of diabetes: estimates for the year 2000 and projections for 2030. Diabetes Care. 2004;27(5):104753.

74. Torres HC, Rozemberg B, Amaral MA, Bodstein RC. Perceptions of primary healthcare professionals towards their role in type 2 diabetes mellitus patient education in Brazil. BMC Public Health. 2010;10:583.

75. Hu FB. Globalization of diabetes: the role of diet, lifestyle, and genes. Diabetes Care. 2011;34(6):1249-57. 
76. Shaw JE, Sicree RA, Zimmet PZ. Global estimates of the prevalence of diabetes for 2010 and 2030. Diabetes Research and Clinical Practice.87(1):4-14.

77. Ginter E, Simko V. Global prevalence and future of diabetes mellitus. Adv Exp Med Biol. 2013;771:35-41.

78. Kelly T, Yang W, Chen CS, Reynolds K, He J. Global burden of obesity in 2005 and projections to 2030. Int J Obes (Lond). 2008;32(9):1431-7.

79. IDF;. Diabetes Atlas. . International Diabetes Federation. 2013.

80. IDF;. Epidemiology and Mobidity. In: International Diabetes Federation.: Available from http://www.idf.org/. 2011 [cited Accessed on 1 March 2011].

81. Care D. Standards of medical care in diabetes. Diabetes Care. 2014;37 Suppl 1:S14-80.

82. Seuring T, Archangelidi O, Suhrcke M. The Economic Costs of Type 2 Diabetes: A Global Systematic Review. PharmacoEconomics. 2015;33(8):811-31.

83. Iser; MBP, Stopa; SR, Cols. PSCe. Self-reported diabetes prevalence in Brazil: results from National Health Survey 2013. Epidemiol Serv Saúde. 2015: 305-14.

84. Adams OP. The impact of brief high-intensity exercise on blood glucose levels. Diabetes Metab Syndr Obes. 2013;6:113-22.

85. Stumvoll M, Goldstein BJ, van Haeften TW. Type 2 diabetes: principles of pathogenesis and therapy. Lancet. 2005;365(9467):1333-46.

86. Davis GE, Lowell WE. Variation in ultraviolet radiation and diabetes: evidence of an epigenetic effect that modulates diabetics' lifespan. Clin Epigenetics. 2013;5(1):5.

87. Ahlqvist E, Ahluwalia TS, Groop L. Genetics of type 2 diabetes. Clin Chem. 2010;57(2):241-54.

88. American Diabetes A. 7. Approaches to Glycemic Treatment. Diabetes Care. 2016;39 Suppl 1:S52-9.

89. Kim DJ, Lee MS, Kim KW, Lee MK. Insulin secretory dysfunction and insulin resistance in the pathogenesis of korean type 2 diabetes mellitus. Metabolism. 2001;50(5):590-3.

90. Jang $\mathrm{EH}$, Kwon HS. beta-Cell dysfunction and insulin resistance in gestational glucose intolerance. Korean J Intern Med. 2013;28(3):294-6. 
91. Brownlee M. The pathobiology of diabetic complications: a unifying mechanism. Diabetes. 2005;54(6):1615-25.

92. Fiorentino TV, Prioletta A, Zuo P, Folli F. Hyperglycemia-induced oxidative stress and its role in diabetes mellitus related cardiovascular diseases. Curr Pharm Des. 2013;19(32):5695-703.

93. Kovacic JC, Castellano JM, Farkouh ME, Fuster V. The relationships between cardiovascular disease and diabetes: focus on pathogenesis. Endocrinol Metab Clin North Am. 2014;43(1):41-57.

94. Rheinberger $M$, Boger CA. [Diabetic nephropathy: new insights into diagnosis, prevention and treatment]. Dtsch Med Wochenschr. 2014;139(14):704-6.

95. Marseglia L, Manti S, D'Angelo G, Nicotera A, Parisi E, Di Rosa G, et al. Oxidative stress in obesity: a critical component in human diseases. International journal of molecular sciences. 2015;16(1):378-400.

96. Report of the Expert Committee on the Diagnosis and Classification of Diabetes Mellitus. Diabetes Care. 1997;20(7):1183-97.

97. American Diabetes A. 6. Obesity Management for the Treatment of Type 2 Diabetes. Diabetes Care. 2016;39 Suppl 1:S47-51.

98. McCulloch DK, Robertson RP. Pathogenesis of type 2 diabetes mellitus. UpToDate [Internet]. 2011 2610812014.

99. Ellervik C, Birgens H, Mandrup-Poulsen T. Need for reclassification of diabetes secondary to iron overload in the ADA and WHO classifications. Diabetes Care. 2014;37(6):e137-8.

100. Vacante $M$, Malaguarnera M, Motta M. Revision of the ADA-classification of diabetes mellitus type 2 (DMT2): the importance of maturity onset diabetes (MOD), and senile diabetes (DS). Arch Gerontol Geriatr. 2010;53(1):113-9.

101. Adams J, Martin-Ruiz C, Pearce MS, White M, Parker L, von Zglinicki T. No association between socio-economic status and white blood cell telomere length. Aging Cell. 2007;6(1):125-8.

102. Report of the expert committee on the diagnosis and classification of diabetes mellitus. Diabetes Care. 2003;26 Suppl 1:S5-20. 
103. American Diabetes A. 5. Glycemic Targets. Diabetes Care. 2016;39 Suppl 1:S3946.

104. Halliwell B, Whiteman M. Measuring reactive species and oxidative damage in vivo and in cell culture: how should you do it and what do the results mean? $\mathrm{Br} \mathrm{J}$ Pharmacol. 2004;142(2):231-55.

105. Oglesby AK, Secnik K, Barron J, Al-Zakwani I, Lage MJ. The association between diabetes related medical costs and glycemic control: a retrospective analysis. Cost Eff Resour Alloc. 2006;4:1.

106. Batsis JA, Romero-Corral A, Collazo-Clavell ML, Sarr MG, Somers VK, Brekke L, et al. Effect of weight loss on predicted cardiovascular risk: change in cardiac risk after bariatric surgery. Obesity (Silver Spring). 2007;15(3):772-84.

107. Cao L, Choi EY, Liu X, Martin A, Wang C, Xu X, et al. White to brown fat phenotypic switch induced by genetic and environmental activation of a hypothalamicadipocyte axis. Cell Metab. 2011;14(3):324-38.

108. Achike FI, To NH, Wang H, Kwan CY. Obesity, metabolic syndrome, adipocytes and vascular function: A holistic viewpoint. Clin Exp Pharmacol Physiol.38(1):1-10.

109. Evans JL, Maddux BA, Goldfine ID. The molecular basis for oxidative stressinduced insulin resistance. Antioxidants \& redox signaling. 2005;7(7-8):1040-52.

110. Pramanik KC, Pandey A. Critical Role of Oxidant and Anti-oxidant in Cancer. Molecular Biology. 2013;2::e110.

111. Porte D, Jr. Clinical importance of insulin secretion and its interaction with insulin resistance in the treatment of type 2 diabetes mellitus and its complications. Diabetes Metab Res Rev. 2001;17(3):181-8.

112. Tabak O, Gelisgen R, Erman H, Erdenen F, Muderrisoglu C, Aral H, et al. Oxidative lipid, protein, and DNA damage as oxidative stress markers in vascular complications of diabetes mellitus. Clinical and investigative medicine Medecine clinique et experimentale. 2011;34(3):E163-71.

113. Lin $N$, Zhang $H$, Su $Q$. Advanced glycation end-products induce injury to pancreatic beta cells through oxidative stress. Diabetes \& metabolism. 2012;38(3):2507. 
114. Khan MS, Tabrez S, Rabbani N, Shah A. Oxidative Stress Mediated Cytotoxicity of Glycated Albumin: Comparative Analysis of Glycation by Glucose Metabolites. Journal of fluorescence. 2015;25(6):1721-6.

115. Wang X, Hai CX. ROS acts as a double-edged sword in the pathogenesis of type 2 diabetes mellitus: is Nrf2 a potential target for the treatment? Mini Rev Med Chem.11(12):1082-92.

116. Wang X, Li YL, Wu H, Liu JZ, Hu JX, Liao N, et al. Antidiabetic effect of oleanolic acid: a promising use of a traditional pharmacological agent. Phytotherapy research : PTR. 2011;25(7):1031-40.

117. Choi SW, Benzie IF, Ma SW, Strain JJ, Hannigan BM. Acute hyperglycemia and oxidative stress: direct cause and effect? Free Radic Biol Med. 2008;44(7):1217-31.

118. Huebschmann AG, Regensteiner JG, Vlassara H, Reusch JE. Diabetes and advanced glycoxidation end products. Diabetes Care. 2006;29(6):1420-32.

119. Nowotny K, Jung T, Hohn A, Weber D, Grune T. Advanced glycation end products and oxidative stress in type 2 diabetes mellitus. Biomolecules. 2015;5(1):194222.

120. Dragana N, Julijana S, Predrag B, Esma RI. Oxidative stress and the role of antioxidative treatment in diabetes mellitus. Oxid Antioxid Med Sci. 2014;3(1):9-14.

121. Nikolic D, Stanimirovic J, Bjelogrlic $P$, Isenovic ER. Oxidative stress and the role of antioxidative treatment in diabetes mellitus. Oxid Antioxid Med Sci. 2014;3(1):9-14.

122. Lacourciere $\mathrm{Y}$, Poirier $\mathrm{L}$. Valsartan is more effective than placebo in reducing the incidence of diabetes in people with impaired glucose tolerance and cardiovascular disease or risk factors but has no effect on cardiovascular outcomes. Evid Based Med. 2011;16(4):122-3.

123. Farmer JA. Diabetic dyslipidemia and atherosclerosis: evidence from clinical trials. Curr Diab Rep. 2008;8(1):71-7.

124. Ginsberg HN, Maccallum PR. The obesity, metabolic syndrome, and type 2 diabetes mellitus pandemic: II. Therapeutic management of atherogenic dyslipidemia. $\mathrm{J}$ Clin Hypertens (Greenwich). 2009;11(9):520-7.

125. Chahil TJ, Ginsberg HN. Diabetic dyslipidemia. Endocrinol Metab Clin North Am. 2006;35(3):491-510, vii-viii. 
126. Sakurai K, Yokote K. [Diabetes mellitus with dyslipidemia]. Nihon Rinsho. 2012;70 Suppl 5:131-6.

127. Bastos A, Graves DT, Loureiro AM, Junior CR, Abdalla PSiS, Faulin TSE, et al. Lipid Peroxidation Is Associated with the Severity of Periodontal Disease and Local Inflammatory Markers in Patients with Type 2 Diabetes. J Clin Endocrinol Metab. 2012;97(8):E1353-E62

128. Williams M, Hogg RE, Chakravarthy $U$. Antioxidants and diabetic retinopathy. Curr Diab Rep. 2013;13(4):481-7.

129. Zatalia SR, Sanusi H. The role of antioxidants in the pathophysiology, complications, and management of diabetes mellitus. Acta medica Indonesiana. 2013;45(2):141-7.

130. Tabatabaei-Malazy $O$, Fakhrzadeh H, Sharifi F, Mirarefin M, Arzaghi SM, Badamchizadeh Z, et al. Effect of metabolic control on oxidative stress, subclinical atherosclerosis and peripheral artery disease in diabetic patients. Journal of diabetes and metabolic disorders. 2015;14:84.

131. Yu H, Li Q, Herbert B, Zinna R, Martin K, Junior CR, et al. Anti-inflammatory effect of MAPK phosphatase-1 local gene transfer in inflammatory bone loss. Gene Ther. 2011;18(4):344-53.

132. Rizzo MR, Barbieri M, Marfella R, Paolisso G. Reduction of oxidative stress and inflammation by blunting daily acute glucose fluctuations in patients with type 2 diabetes: role of dipeptidyl peptidase-IV inhibition. Diabetes Care. 2012;35(10):2076-82.

133. Tsakanova GV, Ayvazyan VA, Boyajyan AS, Arakelova EA, Grigoryan GS, Guevorkyan AA, et al. A comparative study of antioxidant system and intensity of lipid peroxidation in type 2 diabetes mellitus and ischemic stroke aggravated and not aggravated by type 2 diabetes mellitus. Bull Exp Biol Med. 2012;151(5):564-6.

134. Annadurai T, Vasanthakumar A, Geraldine P, Thomas PA. Variations in erythrocyte antioxidant levels and lipid peroxidation status and in serum lipid profile parameters in relation to blood haemoglobin A1c values in individuals with type 2 diabetes mellitus. Diabetes Res Clin Pract. 2014;105(1):58-69. 
135. Kumawat M, Sharma TK, Singh I, Singh N, Ghalaut VS, Vardey SK, et al. Antioxidant Enzymes and Lipid Peroxidation in Type 2 Diabetes Mellitus Patients with and without Nephropathy. N Am J Med Sci. 2013;5(3):213-9.

136. Marjani A. Lipid peroxidation alterations in type 2 diabetic patients. Pak J Biol Sci. 2011;13(15):723-30.

137. La Vignera S, Condorelli RA, Vicari E, D'Agata R, Salemi M, Calogero AE. High levels of lipid peroxidation in semen of diabetic patients. Andrologia. 2012;44 Suppl 1:565-70.

138. Valko M, Jomova K, Rhodes CJ, Kuca K, Musilek K. Redox- and non-redoxmetal-induced formation of free radicals and their role in human disease. Archives of toxicology. 2016;90(1):1-37.

139. Valko M, Leibfritz D, Moncol J, Cronin MT, Mazur M, Telser J. Free radicals and antioxidants in normal physiological functions and human disease. The international journal of biochemistry \& cell biology. 2007;39(1):44-84.

140. Palem SP, Abraham P. A Study on the Level of Oxidative Stress and Inflammatory Markers in Type 2 Diabetes Mellitus Patients with Different Treatment Modalities. Journal of clinical and diagnostic research : JCDR. 2015;9(9):BC04-7.

141. Dikalov S. Cross talk between mitochondria and NADPH oxidases. Free Radic Biol Med. 2011;51(7):1289-301.

142. Rizzo MR, Barbieri M, Marfella R, Paolisso G. Response to Comment on: Rizzo et al. Reduction of oxidative stress and inflammation by blunting daily acute glucose fluctuations in patients with type 2 diabetes: role of dipeptidyl peptidase-IV inhibition. Diabetes Care 2012;35:2076-2082. Diabetes Care. 2012;36(1):e13.

143. Daniele G, Guardado Mendoza R, Winnier D, Fiorentino TV, Pengou Z, Cornell J, et al. The inflammatory status score including IL-6, TNF-alpha, osteopontin, fractalkine, MCP-1 and adiponectin underlies whole-body insulin resistance and hyperglycemia in type 2 diabetes mellitus. Acta Diabetol. 2013;51(1):123-31.

144. Khalkhal A, Haddar A, Semiane N, Mallek A, Abdelmalek A, Castex F, et al. Obesity, insulin resistance and diabetes in the sand rat exposed to a hypercaloric diet; possible protective effect for IL1-beta. C R Biol. 2012;335(4):271-8. 
145. Palmieri D, Cafueri G, Mongelli F, Pezzolo A, Pistoia V, Palombo D. Telomere shortening and increased oxidative stress are restricted to venous tissue in patients with varicose veins: A merely local disease? Vascular medicine. 2014;19(2):125-30.

146. Montane J, Cadavez L, Novials A. Stress and the inflammatory process: a major cause of pancreatic cell death in type 2 diabetes. Diabetes Metab Syndr Obes. 2014;7:25-34.

147. Montero-Vega MT. The inflammatory process underlying atherosclerosis. Crit Rev Immunol. 2013;32(5):373-462.

148. Murillo-Ortiz B, Albarran-Tamayo F, Arenas-Aranda D, Benitez-Bribiesca L, Malacara-Hernandez JM, Martinez-Garza S, et al. Telomere length and type 2 diabetes in males, a premature aging syndrome. Aging Male. 2011;15(1):54-8.

149. Adaikalakoteswari $A$, Balasubramanyam $M$, Mohan V. Telomere shortening occurs in Asian Indian Type 2 diabetic patients. Diabet Med. 2005;22(9):1151-6.

150. Azeem E, Gillani SW, Siddiqui A, Mian RI, Poh V, Sulaiman SA, et al. Oxidative Stress Correlates (OSC) in Diabetes Mellitus Patients. Curr Diabetes Rev. 2015.

151. Shimizu MH, Danilovic A, Andrade L, Volpini RA, Liborio AB, Sanches TR, et al. $\mathrm{N}$-acetylcysteine protects against renal injury following bilateral ureteral obstruction. Nephrol Dial Transplant. 2008;23(10):3067-73.

152. Maier CS, Chavez J, Wang J, Wu J. Protein adducts of aldehydic lipid peroxidation products identification and characterization of protein adducts using an aldehyde/keto-reactive probe in combination with mass spectrometry. Methods Enzymol. 2010;473:305-30.

153. Ohkawa H, Ohishi N, Yagi K. Assay for lipid peroxides in animal tissues by thiobarbituric acid reaction. Anal Biochem. 1979;95(2):351-8.

154. Nakhjavani M, O.; K, Khajeali L, Esteghamati A, Morteza A, Jamali A. Serum oxidized-LDL is associated with diabetes duration independent of maintaining optimized levels of LDL-cholesterol. Lipids Health Dis. 2010; 45: :321-7.

155. Mooradian AD. Dyslipidemia in type 2 diabetes mellitus. Nat Clin Pract Endocrinol Metab. 2009;5(3):150-9.

156. Al-Rawi NH. Oxidative stress, antioxidant status and lipid profile in the saliva of type 2 diabetics. Diab Vasc Dis Res. 2011;8(1):22-8. 
157. Benzie IF, Strain JJ. The ferric reducing ability of plasma (FRAP) as a measure of "antioxidant power": the FRAP assay. Anal Biochem. 1996;239(1):70-6.

158. Laight DW, Carrier MJ, Anggard EE. Antioxidants, diabetes and endothelial dysfunction. Cardiovascular research. 2000;47(3):457-64.

159. McSorley PT, Bell PM, Young IS, Atkinson AB, Sheridan B, Fee JP, et al. Endothelial function, insulin action and cardiovascular risk factors in young healthy adult offspring of parents with Type 2 diabetes: effect of vitamin $E$ in a randomized doubleblind, controlled clinical trial. Diabet Med. 2005;22(6):703-10.

160. Cadenas E. Basic mechanisms of antioxidant activity. BioFactors. 1997;6(4):3917.

161. Al-Daghri NM, Al-Attas OS, Alokail MS, Alkharfy KM, Yousef M, Sabico SL, et al. Diabetes mellitus type 2 and other chronic non-communicable diseases in the central region, Saudi Arabia (Riyadh cohort 2): a decade of an epidemic. BMC Med. 2011;9:76. 162. Duvvuri LS, Katiyar S, Kumar A, Khan W. Delivery aspects of antioxidants in diabetes management. Expert opinion on drug delivery. 2015;12(5):827-44.

163. A. N. K, R. A. K, M. A, N. M. Role of antioxidant in oxidative stress and diabetes mellitus. Journal of Pharmacognosy and Phytochemistry 2015;(6)(3):217-20.

164. Jacobs JM, Adkins JN, Qian WJ, Liu T, Shen Y, Camp DG, 2nd, et al. Utilizing human blood plasma for proteomic biomarker discovery. Journal of proteome research. 2005;4(4):1073-85.

165. Vasconcelos SML, Goulart MOF, de França Moura JB, Manfredini V, Benfato MS. Reactive oxygen and nitrogen species, antioxidants and markers of oxidative damage in human blood: main analytical methods for their determination. Quim Nova. 2007:132338 ,.

166. Pandey KB, Rizvi SI. Markers of oxidative stress in erythrocytes and plasma during aging in humans. Oxid Med Cell Longev. 2010;3(1):2-12.

167. Schiffrin EL. Antioxidants in hypertension and cardiovascular disease. Molecular interventions. 2010;10(6):354-62.

168. Choudhry AA, Gururaja A, Prabhu K. Correlation of Plasma Lipid Profile with Salivary Oxidative Stress Markers in Type II Diabetes Mellitus Patients. Journal of clinical and diagnostic research : JCDR. 2014;8(6):CC08-10. 
169. Berry C, Brosnan MJ, Fennell J, Hamilton CA, Dominiczak AF. Oxidative stress and vascular damage in hypertension. Current opinion in nephrology and hypertension. 2001;10(2):247-55.

170. Madian AG, Diaz-Maldonado N, Gao Q, Regnier FE. Oxidative stress induced carbonylation in human plasma. Journal of proteomics. 2011;74(11):2395-416.

171. Yan X, Lee S, Gugiu BG, Koroniak L, Jung ME, Berliner J, et al. Fatty acid epoxyisoprostane E2 stimulates an oxidative stress response in endothelial cells. Biochem Biophys Res Commun. 2014;444(1):69-74.

172. Slatter DA, Bolton $\mathrm{CH}$, Bailey AJ. The importance of lipid-derived malondialdehyde in diabetes mellitus. Diabetologia. 2000;43(5):550-7.

173. Gupta S, Gambhir JK, Kalra O, Gautam A, Shukla K, Mehndiratta M, et al. Association of biomarkers of inflammation and oxidative stress with the risk of chronic kidney disease in Type 2 diabetes mellitus in North Indian population. Journal of diabetes and its complications. 2013;27(6):548-52.

174. Lodovici M, Bigagli E, Bardini G, Rotella CM. Lipoperoxidation and antioxidant capacity in patients with poorly controlled type 2 diabetes. Toxicology and industrial health. 2009;25(4-5):337-41.

175. Hisalkar PJ, Patne AB, Karnik AC, Fawade MM, Mumbare SS. Ferric Reducing Ability of Plasma with Lipid Peroxidation in type 2 diabetes. Int $\mathrm{J}$ Pharm Bio Sci. 2012; Volume 2(2):53-6.

176. Singh N, Bhardwaj P, Pandey RM, Saraya A. Oxidative stress and antioxidant capacity in patients with chronic pancreatitis with and without diabetes mellitus. Indian journal of gastroenterology : official journal of the Indian Society of Gastroenterology. 2012;31(5):226-31.

177. Lodovici M, Giovannelli L, Pitozzi V, Bigagli E, Bardini G, Rotella CM. Oxidative DNA damage and plasma antioxidant capacity in type 2 diabetic patients with good and poor glycaemic control. Mutat Res. 2008;638(1-2):98-102.

178. Wayner DD, Burton GW, Ingold KU, Locke S. Quantitative measurement of the total, peroxyl radical-trapping antioxidant capability of human blood plasma by controlled peroxidation. The important contribution made by plasma proteins. FEBS Lett. 1985;187(1):33-7. 
179. Sies H. Glutathione and its role in cellular functions. Free Radic Biol Med. 1999;27(9-10):916-21.

180. Beretta G, Facino RM. Recent advances in the assessment of the antioxidant capacity of pharmaceutical drugs: from in vitro to in vivo evidence. Anal Bioanal Chem. 2010;398(1):67-75.

181. Niki E. Assessment of antioxidant capacity in vitro and in vivo. Free Radic Biol Med. 2010;49(4):503-15.

182. Fraga CG, Oteiza PI, Galleano M. In vitro measurements and interpretation of total antioxidant capacity. Biochimica et biophysica acta. 2014;1840(2):931-4 .

183. Huang D, Ou B, Prior RL. The chemistry behind antioxidant capacity assays. Journal of agricultural and food chemistry. 2005;53(6):1841-56.

184. Blackburn EH. Structure and function of telomeres. Nature. 1991;350(6319):56973.

185. McClintock B, Hill HE. The Cytological Identification of the Chromosome Associated with the R-G Linkage Group in ZEA MAYS. Genetics. 1931;16(2):175-90.

186. Yao MC, Blackburn E, Gall J. Tandemly repeated C-C-C-C-A-A hexanucleotide of Tetrahymena rDNA is present elsewhere in the genome and may be related to the alteration of the somatic genome. J Cell Biol. 1981;90(2):515-20.

187. Blackburn EH, Gall JG. A tandemly repeated sequence at the termini of the extrachromosomal ribosomal RNA genes in Tetrahymena. J Mol Biol. 1978;120(1):3353.

188. Szostak JW, Blackburn EH. Cloning yeast telomeres on linear plasmid vectors. Cell. 1982;29(1):245-55.

189. Greider CW, Blackburn EH. Identification of a specific telomere terminal transferase activity in Tetrahymena extracts. Cell. 1985;43(2 Pt 1):405-13.

190. Vega LR, Mateyak MK, Zakian VA. Getting to the end: telomerase access in yeast and humans. Nat Rev Mol Cell Biol. 2003;4(12):948-59.

191. de Lange T. T-loops and the origin of telomeres. Nat Rev Mol Cell Biol. 2004;5(4):323-9.

192. Greider CW, Blackburn EH. Telomeres, telomerase and cancer. Sci Am. 1996;274(2):92-7. 
193. Wai LK. Telomeres, telomerase, and tumorigenesis--a review. MedGenMed. 2004;6(3):19.

194. Lu W, Zhang Y, Liu D, Songyang Z, Wan M. Telomeres-structure, function, and regulation. Exp Cell Res. 2013;319(2):133-41.

195. Mowla SN, Lam EW, Jat PS. Cellular senescence and aging: the role of B-MYB. Aging Cell. 2014;13(5):773-9.

196. Blackburn EH, Greider CW, Szostak JW. Telomeres and telomerase: the path from maize, Tetrahymena and yeast to human cancer and aging. Nat Med. 2006;12(10):1133-8.

197. Katakura Y. Molecular basis for the cellular senescence program and its application to anticancer therapy. Biosci Biotechnol Biochem. 2006;70(5):1076-81.

198. Stewart SA, Weinberg RA. Telomeres: cancer to human aging. Annu Rev Cell Dev Biol. 2006;22:531-57.

199. Hayflick L, Frederick L. Dr. Hayflick deplores our 'outrageous' article. Med World News. 1982;23(18):119, 23.

200. Axelrad MD, Budagov T, Atzmon G. Telomere length and telomerase activity; a yin and yang of cell senescence. J Vis Exp. 2013(75).

201. Etcheverry GJ. [Where chromosomes end. Nobel Prize of Physiology or Medicine 2009]. Medicina (B Aires). 2009;69(6):681-4.

202. Mengual Gomez DL, Armando RG, Farina HG, Gomez DE. [Telomerase and telomere: their structure and dynamics in health and disease]. Medicina (B Aires). 2014;74(1):69-76.

203. Yeh CK. Cellular senescence and aging. Oral Dis. 2016;22(7):587-90.

204. Murillo-Ortiz B, Ramirez Emiliano J, Hernandez Vazquez WI, Martinez-Garza S, Solorio-Meza S, Albarran-Tamayo F, et al. Impact of Oxidative Stress in Premature Aging and Iron Overload in Hemodialysis Patients. Oxid Med Cell Longev. 2016;2016:1578235.

205. Dierick JF, Eliaers F, Remacle J, Raes M, Fey SJ, Larsen PM, et al. Stressinduced premature senescence and replicative senescence are different phenotypes, proteomic evidence. Biochemical pharmacology. 2002;64(5-6):1011-7. 
206. Barnes PJ. Mechanisms of development of multimorbidity in the elderly. Eur Respir J. 2015;45(3):790-806.

207. Smogorzewska A, de Lange T. Regulation of telomerase by telomeric proteins. Annu Rev Biochem. 2004;73:177-208.

208. Greider CW, Blackburn EH. A telomeric sequence in the RNA of Tetrahymena telomerase required for telomere repeat synthesis. Nature. 1989;337(6205):331-7.

209. Corey DR. Telomeres and telomerase: from discovery to clinical trials. Chem Biol. 2009;16(12):1219-23.

210. Sekhri K. Telomeres and telomerase: Understanding basic structure and potential new therapeutic strategies targeting it in the treatment of cancer. J Postgrad Med. 2014;60(3):303-8.

211. Nakamura TM, Morin GB, Chapman KB, Weinrich SL, Andrews WH, Lingner J, et al. Telomerase catalytic subunit homologs from fission yeast and human. Science. 1997;277(5328):955-9.

212. Podlevsky JD, Chen JJ. It all comes together at the ends: telomerase structure, function, and biogenesis. Mutat Res. 2012;730(1-2):3-11.

213. Daniel M, Peek GW, Tollefsbol TO. Regulation of the human catalytic subunit of telomerase (hTERT). Gene. 2012;498(2):135-46.

214. Rubtsova MP, Vasilkova DP, Malyavko AN, Naraikina YV, Zvereva MI, Dontsova $\mathrm{OA}$. Telomere lengthening and other functions of telomerase. Acta naturae. 2012;4(2):44-61.

215. Londono-Vallejo JA, Wellinger RJ. Telomeres and telomerase dance to the rhythm of the cell cycle. Trends in biochemical sciences. 2012;37(9):391-9.

216. Blackburn EH, Collins K. Telomerase: an RNP enzyme synthesizes DNA. Cold Spring Harb Perspect Biol. 2011;3(5).

217. Meier UT. The many facets of H/ACA ribonucleoproteins. Chromosoma. 2005;114(1):1-14.

218. Mitchell JR, Cheng J, Collins K. A box H/ACA small nucleolar RNA-like domain at the human telomerase RNA 3' end. Mol Cell Biol. 1999;19(1):567-76.

219. Jady BE, Bertrand E, Kiss T. Human telomerase RNA and box H/ACA scaRNAs share a common Cajal body-specific localization signal. J Cell Biol. 2004;164(5):647-52. 
220. Stanley SE, Armanios M. The short and long telomere syndromes: paired paradigms for molecular medicine. Curr Opin Genet Dev. 2015;33:1-9.

221. Blackburn EH. Telomeres and telomerase: their mechanisms of action and the effects of altering their functions. FEBS Lett. 2005;579(4):859-62.

222. Allsopp RC, Vaziri H, Patterson C, Goldstein S, Younglai EV, Futcher AB, et al. Telomere length predicts replicative capacity of human fibroblasts. Proc Natl Acad Sci U S A. 1992;89(21):10114-8.

223. Novo CL, Londono-Vallejo JA. Telomeres and the nucleus. Semin Cancer Biol. 2013;23(2):116-24.

224. Greider CW. Telomerase RNA levels limit the telomere length equilibrium. Cold Spring Harb Symp Quant Biol. 2006;71:225-9.

225. Feng J, Funk WD, Wang SS, Weinrich SL, Avilion AA, Chiu CP, et al. The RNA component of human telomerase. Science. 1995;269(5228):1236-41.

226. Neidle S, Parkinson G. Telomere maintenance as a target for anticancer drug discovery. Nature reviews Drug discovery. 2002;1(5):383-93.

227. Liu D, O'Connor MS, Qin J, Songyang Z. Telosome, a mammalian telomereassociated complex formed by multiple telomeric proteins. $J$ Biol Chem. 2004;279(49):51338-42.

228. Armanios $\mathrm{M}$, Blackburn $\mathrm{EH}$. The telomere syndromes. Nat Rev Genet. 2012;13(10):693-704.

229. Sarek G, Marzec P, Margalef P, Boulton SJ. Molecular basis of telomere dysfunction in human genetic diseases. Nature structural \& molecular biology. 2015;22(11):867-74.

230. O'Connor MS, Safari A, Xin H, Liu D, Songyang Z. A critical role for TPP1 and TIN2 interaction in high-order telomeric complex assembly. Proc Natl Acad Sci U S A. 2006;103(32):11874-9.

231. Takai KK, Kibe T, Donigian JR, Frescas D, de Lange T. Telomere protection by TPP1/POT1 requires tethering to TIN2. Mol Cell. 2011;44(4):647-59.

232. Hukezalie KR, Wong JM. Structure-function relationship and biogenesis regulation of the human telomerase holoenzyme. FEBS J. 2013;280(14):3194-204. 
233. Hirashima K, Migita T, Sato S, Muramatsu $Y$, Ishikawa $Y$, Seimiya H. Telomere length influences cancer cell differentiation in vivo. Mol Cell Biol.33(15):2988-95.

234. Kurz DJ, Decary S, Hong Y, Trivier E, Akhmedov A, Erusalimsky JD. Chronic oxidative stress compromises telomere integrity and accelerates the onset of senescence in human endothelial cells. J Cell Sci. 2004;117(Pt 11):2417-26.

235. Best BP. Nuclear DNA damage as a direct cause of aging. Rejuvenation Res. 2009;12(3):199-208.

236. Baird DM. Mechanisms of telomeric instability. Cytogenet Genome Res. 2008;122(3-4):308-14.

237. Ma D, Yu Y, Yu X, Zhang M, Yang Y. The changes of leukocyte telomere length and telomerase activity after sitagliptin intervention in newly diagnosed type 2 diabetes. Diabetes Metab Res Rev. 2014.

238. You NC, Chen BH, Song Y, Lu X, Chen Y, Manson JE, et al. A prospective study of leukocyte telomere length and risk of type 2 diabetes in postmenopausal women. Diabetes. 2012;61(11):2998-3004.

239. Hamel FG. Telomeres and type 2 diabetes. Transl Res. 2010;155(4):164-5.

240. Shen Q, Zhao X, Yu L, Zhang Z, Zhou D, Kan M, et al. Association of leukocyte telomere length with type 2 diabetes in mainland Chinese populations. J Clin Endocrinol Metab. 2012;97(4):1371-4.

241. Kejariwal D, Stepien KM, Smith T, Kennedy H, Hughes DA, Sampson MJ. Lack of association of colonic epithelium telomere length and oxidative DNA damage in Type 2 diabetes under good metabolic control. BMC Endocr Disord. 2008;8:12.

242. Olivieri F, Lorenzi M, Antonicelli R, Testa R, Sirolla C, Cardelli M, et al. Leukocyte telomere shortening in elderly Type2DM patients with previous myocardial infarction. Atherosclerosis. 2009;206(2):588-93.

243. Salpea KD, Humphries SE. Telomere length in atherosclerosis and diabetes. Atherosclerosis. 2010;209(1):35-8.

244. Hovatta I, de Mello VD, Kananen L, Lindstrom J, Eriksson JG, llanne-Parikka P, et al. Leukocyte telomere length in the Finnish Diabetes Prevention Study. PLoS One. 2012;7(4):e34948. 
245. Harte AL, da Silva NF, Miller MA, Cappuccio FP, Kelly A, O'Hare JP, et al. Telomere length attrition, a marker of biological senescence, is inversely correlated with triglycerides and cholesterol in South Asian males with type 2 diabetes mellitus. Exp Diabetes Res. 2012;2012:895185.

246. Al Khaldi R, Mojiminiyi O, AlMulla F, Abdella N. Associations of TERC Single Nucleotide Polymorphisms with Human Leukocyte Telomere Length and the Risk of Type 2 Diabetes Mellitus. PLoS One. 2015;10(12):e0145721.

247. Ma D, Zhu W, Hu S, Yu X, Yang Y. Association between oxidative stress and telomere length in type 1 and type 2 diabetic patients. J Endocrinol Invest.

248. Ma DL, Yu Y, Yu XF, Zhang MX, Yang Y. The changes of leukocyte telomere length and telomerase activity after sitagliptin intervention in newly diagnosed type 2 diabetes. Diabetes-Metabolism Research and Reviews. 2015;31(3):256-61.

249. Ma RC, So WY, Tam CH, Luk AO, Ho JS, Wang Y, et al. Genetic variants for type 2 diabetes and new-onset cancer in Chinese with type 2 diabetes. Diabetes Res Clin Pract. 2014;103(2):328-37.

250. von Zglinicki T, Martin-Ruiz CM. Telomeres as biomarkers for ageing and agerelated diseases. Curr Mol Med. 2005;5(2):197-203.

251. Lange K, Holm L, Vang Nielsen K, Hahn A, Hofmann W, Kreipe H, et al. Telomere shortening and chromosomal instability in myelodysplastic syndromes. Genes Chromosomes Cancer. 2010;49(3):260-9.

252. Armanios M. Syndromes of telomere shortening. Annu Rev Genomics Hum Genet. 2009;10.

253. Elks CE, Scott RA. The long and short of telomere length and diabetes. Diabetes. 2013;63(1):65-7.

254. Zhou Y, Ning Z, Lee Y, Hambly BD, McLachlan CS. Shortened leukocyte telomere length in type 2 diabetes mellitus: genetic polymorphisms in mitochondrial uncoupling proteins and telomeric pathways. Clinical and translational medicine. 2016;5(1):8.

255. Dudinskaya EN, Tkacheva ON, Shestakova MV, Brailova NV, Strazhesko ID, Akasheva DU, et al. Telomere length and vascular wall in patients with type 2 diabetes mellitus. Diabetes Mellitus. 2014;2014(3):31-8. 
256. Dudinskaya EN, Tkacheva ON, Shestakova MV, Brailova NV, Strazhesko ID, Akasheva DU, et al. Short telomere length is associated with arterial aging in patients with type 2 diabetes mellitus. Endocrine connections. 2015;4(3):136-43.

257. Heidinger BJ, Blount JD, Boner W, Griffiths K, Metcalfe NB, Monaghan P. Telomere length in early life predicts lifespan. Proc Natl Acad Sci U S A. 2012;109(5):1743-8.

258. Minamino $T$, Orimo $M$, Shimizu I, Kunieda $T$, Yokoyama M, Ito $T$, et al. A crucial role for adipose tissue p53 in the regulation of insulin resistance. Nat Med. 2009;15(9):1082-7.

259. Monickaraj F, Aravind S, Gokulakrishnan K, Sathishkumar C, Prabu P, Prabu D. Accelerated aging as evidenced by increased telomere shortening and mitochondrial DNA depletion in patients with type 2 diabetes. Mol Cell Biochem. 2012;365.

260. Vera E, Blasco MA. Beyond average: potential for measurement of short telomeres. Aging (Albany NY). 2012;4(6):379-92.

261. Southern EM. Detection of specific sequences among DNA fragments separated by gel electrophoresis. J Mol Biol. 1975;98(3):503-17.

262. Lansdorp PM, Verwoerd NP, van de Rijke FM, Dragowska V, Little MT, Dirks RW, et al. Heterogeneity in telomere length of human chromosomes. Hum Mol Genet. 1996;5(5):685-91.

263. Montpetit AJ, Alhareeri AA, Montpetit M, Starkweather AR, Elmore LW, Filler K, et al. Telomere length: a review of methods for measurement. Nurs Res. 2014;63(4):28999.

264. Cawthon RM. Telomere measurement by quantitative PCR. Nucleic Acids Res. 2002;30(10):e47.

265. O'Callaghan N, Dhillon V, Thomas P, Fenech M. A quantitative real-time PCR method for absolute telomere length. Biotechniques. 2008;44(6):807-9.

266. O'Callaghan NJ, Fenech M. A quantitative PCR method for measuring absolute telomere length. Biol Proced Online. 2011;13:3.

267. Cunningham JM, Johnson RA, Litzelman K, Skinner HG, Seo S, Engelman CD, et al. Telomere length varies by DNA extraction method: implications for epidemiologic research. Cancer Epidemiol Biomarkers Prev. 2013;22(11):2047-54. 
268. Hofmann JN, Hutchinson AA, Cawthon R, Liu CS, Lynch SM, Lan $Q$, et al. Telomere length varies by DNA extraction method: implications for epidemiologic research-letter. Cancer Epidemiol Biomarkers Prev. 2014;23(6):1129-30.

269. Aviv A, Hunt SC, Lin J, Cao X, Kimura M, Blackburn E. Impartial comparative analysis of measurement of leukocyte telomere length/DNA content by Southern blots and qPCR. Nucleic Acids Res. 2011;39(20):e134.

270. Gardner JP, Li S, Srinivasan SR, Chen W, Kimura M, Lu X, et al. Rise in insulin resistance is associated with escalated telomere attrition. Circulation. 2005;111(17):2171-7.

271. Fyhrquist F, Tiitu A, Saijonmaa O, Forsblom C, Groop PH. Telomere length and progression of diabetic nephropathy in patients with type 1 diabetes. J Intern Med.267(3):278-86.

272. Masi S, Nightingale CM, Day IN, Guthrie P, Rumley A, Lowe GD, et al. Inflammation and not cardiovascular risk factors is associated with short leukocyte telomere length in 13- to 16-year-old adolescents. Arterioscler Thromb Vasc Biol.32(8):2029-34.

273. Salpea KD, Humphries SE. Telomere length in atherosclerosis and diabetes. Atherosclerosis.209(1):35-8.

274. Risques RA, Vaughan TL, Li X, Odze RD, Blount PL, Ayub K, et al. Leukocyte telomere length predicts cancer risk in Barrett's esophagus. Cancer Epidemiol Biomarkers Prev. 2007;16(12):2649-55.

275. Tentolouris N, Nzietchueng R, Cattan V, Poitevin G, Lacolley P, Papazafiropoulou $A$, et al. White blood cells telomere length is shorter in males with type 2 diabetes and microalbuminuria. Diabetes Care. 2007;30(11):2909-15.

276. Su Y, Liu XM, Sun YM, Jin HB, Fu R, Wang YY, et al. The relationship between endothelial dysfunction and oxidative stress in diabetes and prediabetes. Int $\mathrm{J}$ Clin Pract. 2008;62(6):877-82.

277. Anvisa. Boas Práticas no Ciclo do Sangue In: Sanitária. MdSANdV, editor. Brasilia: DOU de 02 de junho de 2014; 2014. 
278. Anvisa. Ciclo produtivo do sangue humano e componentes e procedimentos transfusionais. In: Sanitária MdSANdV, editor. Brasilia: Diário Oficial - Imprensa Nacional - № 241 - 17/12/10 - Seção 1 p.; 2010.

279. Callegari-Jacques;, M.; S. Bioestatística: princípios e aplicações. Porto Alegre2003.

280. Faul F, Erdfelder E, Lang AG, Buchner A. G*Power 3: a flexible statistical power analysis program for the social, behavioral, and biomedical sciences. Behavior research methods. 2007;39(2):175-91.

281. Faul F, Erdfelder E, Buchner A, Lang AG. Statistical power analyses using G*Power 3.1: tests for correlation and regression analyses. Behavior research methods. 2009;41(4):1149-60.

282. WHO. BMI classification: Geneva, Switzerland:; 2008 [cited 2014. 13 out]. Available from: <http://apps.who.int/bmi/index.jsp?introPage=intro 3.html>.

283. Haskell WL, Lee IM, Pate RR, Powell KE, Blair SN, Franklin BA, et al. Physical activity and public health: updated recommendation for adults from the American College of Sports Medicine and the American Heart Association. Medicine and science in sports and exercise. 2007;39(8):1423-34.

284. Gutteridge JM. Lipid peroxidation and antioxidants as biomarkers of tissue damage. Clin Chem. 1995;41(12 Pt 2):1819-28.

285. van der Velden VH, Cazzaniga G, Schrauder A, Hancock J, Bader P, PanzerGrumayer ER, et al. Analysis of minimal residual disease by $\mathrm{lg} / \mathrm{TCR}$ gene rearrangements: guidelines for interpretation of real-time quantitative PCR data. Leukemia. 2007;21(4):604-11.

286. IBM Corp. IBM SPSS Statistics for Windows VA, NY: IBM Corp. 2013.

287. La Jolla California USA wgc.

288. Ahmed FN, Naqvi FN, Shafiq F. Lipid peroxidation and serum antioxidant enzymes in patients with type 2 diabetes mellitus. Ann N Y Acad Sci. 2006;1084:481-9. 289. Butt HZ, Atturu G, London NJ, Sayers RD, Bown MJ. Telomere length dynamics in vascular disease: a review. European journal of vascular and endovascular surgery : the official journal of the European Society for Vascular Surgery. 2010;40(1):17-26. 
290. Liu Z, Zhang J, Yan J, Wang Y, Li Y. Leucocyte telomere shortening in relation to newly diagnosed type 2 diabetic patients with depression. Oxid Med Cell Longev. 2014;2014:673959.

291. Grillo M, Gorini M. Caracterização de pessoas com Diabetes Mellitus Tipo 2. Rev Bras Enferm 2007:49-54.

292. Bozorgmehr K, Szecsenyi J, Ose D, Besier W, Mayer M, Krisam J, et al. Practice network-based care management for patients with type 2 diabetes and multiple comorbidities (GEDIMAplus): study protocol for a randomized controlled trial. Trials. 2014;15:243.

293. Kilpatrick ES. Arguments for and against the role of glucose variability in the development of diabetes complications. Journal of diabetes science and technology. 2009;3(4):649-55.

294. Morsi HK, Ismail MM, Gaber HA, Elbasmy AA. Macrophage Migration Inhibitory Factor and Malondialdehyde as Potential Predictors of Vascular Risk Complications in Type 2 Diabetes Mellitus: Cross-Sectional Case Control Study in Saudi Arabia. Mediators of inflammation. 2016;2016:5797930.

295. Tiwari BK, Pandey KB, Abidi AB, Rizvi SI. Markers of Oxidative Stress during Diabetes Mellitus. Journal of biomarkers. 2013;2013:378790.

296. Ginter E, Simko V. Type 2 diabetes mellitus, pandemic in 21 st century. Adv Exp Med Biol. 2012;771:42-50.

297. American Diabetes A. 9. Microvascular Complications and Foot Care. Diabetes Care. 2016;39 Suppl 1:S72-80.

298. de Kreutzenberg SV, Ceolotto G, Cattelan A, Pagnin E, Mazzucato M, Garagnani $P$, et al. Metformin improves putative longevity effectors in peripheral mononuclear cells from subjects with prediabetes. A randomized controlled trial. Nutrition, metabolism, and cardiovascular diseases : NMCD. 2015;25(7):686-93.

299. Molmen-Hansen HE, Stolen T, Tjonna AE, Aamot IL, Ekeberg IS, Tyldum GA, et al. Aerobic interval training reduces blood pressure and improves myocardial function in hypertensive patients. European journal of preventive cardiology. 2012;19(2):151-60. 
300. Verdecchia P, Angeli F. [The Seventh Report of the Joint National Committee on the Prevention, Detection, Evaluation and Treatment of High Blood Pressure: the weapons are ready]. Rev Esp Cardiol. 2003;56(9):843-7.

301. Bjarnason TA, Kristinsdottir LB, Oskarsdottir ES, Hafthorsson SO, Olafsson I, Lund $\mathrm{SH}$, et al. Diagnosis of type 2 diabetes and prediabetes among patients with acute coronary syndromes. European heart journal Acute cardiovascular care. 2016.

302. Santos AL, al.; e. Microvascular complications in type 2 diabetes and associated factors: a telephone survey of self-reported morbidity. Ciência e Saúde Coletiva. 2015:761-70.

303. Wium-Andersen MK, Orsted DD, Rode L, Bojesen SE, Nordestgaard BG. Telomere length and depression: prospective cohort study and Mendelian randomisation study in 67306 individuals. The British journal of psychiatry : the journal of mental science. 2016.

304. Czepielewski LS, Massuda R, Panizzutti B, da Rosa ED, de Lucena D, Macedo $D$, et al. Telomere length in subjects with schizophrenia, their unaffected siblings and healthy controls: Evidence of accelerated aging. Schizophr Res. 2016;174(1-3):39-42.

305. Sakamoto M, Nishimura R, Irako T, Tsujino D, Ando K, Utsunomiya K. Comparison of vildagliptin twice daily vs. sitagliptin once daily using continuous glucose monitoring (CGM): crossover pilot study (J-VICTORIA study). Cardiovascular diabetology. 2012;11:92.

306. Al-Daghri NM, Al-Attas OS, Wani K, Alnaami AM, Sabico S, Al-Ajlan A, et al. Sensitivity of various adiposity indices in identifying cardiometabolic diseases in Arab adults. Cardiovascular diabetology. 2015;14:101.

307. American Diabetes A. (2) Classification and diagnosis of diabetes. Diabetes Care. 2015;38 Suppl:S8-S16.

308. Radenkovic SP, Kocic RD, Pesic MM, Dimic DN, Golubovic MD, Radojkovic DB, et al. The hypertriglyceridemic waist phenotype and metabolic syndrome by differing criteria in type 2 diabetic patients and their relation to lipids and blood glucose control. Endokrynologia Polska. 2011;62(4):316-23.

309. Urso C, Caimi G. [Oxidative stress and endothelial dysfunction]. Minerva medica. 2011;102(1):59-77. 
310. Babizhayev MA, Strokov IA, Nosikov VV, Savel'yeva EL, Sitnikov VF, Yegorov YE, et al. The Role of Oxidative Stress in Diabetic Neuropathy: Generation of Free Radical Species in the Glycation Reaction and Gene Polymorphisms Encoding Antioxidant Enzymes to Genetic Susceptibility to Diabetic Neuropathy in Population of Type I Diabetic Patients. Cell biochemistry and biophysics. 2015;71(3):1425-43.

311. Tangvarasittichai S. Oxidative stress, insulin resistance, dyslipidemia and type 2 diabetes mellitus. World journal of diabetes. 2015;6(3):456-80.

312. D'Souza JM, D'Souza RP, Vijin VF, Shetty A, Arunachalam C, Pai VR, et al. High predictive ability of glycated hemoglobin on comparison with oxidative stress markers in assessment of chronic vascular complications in type 2 diabetes mellitus. Scandinavian journal of clinical and laboratory investigation. 2016;76(1):51-7.

313. Cortez D, Reis I, Souza D, Macedo M, Torres H. Complications and the time of diagnosis of diabetes mellitus in primary care. Acta Paul Enferm 2015;28(3):250-5.

314. Phillips M, Cataneo RN, Cheema T, Greenberg J. Increased breath biomarkers of oxidative stress in diabetes mellitus. Clinica chimica acta; international journal of clinical chemistry. 2004;344(1-2):189-94.

315. Monickaraj F, Aravind S, Nandhini P, Prabu P, Sathishkumar C, Mohan V, et al. Accelerated fat cell aging links oxidative stress and insulin resistance in adipocytes. $J$ Biosci. 2013;38(1):113-22.

316. Likidlilid A, Patchanans N, Peerapatdit T, Sriratanasathavorn C. Lipid peroxidation and antioxidant enzyme activities in erythrocytes of type 2 diabetic patients. Journal of the Medical Association of Thailand $=$ Chotmaihet thangphaet. 2010;93(6):682-93.

317. Rizvi SI, Maurya PK. Markers of oxidative stress in erythrocytes during aging in humans. Ann N Y Acad Sci. 2007;1100:373-82.

318. Esposito K, Nappo F, Marfella R, Giugliano G, Giugliano F, Ciotola M, et al. Inflammatory cytokine concentrations are acutely increased by hyperglycemia in humans: role of oxidative stress. Circulation. 2002;106(16):2067-72.

319. Pinton P, Rizzuto R. p66Shc, oxidative stress and aging: importing a lifespan determinant into mitochondria. Cell cycle. 2008;7(3):304-8. 
320. Laurent G, Solari F, Mateescu B, Karaca M, Castel J, Bourachot B, et al. Oxidative stress contributes to aging by enhancing pancreatic angiogenesis and insulin signaling. Cell Metab. 2008;7(2):113-24.

321. Joao Cabrera E, Valezi AC, Delfino VD, Lavado EL, Barbosa DS. Reduction in plasma levels of inflammatory and oxidative stress indicators after Roux-en-Y gastric bypass. Obesity surgery. 2010;20(1):42-9.

322. Olusi SO. Obesity is an independent risk factor for plasma lipid peroxidation and depletion of erythrocyte cytoprotectic enzymes in humans. International journal of obesity and related metabolic disorders : journal of the International Association for the Study of Obesity. 2002;26(9):1159-64.

323. Whayne TF, Saha SP, Mukherjee D. Antioxidants in the Practice of Medicine; What Should the Clinician Know? Cardiovascular \& hematological disorders drug targets. 2016.

324. Sivonova M, Tatarkova Z, Durackova Z, Dobrota D, Lehotsky J, Matakova T, et al. Relationship between antioxidant potential and oxidative damage to lipids, proteins and DNA in aged rats. Physiological research / Academia Scientiarum Bohemoslovaca. 2007;56(6):757-64.

325. Gawlik K, Naskalski JW, Fedak D, Pawlica-Gosiewska D, Grudzien U, Dumnicka $P$, et al. Markers of Antioxidant Defense in Patients with Type 2 Diabetes. Oxid Med Cell Longev. 2016;2016:2352361.

326. Paolisso G, D'Amore A, Galzerano D, Balbi V, Giugliano D, Varricchio M, et al. Daily vitamin $E$ supplements improve metabolic control but not insulin secretion in elderly type II diabetic patients. Diabetes Care. 1993;16(11):1433-7.

327. Czernichow S, Couthouis A, Bertrais S, Vergnaud AC, Dauchet L, Galan P, et al. Antioxidant supplementation does not affect fasting plasma glucose in the Supplementation with Antioxidant Vitamins and Minerals (SU.VI.MAX) study in France: association with dietary intake and plasma concentrations. Am $\mathrm{J}$ Clin Nutr. 2006;84(2):395-9.

328. Elbers CC, Garcia ME, Kimura M, Cummings SR, Nalls MA, Newman AB, et al. Comparison between southern blots and qPCR analysis of leukocyte telomere length in the health ABC study. J Gerontol A Biol Sci Med Sci. 2014;69(5):527-31. 
329. Vogelstein B, Kinzler KW. Digital PCR. Proc Natl Acad Sci U S A. 1999;96(16):9236-41.

330. Heyries KA, Tropini C, Vaninsberghe M, Doolin C, Petriv OI, Singhal A, et al. Megapixel digital PCR. Nature methods. 2011;8(8):649-51.

331. You NCY, Chen BH, Song YQ, Lu XY, Chen YL, Manson JE, et al. A Prospective Study of Leukocyte Telomere Length and Risk of Type 2 Diabetes in Postmenopausal Women. Diabetes. 2012;61(11):2998-3004.

332. Ahmad S, Heraclides A, Sun Q, Elgzyri T, Ronn T, Ling C, et al. Telomere length in blood and skeletal muscle in relation to measures of glycaemia and insulinaemia. Diabet Med. 2012;29(10):e377-81.

333. Xiao F, Zheng X, Cui M, Shi G, Chen X, Li R. Telomere dysfunction-related serological markers are associated with type 2 diabetes. Diabetes Care. 2011;34.

334. Al-Daghri NM, Alfawaz H, Aljohani NJ, Al-Saleh Y, Wani K, Alnaami AM, et al. A 6-month "self-monitoring" lifestyle modification with increased sunlight exposure modestly improves vitamin D status, lipid profile and glycemic status in overweight and obese Saudi adults with varying glycemic levels. Lipids Health Dis. 2014;13:87.

335. Zee RY, Castonguay AJ, Barton NS, Germer S, Martin M. Mean leukocyte telomere length shortening and type 2 diabetes mellitus: a case-control study. Transl Res. 2010;155(4):166-9.

336. Sampson MJ, Winterbone MS, Hughes JC, Dozio N, Hughes DA. Monocyte telomere shortening and oxidative DNA damage in type 2 diabetes. Diabetes Care. 2006;29(2):283-9.

337. Murillo-Ortiz B, Albarran-Tamayo F, Arenas-Aranda D, Benitez-Bribiesca L, Malacara-Hernandez JM, Martinez-Garza S. Telomere length and type 2 diabetes in males, a premature aging syndrome. Aging Male. 2012;15.

338. Carmona JJ, Michan S. Biology of Healthy Aging and Longevity. Revista de investigacion clinica; organo del Hospital de Enfermedades de la Nutricion. 2016;68(1):7-16.

339. Cawthon RM, Smith KR, O'Brien E, Sivatchenko A, Kerber RA. Association between telomere length in blood and mortality in people aged 60 years or older. Lancet. 2003;361(9355):393-5. 
340. Aviv A, Kark JD, Susser E. Telomeres, atherosclerosis, and human longevity: a causal hypothesis. Epidemiology. 2015;26. 


\title{
ANEXO I - PARECER DO COMITÊ DE ÉTICA EM PESQUISA EM SERES HUMANOS (FACULDADE DE CIÊNCIAS DA SAÚDE, UNIVERSIDADE DE BRASÍLIA)
}

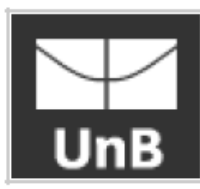

\author{
FACULDADE DE CIÊNCIAS DA \\ SAÚDE DA UNIVERSIDADE DE \\ BRASÍLIA - CEP/FS-UNB
}

\section{PARECER CONSUBSTANCIADO DO CEP}

\section{DADOS DO PROJETO DE PESQUISA}

Título da Pesquisa: Investigação da associação entre o comprimento dos telômeros de leucócitos do sangue periférico e a presença de diabetes mellitus tipo 2 e de suas complicações crônicas entre pacientes acompanhados no Hospital Universitário de Brasilia.

Pesquisador: Angélica Amorim Amato

Área Temática: Área 1. Genética Humana.

(Trata-se de pesquisa envolvendo genética humana não contemplada acima.);

Versão: 1

CAAE: 13686213.1 .0000 .0030

Instituição Proponente: Faculdade de Ciências da Saúde da Universidade de Brasilia

Patrocinador Principal: Financiamento Próprio

\section{DADOS DO PARECER}

Número do Parecer: 392.623

Data da Relatoria: 10/09/2013

Apresentação do Projeto:

Trata-se de projeto de pesquisa apresentado pela prof. Angélica Amorim Amato professora Adjunta do Departamento de Farmácia da UnB como projeto de doutorado junto a FS em nome da equipe do Laboratório de Farmacologia Molecular da FS, composta por Michella Soares Coelho Araújo (pesquisadora colaboradora, programa de Pós-Graduação em Ciências da Saúde, UnB), Érica Carine Campos Caldas Silva Rosa (aluna de doutorado em Ciências da Saúde, UnB) e Luis Fernando Amarante (aluno de graduação em Medicina, UnB).

\section{Objetivo da Pesquisa:}

Investigar a associação entre o comprimento dos telômeros e a presença de DM2 entre pacientes acompanhados no ambulatório de Endocrinologia do HUB.

Objetivos específicos: Comparar o comprimento de telômeros entre portadores de DM2 e indivíduos controles com tolerância normal à glicose (TNG); Comparar o comprimento de telômeros entre portadores de DM2 e indivíduos controles com TNG, de acordo com a presença e índice de massa corporal (IMC) normal ou elevado.

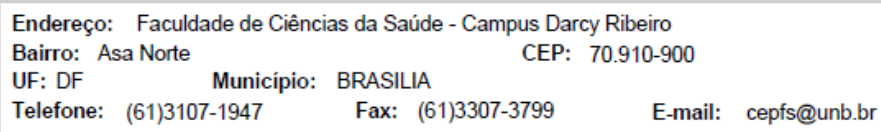




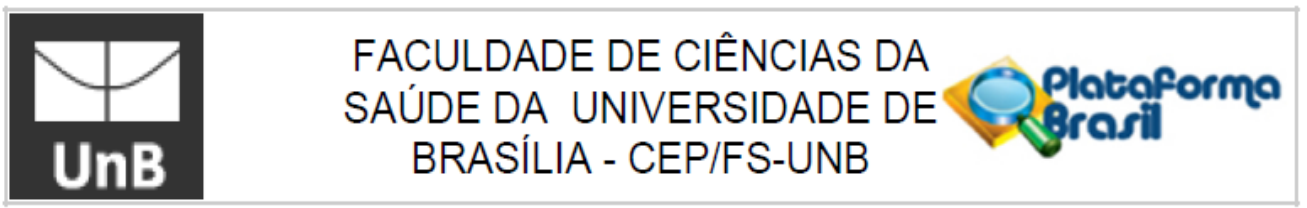

Continuação do Parecer. 392.623

Correlacionar o comprimento dos telômeros de portadores de DM2 com indicadores de controle metabólico do diabetes; Correlacionar o comprimento dos telômeros de portadores de DM2 a presença de complicações crônicas da doença.

Avaliação dos Riscos e Benefícios:

A participação dos sujeitos de pesquisa envolverá a coleta de $08 \mathrm{~mL}$ de sangue venoso para a extração de DNA e avaliação do comprimento dos telômeros por reação em cadeia de polimerase em tempo real. A coleta será feita com material totalmente descartável, sem necessidade de prepare prévio. Os riscos e desconfortos relacionados à coleta de sangue venoso são mínimos. Pode ocorrer dor leve ou formação de pequeno hematoma no local da coleta. O hematoma, se ocorrer, é reabsorvido espontaneamente, e não necessita de tratamento. Não há risco de contaminação nem de transmissão de doenças, uma vez que todo material utilizado é descartável, e a coleta será feita sob condições de assepsia. Os benefícios do projeto de pesquisa envolvem a ampliação dos conhecimentos a respeito da fisiopatologia do DM2 e de suas complicações. Embora os resultados gerados não possam ser traduzidos em benefícios imediatos para os participantes da pesquisa, é possível que permitam elaborar estratégias futuras de evitar ou retardar 0 aparecimento das doenças e de suas complicações. A identificação do comprimento dos telômeros como marcador de risco de complicações crônicas, por exemplo, poderia representar uma ferramenta no seguimento de pacientes com a doença.

\section{Comentários e Considerações sobre a Pesquisa:}

Serão recrutados 200 pacientes portadores de DM2, com idade superior a 45 anos, acompanhado no ambulatório de Endocrinologia do HUB. Serão selecionados também 400 indivíduos com tolerância normal à glicose (200 com IMC normal e 200 com IMC elevado), da mesma faixa etária, a partir do quadro de funcionários da Universidade de Brasília e de voluntários doadores de sangue no Hemocentro da cidade, que constituirão o grupo controle.

Os sujeitos serão convidados a responder a um questionário contendo dados de identificação, demográficos, socioeconômicos e clínicos (anexo III). Serão ainda consultados os prontuários médicos dos pacientes diabéticos, para obtenção de informações relativas ao seu seguimento (anexo II). Todos os sujeitos serão submetidos à coleta de $8 \mathrm{~mL}$ de sangue venoso periférico, em tubo contendo EDTA. Serão isolados os leucócitos do sangue periférico e extraído seu DNA pelo método de precipitação de sal, para determinação do comprimento de seus telômeros por PCR quantitativa em tempo real, utilizando kit específico.

Os pacientes diabéticos e os indivíduos com tolerância normal serão comparados com relação ao comprimento de seus telômeros. Nos dois grupos, o comprimento dos telômeros será

Endereço: Faculdade de Ciências da Saúde - Campus Darcy Ribeiro

Bairro: Asa Norte CEP: $70.910-900$

UF: DF Município: BRASILIA

Telefone: (61)3107-1947_ Fax: (61)3307-3799_ E-mail: cepfs@unb.br 


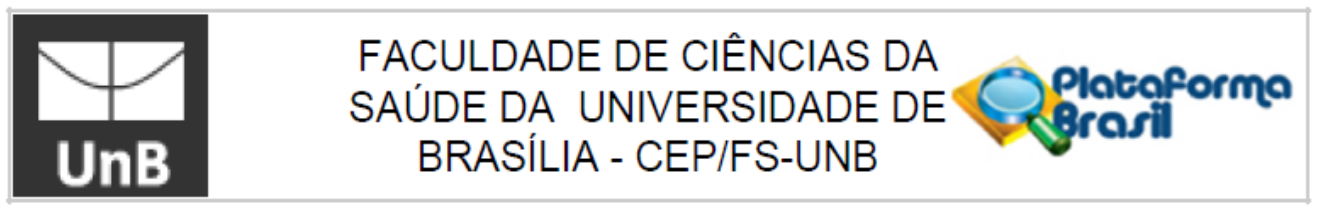

Continuação do Parecer. 392.623

correlacionado com fatores demográficos, socioeconômicos e clínicos. No grupo de pacientes diabéticos, esses dados serão ainda correlacionados com o resultado de parâmetros bioquímicos indicativos de controle metabólico e com a presença de complicações crônicas da doença.

Para avaliar as diferenças entre as médias dos resultados obtidos nos diversos grupos experimentais os resultados serão analisados por ANOVA seguida do pós-teste Newman-Keuls.

\section{Considerações sobre os Termos de apresentação obrigatória:}

O projeto apresenta carta de apresentação e folha de rosto devidamente assinada pela direção da FS e preenchida corretamente, onde consta um n de 600 sujeitos. Foram apresentados o termo de concordância da Fundação Hemocentro de Brasília assinado pelo diretor executivo José Antônio de Farias Vilaça e chefia da unidade clínica e o termo de ciência institucional co-participante do HUB e da COREME.

O cronograma apesar de estar em formato anual no projeto foi apresentado por data no projeto da plataforma e está atualizado. Foi apresentado orçamento detalhado, constando que o Laboratório de Farmacologia Molecular da Universidade de Brasília, onde a pesquisa será conduzida, dispõe de toda a infraestrutura e material de

custeio necessários à realização do projeto de pesquisa. O TCLE foi redigido adequadamente de acordo com Resolução CONEP 466/12 e foi explicitado ainda que ¿O DNA que não for utilizado com essa finalidade ficará armazenado, SOMENTE APÓS A SUA AUTORIZAÇÃO, no laboratório de Farmacologia Molecular da UnB, e será eventualmente utilizado com outra finalidade somente (i) após autorização do Comitê de Ética em Pesquisa E, PRINCIPALMENTE (ii) após o seu consentimento esclarecidoj. Junto ao projeto foi encaminhado o Regimento Interno para Operacionalização de Coleta, Armazenamento e Processamento de Amostras do Grupo de Pesquisa em Endocrinologia da Universidade de Brasília - Linha de pesquisa em Avaliação de Mecanismos de Resistência Insulínica e Diabetes Mellitus.

A ficha de avaliação dos pacientes e controles foi apresentada onde constam dados de identificação, demográficos e hábitos de vida e doenças.

\section{Recomendações:}

Buscar termo de fácil entendimento para facilitar a compreensão de leigos (telômeros), como por exemplo, ponta do cromossomo.

Conclusões ou Pendências e Lista de Inadequações:

Projeto adequado as normas da Resolução CONEP 466/2012 e sem pendências.

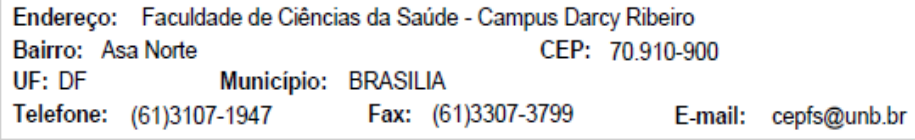




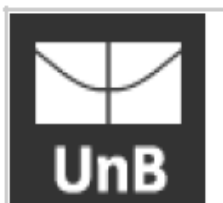

FACULDADE DE CIÊNCIAS DA SAÚDE DA UNIVERSIDADE DE BRASÍLIA - CEP/FS-UNB

Continuação do Parecer. 392.623

Situação do Parecer:

Aprovado

Necessita Apreciação da CONEP:

Não

Considerações Finais a critério do CEP:

BRASILIA, 12 de Setembro de 2013

\begin{tabular}{c}
\hline Assinador por: \\
Natan Monsores de Sá \\
(Coordenador)
\end{tabular}




\title{
ANEXO II - PARECER DO COMITÊ DE ÉTICA EM PESQUISA EM SERES HUMANOS -FUNDAÇÃO DE ENSINO E PESQUISA EM CIÊNCIAS DA SAÚDE, FEPECSISES-DF
}

\author{
FACULDADE DE CIÊNCIAS DA
SAÚDE DA UNIVERSIDADE DE Slotoformo
BnB \\ PARECER CONSUBSTANCIADO DO CEP \\ Elaborado pela Institulç̧o coparticipante \\ DADOS DO PROJETO DE PESQUISA \\ Titulo da Pisqulsa: Assoclaçăo entre o comprimento de Telomeros e a presença de Dlabetes Mellitus \\ Tipo 2 em paclentes do Hospltal Universitario de Brasila. \\ Pegqulazdor: ERICA CARINE CAMPOS CALDAS ROSA \\ Area Tematica: \\ Versac: 2 \\ CAAE: 23433013.4 .3001 .0030 \\ Institulçso Proponente: FUNDAÇÅ HEMOCENTRO DE BRASILLA \\ Patrocinador Principal: Financlamento Proprio \\ DADOS DO PARECER \\ Número do Parecer: 604.797-0 \\ Data da Relatoria: 12/03/2014 \\ Apreeentaça do Projeto: \\ Trata-se de projeto de pesquisa exploratoria que busca constatar a assoclaçăo existente entre o \\ comprimento de TelOmeros e a presença de Dlabetes Melltus Tlpo 2 em paclentes do Hospital Universitario \\ de Braslla e que tera pacientes do grupo de controle recrutados entre doadores da Fundaçálo Hemocentro \\ de Braslla. \\ Objettvo da Pesquisa: \\ Objettvo Primario: \\ Investigar a 36sociaçăo entre o comprimento dos telomeros e a presença de DN2 entre paciertes \\ acompanhados no ambulatorio de Endocrinologla do Hospital Universitario de Braslla. \\ Objettvo Secundario \\ 1) Comparar o comprimento de telomeros entre portadores de DM2 e individuos controles com tolerancla \\ nomal a glcose (TNG). 2) Comparar o comprimento de telomeros entre portadores de DM2 e individuos \\ controles com TNG, de acordo com a presença e indloe de massa corporal (IMC)normal cu elevado. 3) \\ Correlacionar o comprimento dos telomeros de portadores de DN2 com indicadores de controle
}

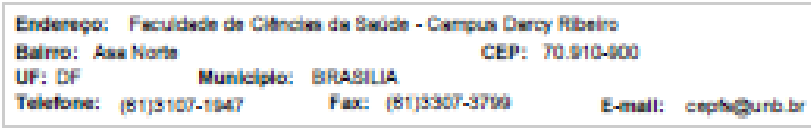




FACULDADE DE CIENCIAS DA
SAÚDE DA UNIVERSIDADE DE Q Pratoformo
BnB

Continuação do Parecer. 604.797-0

metabólico do diabetes. 4) Correlacionar o comprimento dos telômeros de portadores de DM2 a presença de complicações crônicas da doença.

Avaliação dos Riscos e Benefícios:

Como bem referido pelo relator da FEPECS, foi apresentado junto ao TCLE a análise de riscos e benefícios.

Comentários e Considerações sobre a Pesquisa:

O projeto de pesquisa busca verificar características cromossômicas correlacionando com uma condição prévia em pacientes sob tratamento médico e utilizando grupo de controle de pacientes na Fundação Hemocentro de Brasília na forma do protocolo de pesquisa. A pesquisa inclui, além de entrevista obtenção de material biológico para análise genética.

\section{Consideraçōes sobre os Termos de apresentação obrigatória:}

Foram apresentados os seguintes documentos:

Folha de Rosto; Projeto de Pesquisa em Português; Termo de Consentimento Livre e Esclarecido; Critérios de Inclusão e Exclusão; Orçamento do Projeto de Pesquisa com financiador; Curricullum vital dos pesquisadores; Termos de Concordância.

Recomendaçōes:

Não se aplica

Conclusões ou Pendências e Lista de Inadequaçōes:

Concordamos com o parecer consubstanciado da FEPECS.

Situação do Parecer:

Aprovado

Necessita Apreciação da CONEP:

Não

Consideraçōes Finais a critério do CEP:

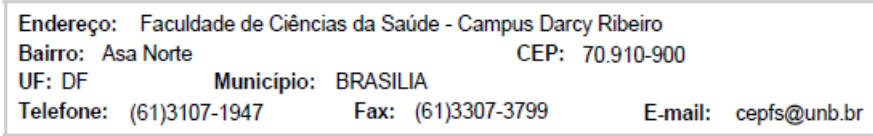




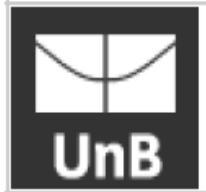

\section{FACULDADE DE CIÊNCIAS DA} SAÚDE DA UNIVERSIDADE DE Protofil
BRASÍLIA - CEPIFS-UNB

Continuação do Parecer. 604.797-0

BRASILIA, 12 de Abril de 2014

Assinador por:

Natan Monsores de Sá

(Coordenador)

Este parecer reemitido substitui o parecer número 604797 gerado na data 31/03/2014 16:06:23, onde o número CAAE foi alterado de 23433013.4 .0000 .5553 para 23433013.4.3001.0030. 
ANEXO III - QUESTIONÁRIO DO DOADOR (FHB/SES-DF) PRÉ- TRIAGEM

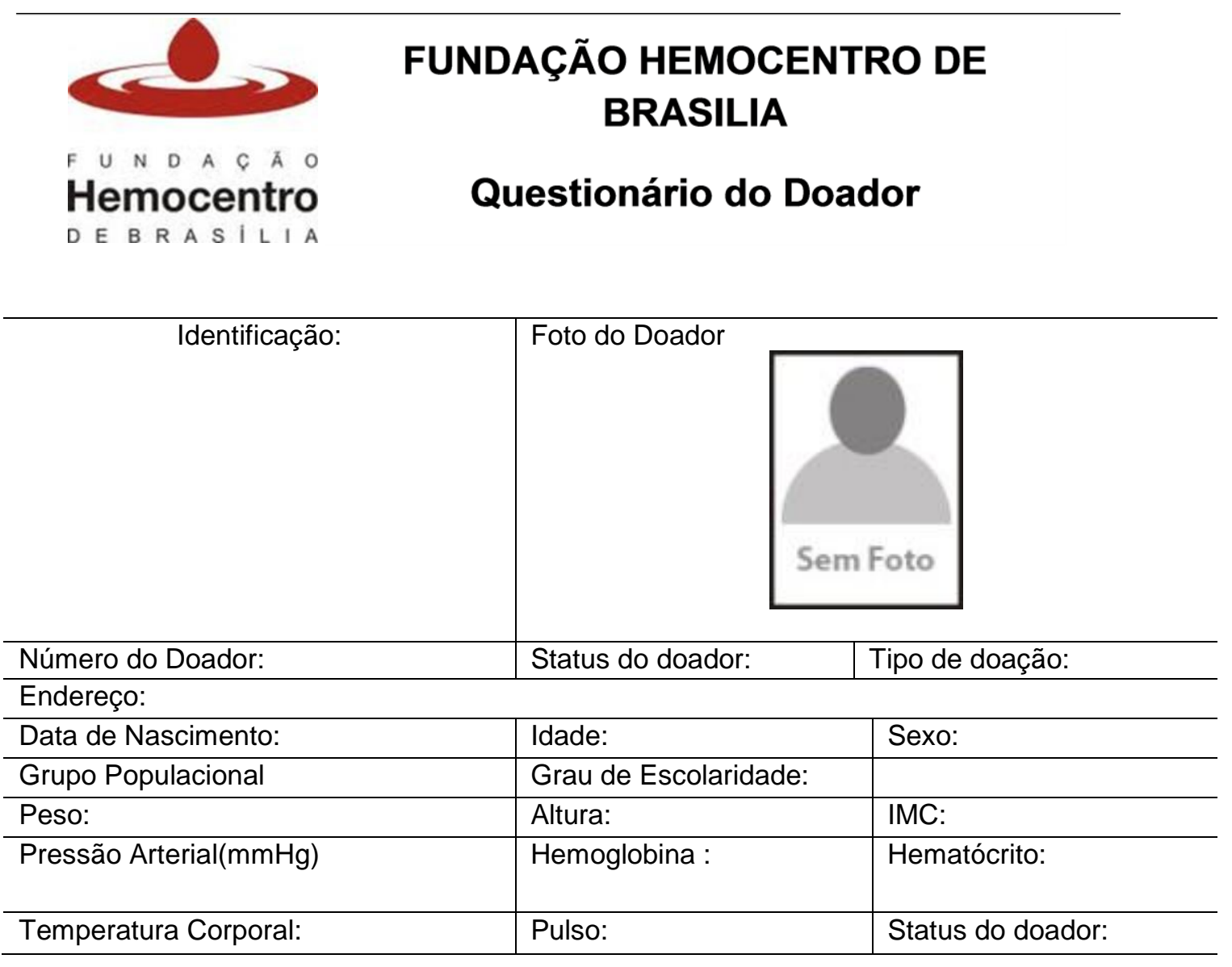




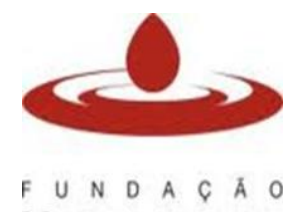

Hemocentro

DE B R A S I L I A

\section{FUNDAÇÃO HEMOCENTRO DE BRASILIA}

\author{
Questionário do Doador
}

\author{
Triagem Clinica
}

Dados da

Data:

Senha do Dia:

Data de

Doação:

Código:

Nome do doador:

Nascimento:

Pergunta

Está se sentindo bem?

Já doou sangue alguma vez? Quando foi a ultima doação?

Teve algum problema após?

Dormiu no mínimo 6 horas na última noite?

Alimentou-se bem ontem?

Comeu alimentos gordurosos nas últimas 4 horas? (pex:

frituras, linguiça, miojo, churrasco, feijoada, estrogonofe, etc)

7.

Fumou nas últimas 2 horas?

8. Ingeriu bebida alcoólica? Quanto ? Quando?

9. Fez esforço físico nas ultimas 12 horas?

10. Perdeu peso nos últimos meses?

11. Teve febre, gripe, diarreia ou outra infecção no ultimo mês ?
12. Tomou algum medicamento nos últimos 3 meses para(acne,

12.

13. queda de cabelo, próstata ?)

Hoje está com corte, ferida ou dor?

14. Fez tratamento dentário recente?

15. Tomou vacina nos últimos meses?

16. Tem ou teve alguma doença(coração, pulmão, asma (bronquite, rins ,fígado, reumatismo, alergias?)

17. Tem ou Teve diabetes ou doença da tireoide?

18. Tem ou teve hanseníase ou tuberculose?

19.

20.

21.

Tem ou teve epilepsia, convulsão, desmaio ou tonturas?

Tem ou teve doenças de pele (herpes, cobreiro)?

Tem ou já teve câncer ou doenças do sangue?

22. Esteve por mais de 6 meses consecutivos ou não, fora do
Sexo:

Resposta

Registro: 
Brasil?(Vide POP GCD NTC001,pags 66 e 67 para DCJ)

23. Já esteve em regiões onde há malária ou já teve a doença?(Vide POP GCD NTC001 pg 63 para malária)

24. Viajou no ultimo mês ou morou fora de Brasília?

25. Foi operado nos últimos 6 meses ?

26. Já teve contato com barbeiro?

27. Engravidou mais de 2 vezes?

28. Esta grávida, amamentando, com atraso menstrual ou teve algum aborto?

29. Já fez teste para HIV?

30. Você tem parceiro sexual fixo(a) ? Há quanto tempo? Quando foi a primeira relação sexual com o (a) ultimo (a) parceiro (a) sem preservativo?

31. Tem ou teve mais de um parceiro sexual nos últimos 12 meses?

32. Você ou seu parceiro fez algum procedimento endoscópico nos últimos 06 meses?

33. Você ou seu parceiro usa ou já usou drogas anabolizantes?

34. Teve relações sexuais com parceiro do mesmo sexo?

35. Você ou seu parceiro teve hepatite ou receberam sangue nos últimos 12 meses?

36. Você ou seu parceiro tiveram algum acidente com material perfuro cortante nos últimos 12 meses?

37. Teve ou Teve relação sexual com pessoas desconhecidas, suspeitas ou portadoras de HIV ou que fizeram hemodiálise nos últimos 12 meses?

38. Você ou seu parceiro tem ou tiveram doenças venéreas (sífilis, gonorreia ,cancro, condiloma, herpes, HPV) ?

39. Você ou seu parceiro colocou pierceng? Onde? Em qual cavidade?, fez tatuagem, maquiagem definitiva ou acupuntura nos últimos 12 meses?

40. Você ou seu parceiro esteve internado em instituição penal, policial, de recuperação de drogados ou hospital psiquiátrico? 


\title{
ANEXO V - TERMO DE CONSENTIMENTO LIVRE E ESCLARECIDO
}

\author{
UNIVERSIDADE DE BRASÍLIA \\ FACULDADE DE CIÊNCIAS DA SAÚDE \\ LABORATÓRIO DE FARMACOLOGIA MOLECULAR \\ CAMPUS UNIVERSITÁRIO DARCY RIBEIRO, BRASÍLIA - DF \\ TELEFONE (061) 3107-2000, E-mail: farmol@unb.br
}

\section{TERMO DE CONSENTIMENTO LIVRE E ESCLARECIDO - TCLE PACIENTES}

Projeto: "Investigação da associação entre o comprimento dos telômeros de leucócitos do sangue periférico e a presença do diabetes mellitus tipo 2 e de suas complicações crônicas entre pacientes acompanhados no Hospital Universitário de Brasília.”

Nome completo do paciente:

Registro:

$\mathrm{O}$ (a) Senhor(a) está sendo convidado(a) a participar de uma pesquisa, e este documento apresenta uma descrição desta pesquisa e tem como objetivo ajudá-lo(a) a decidir se você deseja ou não participar dela. Os membros da equipe da pesquisa esclarecerão todas as suas dúvidas sobre esta pesquisa e sobre a sua participação nela, antes e no decorrer da pesquisa. O Comitê de Ética em Pesquisa, que tem a responsabilidade de avaliar todas as solicitações de realização de pesquisas clínicas com voluntários, analisou e aprovou este estudo para ser conduzido nesta Instituição. Você pode entrar em contato com os pesquisadores responsáveis por essa pesquisa antes, durante e após o período de sua realização. Os pesquisadores responsáveis são: (i) Érica Carine Campos Caldas Rosa, (ii) Luís Fernando Amarante e (iii) Angélica Amorim Amato, e o número de telefone para contato é 31071748. Você pode ainda entrar em contato com o Comitê de Ética em Pesquisa da Faculdade de Ciências da Saúde, cujo número de telefone é 31071947 e email é cepfs@ unb.br.

\section{Informacões sobre o estudo}

O objetivo deste estudo é investigar a associação entre o comprimento dos telômeros e a presença do diabetes mellitus tipo 2, por meio da comparação entre o comprimento dos telômeros de portadores da doença e de não portadores. Entre os portadores de diabetes, pretende-se avaliar, ainda, se o comprimento dos telômeros se associa à presença de complicações da doença. Os telômeros representam as extremidades do material genético humano, armazenado na forma de cromossomos, e seu encurtamento é associado ao envelhecimento e, mais recentemente, a doenças como o diabetes, em outras populações.

\section{Exames do estudo, riscos e desconfortos}

A sua participação envolverá a coleta de $08 \mathrm{~mL}$ de sangue venoso para a realização dos exames genéticos, em uma única vez, com material totalmente descartável, e não é necessário nenhum preparo para essa coleta, ou seja, não é necessário estar em jejum ou suspender o uso de qualquer medicamento. A coleta será realizada pelos pesquisadores envolvidos no estudo, no dia de sua consulta. Ou seja, a participação do estudo não requer que o(a) senhor(a) altere sua rotina. A duração aproximada da coleta de sangue é de 10 minutos. Os riscos e desconfortos relacionados à coleta de sangue venoso são mínimos. Pode ocorrer dor leve ou formação de pequeno hematoma no local da coleta. O hematoma, se ocorrer, é reabsorvido espontaneamente, e não necessita de tratamento. Não há risco de contaminação nem de transmissão de doenças, uma vez que todo material utilizado é descartável, e a coleta será feita sob 
condições de assepsia, ou seja, sob condições de ausência de germes. A partir do sangue venoso coletado, será extraído o seu material genético, chamado também de DNA, e realizado um experimento para determinar o comprimento dos telômeros, ou das regiões finais do DNA organizado nos cromossomos. Este teste genético não terá nenhum custo para você. O resultado deste teste será informado a você de acordo com a sua vontade. Ou seja, se você quiser o resultado será informado a você. Se não quiser, não será informado. Caso sua vontade seja de ter conhecimento do resultado, serão fornecidas todas as informações que os pesquisadores tiverem disponíveis, a partir da literatura científica, a respeito do resultado. Nem todo o DNA extraído é necessário para a realização desse teste genético. O DNA que não for utilizado com essa finalidade ficará armazenado, SOMENTE APÓS A SUA AUTORIZAÇÃO, no laboratório de Farmacologia Molecular da UnB, e será eventualmente utilizado com outra finalidade somente (i) após autorização do Comitê de Ética em Pesquisa E, PRINCIPALMENTE (ii) após o seu consentimento esclarecido. O Laboratório de Farmacologia Molecular tem toda a infraestrutura para armazenamento e proteção adequados do DNA, e você poderá solicitar para retirar esse material do Laboratório a qualquer momento, caso sua vontade seja de que o material não seja mais utilizado.

A participação envolverá também uma entrevista, realizada por um dos pesquisadores envolvidos no trabalho. Assim, essa entrevista será realizada enquanto você doa o sangue. Você pode se recusar a responder a qualquer uma das perguntas realizadas durante essa entrevista, sem qualquer prejuízo ao seu atendimento rotineiro. Esta entrevista tem o objetivo de pesquisar dados a respeito de seus hábitos de vida e outros eventuais problemas de saúde. A duração esperada da realização da entrevista será de aproximadamente 15 minutos. Algumas informações relacionadas ao seu acompanhamento serão consultadas em seu prontuário médico, como os medicamentos de que você está em uso, a medida de sua pressão arterial, peso, circunferência abdominal e altura. Todos os procedimentos no seu acompanhamento serão realizados normalmente, independentemente da sua participação no estudo.

\section{Benefícios do estudo}

Este estudo não terá nenhum benefício imediato para você. Entretanto, poderá contribuir para definir se, entre indivíduos brasileiros, o comprimento dos telômeros poderia ser indicativo do risco de desenvolvimento do diabetes ou então de suas complicações. Sua participação neste estudo é voluntária. Você pode optar por não participar ou pode deixar de participar a qualquer momento sem qualquer penalidade ou alteração de seu acompanhamento rotineiro no Hospital Universitário de Brasília.

\section{Confidencialidade dos Registros}

A menos que seja exigido por lei, apenas o médico do paciente e os pesquisadores envolvidos no estudo saberão de sua participação neste estudo, bem como do seu diagnóstico. A assinatura deste termo autoriza o acesso, pelos profissionais citados acima, às respostas fornecidas durante a entrevista. Será mantida rigorosa confidencialidade de seus dados por todos esses profissionais, com omissão total de quaisquer informações que permitam identifica-lo(a). Os dados obtidos a partir desse estudo serão apresentados em relatórios ou publicações científicas, porém as informações que o identificam individualmente não serão divulgadas em nenhum relatório nem publicação. Ou seja, os resultados de seu teste genético jamais serão divulgados com seu nome e jamais serão utilizados com outra finalidade além de divulgação do conhecimento científico. Além disso, você terá total acesso a todas as informações obtidas com estudo, se essa for sua vontade.

\section{Custos da participação}

Não se espera que você pague por nenhum dos procedimentos ou exames que são exigidos como parte deste estudo. Sua participação é voluntária, isto é, não há pagamento por sua colaboração.

\section{TERMO DE PARTICIPACÃO E ASSINATURAS}


Eu li as informações acima deste Termo de Consentimento Livre e Esclarecido. Eu entendi os propósitos do estudo, bem com os possíveis riscos e benefícios decorrentes de minha participação. Eu tive a oportunidade de fazer perguntas e todas elas me foram respondidas de forma satisfatória. Ao assinar este termo eu forneço meu consentimento livre e esclarecido para participar deste estudo. Este documento apresenta 2 páginas e todas elas deverão ser rubricadas por mim, sujeito de pesquisa, e pelo pesquisador responsável. Eu autorizo os pesquisadores do estudo a coletar e processar meus dados, incluindo informações sobre minha saúde e a coletar meu sangue, extrair meu material genético, analisar o comprimento dos telômeros e armazenar meu material genético. Eu entendo que a participação neste estudo é voluntária, que posso recusar participar ou deixar de participar do estudo a qualquer momento, sem que este fato possa afetar meus futuros cuidados médicos. Além disso, entendo que tenho total acesso ao meu material genético armazenado, assim como o direito de retirá-lo do local em que se encontra armazenado, a qualquer momento. Esse Termo de Consentimento Livre e Esclarecido encontra-se redigido em duas vias, e eu receberei uma cópia assinada e datada deste Termo de Consentimento Livre e Esclarecido. A outra cópia ficará em posse do pesquisador. Eu não estou desistindo de nenhum de meus direitos legais pela assinatura deste Termo de Consentimento Livre e Esclarecido.

1

Data

Nome e Assinatura do sujeito de pesquisa

$\mathrm{Eu}$, abaixo assinado, expliquei integralmente os detalhes relevantes deste estudo para a paciente acima indicada e fornecerei a este paciente uma cópia deste Termo de Consentimento Livre e Esclarecido assinado e datado.

Data

Nome e Assinatura do Investigador 


\section{ANEXO VI - FICHA DE AVALIAÇÃO PACIENTES HUB

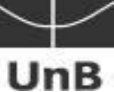 \\ UNIVERSIDADE DE BRASÍLIA \\ FACULDADE DE CIÊNCIAS DA SAÚDE \\ LABORATÓRIO DE FARMACOLOGIA MOLECULAR \\ CAMPUS UNIVERSITÁRIO DARCY RIBEIRO, BRASÍLIA - DF \\ TELEFONE (061) 3107-2000, E-mail: farmol@unb.br}

\begin{tabular}{|l|}
\hline \multicolumn{1}{|c|}{ FICHA DE AVALIAÇÃO } \\
\hline $\begin{array}{l}\text { Projeto: "Investigação da associação entre o comprimento dos telômeros de leucócitos do } \\
\text { sangue periférico e a presença do diabetes mellitus tipo 2 e de suas complicações crônicas } \\
\text { entre pacientes acompanhados no Hospital Universitário de Brasília" }\end{array}$ \\
\hline Paciente número:
\end{tabular}

Dados de identificação:

\begin{tabular}{|c|c|c|}
\hline \multicolumn{3}{|l|}{ Nome: } \\
\hline Data do Nascimento: & & Sexo: $F$ \\
\hline \multicolumn{3}{|c|}{ Número de registro no HUB: } \\
\hline Profissão: & \multicolumn{2}{|r|}{ Telefone: } \\
\hline \multicolumn{3}{|l|}{ Endereço: } \\
\hline \multicolumn{3}{|l|}{ Grau de escolaridade: } \\
\hline \multicolumn{3}{|c|}{ Renda mensal do paciente: } \\
\hline \multicolumn{3}{|c|}{ Renda mensal da família: } \\
\hline \multicolumn{3}{|c|}{ Número de pessoas na residência } \\
\hline \multicolumn{3}{|l|}{ Tabagismo : } \\
\hline Quantos cigarros $\backslash$ dia: & Quanto tempo fuma: & Se parou, há quanto tempo \\
\hline \multicolumn{3}{|l|}{ Etilismo } \\
\hline Quanto consomeldia: & Quanto tempo & Tipo de bebida: \\
\hline \multicolumn{3}{|l|}{ Atividade Física } \\
\hline Tipo: & Frequência: & Quanto tempo por dia \\
\hline
\end{tabular}

Dados demográfi $\underline{\cos }$

\section{Hábitos de} vida

\section{Diabetes}

\begin{tabular}{|l|l|}
\hline Diabetes & \\
\hline Tempo de doença & \\
\hline Complicaçôes crônicas & \\
\hline Retinopatia & \\
\hline Tratamentos anteriores & \\
\hline & \\
\hline & \\
\hline Histórico Familiar de Diabetes & \\
\hline
\end{tabular}




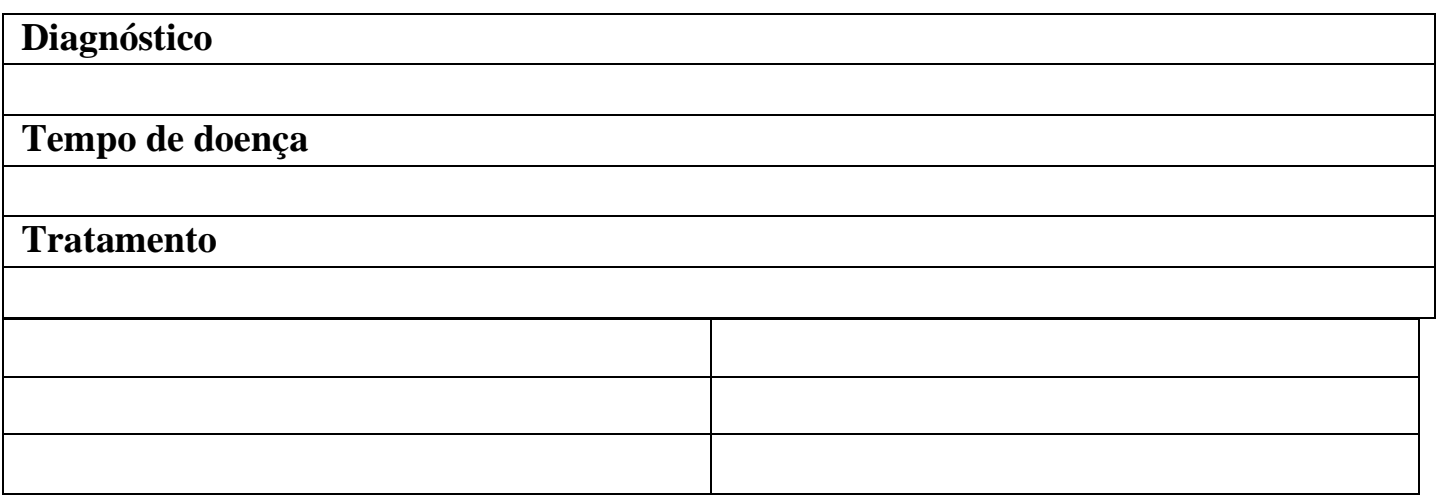

\section{Medicamentos}

\begin{tabular}{|c|c|}
\hline Nome & Dose \\
\hline & \\
\hline & \\
\hline & \\
\hline & \\
\hline
\end{tabular}

\section{Parâmetros clínicos}

\begin{tabular}{|l|l|}
\hline Pressão Arterial & - \\
\hline Peso & - \\
\hline Altura & - \\
\hline Circunferência abdominal $(\mathrm{cm})$ & - \\
\hline Circunferência do Quadril $(\mathrm{cm})$ & - \\
\hline $\mathrm{IMC}\left({\mathrm{Kg} \backslash \mathrm{m}^{2}}^{2}\right.$ & - \\
\hline
\end{tabular}


Parâmetros bioquímicos

\begin{tabular}{|ll|l|}
\hline \multicolumn{2}{|l|}{ Data dos exames revisados: } & $\begin{array}{l}\text { Data dos últimos exames } \\
\end{array}$ \\
\hline- & Glicemia de jejum & - \\
\hline- & Glicemia pós-prandial & - \\
\hline- & Hemoglobina glicada & - \\
\hline- & Colesterol total & - \\
\hline- & Triglicérides & - \\
\hline- & HDL & - \\
\hline- & LDL & - \\
\hline- & Insulinemia & - \\
\hline- & PCR ultrassensível & - \\
\hline- & Ureia & - \\
\hline- & Creatinina & - \\
\hline- & Microalbuminúria & - \\
\hline- & DCE - Depuração creatinina endógena & - \\
\hline- & Proteinúria & - \\
\hline- & FO - Fundo olho & - \\
\hline- & DOA - Dano em órgão-alvo & - \\
\hline
\end{tabular}

\section{Parâmetros ecográficos}

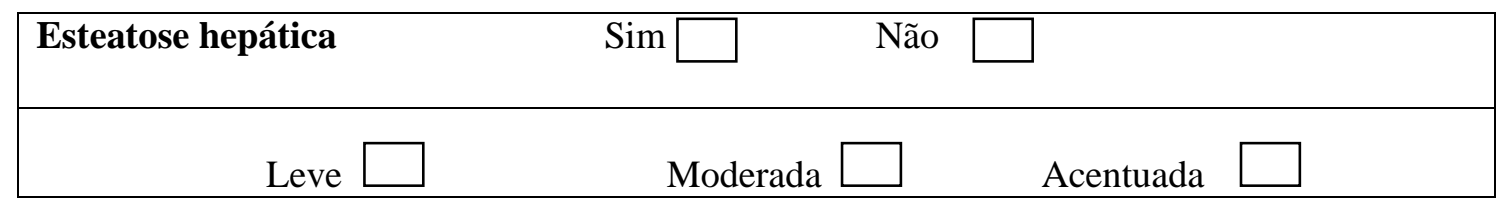




\section{ANEXO VII - TERMO DE CONSENTIMENTO LIVRE E ESCLARECIDO HEMOCENTRO}
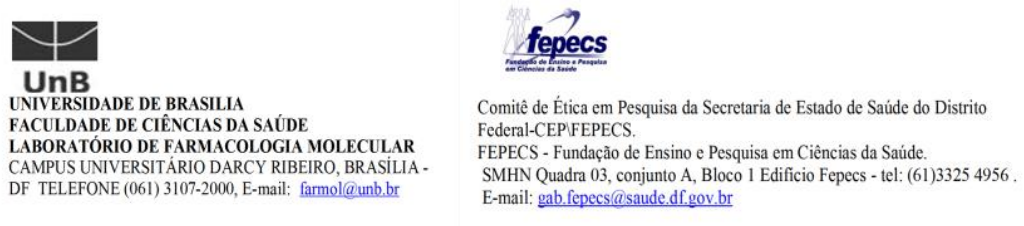

"Associação entre o comprimento de telômeros e a presença de Diabetes Mellitus tipo 2 em pacientes do Hospital Universitário de Brasília”.

\section{TCLE-TERMO DE CONSENTIMENTO LIVRE E ESCLARECIDO- GRUPO CONTROLE(DOADOR)}

Você está sendo convidado (a) a participar de uma pesquisa, e este documento apresenta uma descrição desta pesquisa e tem como objetivo ajudá-lo(a) a decidir se você deseja ou não participar dela. Os membros da equipe da pesquisa esclarecerão todas as suas dúvidas sobre esta pesquisa e sobre a sua participação nela. O Comitê de Ética em Pesquisa, que tem a responsabilidade de avaliar todas as solicitações de realização de pesquisas clínicas com voluntários, analisou e aprovou este estudo para ser conduzido nesta Instituição. Você pode entrar em contato com os pesquisadores responsáveis por essa pesquisa antes, durante e após o período de sua realização em caso de dúvidas. Os pesquisadores responsáveis são: (i) Érica Carine Campos Caldas Rosa, (ii) Luís Fernando Amarante e (iii) Angélica Amorim Amato, e o número de telefone para contato é 31071748. Você pode ainda entrar em contato com o Comitê de Ética em Pesquisa da Faculdade de Ciências da Saúde, cujo número é 3107 1947. Os resultados da pesquisa serão divulgados na Instituição Universidade de Brasília podendo ser publicados posteriormente. Os dados e materiais utilizados na pesquisa ficarão sob a guarda do pesquisador por um período de no mínimo cinco anos, após isso serão destruídos ou mantidos na instituição. Este projeto foi Aprovado pelo Comitê de Ética em Pesquisa da Secretaria de Estado de Saúde do Distrito FederalCEPIFEPECS. As dúvidas com relação à assinatura do TCLE ou os direitos do sujeito da pesquisa podem ser obtidos através do telefone: (61) 3107-1947 ou do e-mail cepfs@ unb.br. Este documento foi elaborado em duas vias, uma ficará com o pesquisador responsável e a outra com o sujeito da pesquisa.

\section{$\underline{\text { Informacões sobre o estudo }}$}

O objetivo deste estudo é investigar a associação entre o comprimento dos telômeros e a presença do diabetes mellitus tipo 2, por meio da comparação entre o comprimento dos telômeros de portadores da doença e de não portadores. Entre os portadores de diabetes, pretende-se avaliar, ainda, se o comprimento dos telômeros se associa à presença de complicações da doença. Os telômeros representam as 
extremidades do material genético humano, armazenado na forma de cromossomos, e seu encurtamento é associado ao envelhecimento e, mais recentemente, a doenças como o diabetes, em outras populações.

\section{Exames do estudo, riscos e desconfortos}

Essa pesquisa destina-se a avaliar 200 indivíduos portadores de diabetes mellitus tipo 2 e 400 indivíduos com tolerância normal à glicose (200 com índice de massa corporal normal e 200 com índice de massa corporal elevado), da mesma faixa etária. A participação envolverá a coleta de $12 \mathrm{~mL}$ de sangue venoso para a realização dos exames genéticos, em uma única vez, com material totalmente descartável, e não é necessário nenhum preparo para essa coleta, ou seja, não é necessário estar em jejum ou suspender o uso de qualquer medicamento. A coleta será realizada pelos pesquisadores envolvidos no estudo. A duração aproximada da coleta de sangue é de 10 minutos. Os riscos e desconfortos relacionados à coleta de sangue venoso são mínimos. Pode ocorrer dor leve ou formação de pequeno hematoma no local da coleta. O hematoma, se ocorrer, é reabsorvido espontaneamente, e não necessita de tratamento. Não há risco de contaminação nem de transmissão de doenças, uma vez que todo material utilizado é descartável, e a coleta será feita sob condições de assepsia, ou seja, sob condições de ausência de germes. A partir do sangue venoso coletado, será extraído o seu material genético, chamado também de DNA, e realizado um experimento para determinar o comprimento dos telômeros, ou das regiões finais do DNA organizado nos cromossomos. Este teste genético não terá nenhum custo para você. O resultado deste teste será informado a você de acordo com a sua vontade. Ou seja, se você quiser o resultado será informado a você. Se não quiser, não será informado. Caso sua vontade seja de ter conhecimento do resultado, serão fornecidas todas as informações que os pesquisadores tiverem disponíveis, a partir da literatura científica, a respeito do resultado. Nem todo o DNA extraído é necessário para a realização desse teste genético. O DNA que não for utilizado com essa finalidade ficará armazenado, SOMENTE APÓS A SUA AUTORIZAÇÃO, no laboratório de Farmacologia Molecular da UnB, e será eventualmente utilizado com outra finalidade somente (i) após autorização do Comitê de Ética em Pesquisa E, PRINCIPALMENTE (ii) após o seu consentimento esclarecido. O Laboratório de Farmacologia Molecular tem toda a infraestrutura para armazenamento e proteção adequados do DNA, e você poderá solicitar para retirar esse material do Laboratório a qualquer momento, caso sua vontade seja de que o material não seja mais utilizado. A participação envolverá uma entrevista, realizada por um dos pesquisadores envolvidos no trabalho. Assim, essa entrevista será realizada enquanto você doa o sangue. Você pode se recusar a responder a qualquer uma das perguntas realizadas durante essa entrevista, sem qualquer prejuízo ao seu atendimento rotineiro. Esta entrevista tem o objetivo de pesquisar seu estilo de vida, uso de medicamentos, índice de massa corporal entre outros fatores. A duração esperada da realização da entrevista será de aproximadamente 15 
minutos. Todos os procedimentos no seu acompanhamento serão realizados normalmente, independentemente da sua participação no estudo.

\section{Benefícios do estudo}

Este estudo não terá nenhum benefício imediato para você. Entretanto, poderá contribuir para definir se, entre indivíduos brasileiros, o comprimento dos telômeros poderia ser indicativo do risco de desenvolvimento do diabetes ou então de suas complicações. Sua participação neste estudo é voluntária. Você pode optar por não participar ou pode deixar de participar a qualquer momento sem qualquer penalidade ou alteração de seu acompanhamento rotineiro no Hospital Universitário de Brasília. Não há remuneração ou benefício financeiro para as pacientes que participarem do estudo.

\section{Confidencialidade dos Registros}

A menos que seja exigido por lei, apenas o médico do paciente e os pesquisadores envolvidos no estudo saberão de sua participação neste estudo, bem como do seu diagnóstico. A assinatura deste termo autoriza o acesso, pelos profissionais citados acima, às respostas fornecidas durante a entrevista. Será mantida a confidencialidade de seus dados por todos esses profissionais. Os dados obtidos a partir desse estudo serão apresentados em relatórios ou publicações científicas, porém as informações que o identificam individualmente não serão divulgadas em nenhum relatório nem publicação. Ou seja, os resultados de seu teste genético jamais serão divulgados com seu nome e jamais serão utilizados com outra finalidade além de divulgação do conhecimento científico. Além disso, você terá total acesso a todas as informações obtidas com estudo, se essa for sua vontade.

\section{Custos da participação}

Não se espera que você pague por nenhum dos procedimentos ou exames que são exigidos como parte deste estudo.

\section{TERMO DE PARTICIPAČ̃̃O E ASSINATURAS}

Eu li as informações acima deste Termo de Consentimento Livre e Esclarecido. Eu entendi os propósitos do estudo, bem com os possíveis riscos e benefícios decorrentes de minha participação. Eu tive a oportunidade de fazer perguntas e todas elas me foram respondidas de forma satisfatória. Ao assinar este termo eu forneço meu consentimento livre e esclarecido para participar deste estudo. Eu autorizo os pesquisadores do estudo a coletar e processar meus dados, incluindo informações sobre minha saúde e a coletar meu sangue, extrair meu material genético, analisar o comprimento dos telômeros e armazenar meu material genético. Eu entendo que a participação neste estudo é voluntária, que posso recusar participar ou deixar de participar do estudo a qualquer momento, sem que este fato possa afetar meus 
futuros cuidados médicos. Além disso, entendo que tenho total acesso ao meu material genético armazenado, assim como o direito de retirá-lo do local em que se encontra armazenado, a qualquer momento. Esse Termo de Consentimento Livre e Esclarecido encontra-se redigido em duas vias, e eu receberei uma cópia assinada e datada deste Termo de Consentimento Livre e Esclarecido. A outra cópia ficará em posse do pesquisador. Eu não estou desistindo de nenhum de meus direitos legais pela assinatura deste Termo de Consentimento Livre e Esclarecido.

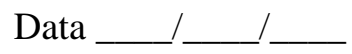

Nome e Assinatura do paciente

$\mathrm{N}^{\mathrm{o}}$ de registro no HEMOCENTRO

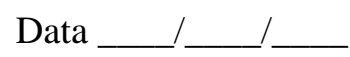

Nome e Assinatura da Testemunha

(Se Aplicável)

Eu, abaixo assinado, expliquei integralmente os detalhes relevantes deste estudo para a paciente acima indicada e fornecerei a este paciente uma cópia deste Termo de Consentimento Livre e Esclarecido assinado e datado.

Data_________

Nome e Assinatura do Investigador 


\section{ANEXO VIII - FICHA DE AVALIAÇÃO DO DOADOR}
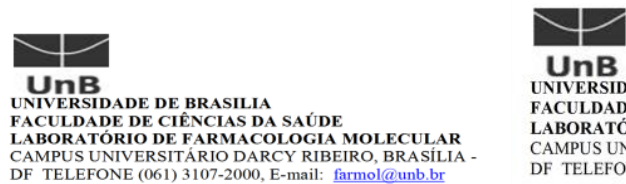

UnB

DADE DE CIÊNCIAS DA SAÚDE

LABORATÓRIO DE FARMACOLOGIA MOLECULAR

CAMPUS UNIVERSITÁRIO DARCY RIBEIRO, BRASILLIA -

DF TELEFONE (061) 3107-2000, E-mail: farmol@unb.br

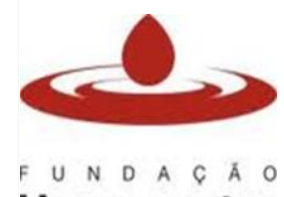

Hemocentro

DE B R A S I L I A

FICHA DE AVALIAÇÃO DO GRUPO- CONTROLE(DOADOR)

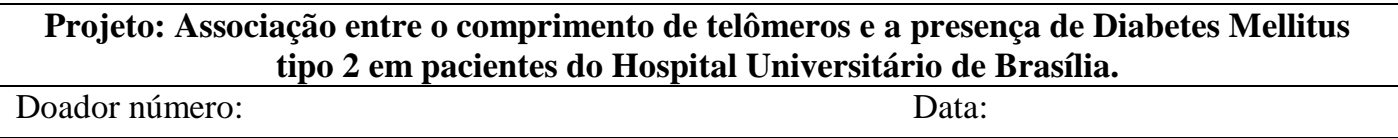

Dados de identificação:

\begin{tabular}{|l|}
\hline Nome: \\
\hline Data de Nascimento: \\
\hline Número do doador(etiqueta da amostra): \\
\hline Profissão (se aposentado, anotar profissão anterior): \\
\hline Endereço: \\
\hline Telefones de contato: \\
\hline
\end{tabular}

\section{Dados demográficos}

Grau de escolaridade (anotar até que ano ou série frequentou a escola):

Renda mensal estimada do paciente:

Renda mensal estimada da família:

Número de pessoas na residência:

\section{Parâmetros clínicos e Bioquímicos}

\begin{tabular}{|l|l|l|}
\hline Pressão Arterial (mmHg): & HIV: & $\begin{array}{l}\text { Hemoglobina } \\
\text { glicada(HbA1C) }\end{array}$ \\
\hline Peso: & Altura $(\mathrm{m}):$ & IMC $\left(\mathrm{kg} / \mathrm{m}^{2}\right):$ \\
\hline
\end{tabular}

